\title{
Hydroclimatic assessment of changing climate on diarrheal diseases with reference to cholera
}

\author{
Fariborz Nasr Azadani
}

Follow this and additional works at: https://researchrepository.wvu.edu/etd

\section{Recommended Citation}

Nasr Azadani, Fariborz, "Hydroclimatic assessment of changing climate on diarrheal diseases with reference to cholera" (2016). Graduate Theses, Dissertations, and Problem Reports. 6296.

https://researchrepository.wvu.edu/etd/6296

This Dissertation is protected by copyright and/or related rights. It has been brought to you by the The Research Repository @ WVU with permission from the rights-holder(s). You are free to use this Dissertation in any way that is permitted by the copyright and related rights legislation that applies to your use. For other uses you must obtain permission from the rights-holder(s) directly, unless additional rights are indicated by a Creative Commons license in the record and/ or on the work itself. This Dissertation has been accepted for inclusion in WVU Graduate Theses, Dissertations, and Problem Reports collection by an authorized administrator of The Research Repository @ WVU.

For more information, please contact researchrepository@mail.wvu.edu. 


\title{
HYDROCLIMATIC ASSESSMENT OF CHANGING CLIMATE ON \\ DIARRHEAL DISEASES WITH REFERENCE TO CHOLERA
}

\author{
Fariborz Nasr Azadani
}

\section{DISSERTATION}

submitted to the Benjamin M. Statler College of Engineering and Mineral Resources at West Virginia University

in partial fulfillment

of the requirements

for the degree of

\section{DOCTOR OF PHILOSOPHY}

Civil and Environmental Engineering

Antar Jutla, PhD., Chair

Avinash Unnikrishnan, $\mathrm{PhD}$.

Lian-Shin Lin, PhD.

Shafqat Akanda, PhD.

Radhey Sharma, PhD.

\section{Department of Civil and Environmental Engineering}

Morgantown, West Virginia

2016

Keywords: Cholera, Vibrio cholera, Climate change, Downscaling, River discharge, Infectious diseases, System dynamic approach

Copyright 2016 Fariborz Nasr Azadani 


\section{ABSTRACT \\ HYDROCLIMATIC ASSESSMENT OF CHANGING CLIMATE ON \\ DIARRHEAL DISEASES WITH REFERENCE TO CHOLERA}

\section{Fariborz Nasr Azadani}

The association of cholera with the climatic processes is well documented. However the effects of changing climate on occurrence of cholera is not yet evaluated, perhaps due to unavailability of geophysical data and their quantitative linkages with cholera. Global climate models (GCMs) outputs are available at coarse resolution of $200-300 \mathrm{~km}$, but the diseases usually occur at $10-15 \mathrm{~km}$, therefore, it is rather challenging to link any GCM outputs with a disease. The goal of this research is to develop algorithms that can link diarrheal diseases with changing climatic conditions. Within this context, cholera is used as a model disease due to availability of epidemiological information for over four decades. The Bengal Delta region of the South Asia has a unique pattern of cholera outbreaks with one in spring and other in the autumn season.

A new framework using data mining technique along with optimization method, Support Vector Machine - Particle Swarm Optimization (SVM-PSO) was developed to downscale GCM output to link with local hydroclimate processes. The method is used following traditional (such as downscale precipitation, then to river discharge) and nontraditional (downscale river discharge directly thereby reducing uncertainty) routes of hydroclimatic principles. Two different types of models were developed to link climate change with cholera including logistical regression and copula based probabilistic algorithms. 
Three research objectives of this dissertation were to (i) develop algorithms to traditionally link geophysical processes with cholera and investigate changing patterns of climate on disease occurrence; (ii) develop statistical algorithms to downscale nontraditional geophysical processes and to link with cholera, and compare it with the traditional approach, and (iii) provide a conceptual systems approach to mechanistically simulate cholera under changing climate. The motivation to use several different techniques is to avoid any mathematical manipulation of the results and interpretations; thus providing a robust means to understand as to what will happen to cholera under changing climate. A mechanistic model using systems approach was developed that linked several hydroclimate variables with cholera outbreaks in the Bengal Delta. The model results suggest that probability of extreme cholera is likely to decrease in the next few decades, provided the regional geomorphology of river systems remains unaltered. 


\section{DEDICATION:}

To my special wife, Nasrin, for her understanding and encouragement during past years, to my parents who provided me with love and support unconditionally throughout my life.

And to my wonderful son, Mateen. 


\section{ACKNOWLEDGEMENTS}

I would like to thank my supervisor, Dr. Antarpreet Jutla, for all of his guidance, understanding, patience, and support during my $\mathrm{PhD}$ studies at West Virginia University. I am grateful to my dissertation committee members, Dr. Avinash Unnikrishnan, Dr.

Lian-Shin Lin, Dr. Shafqat Akanda, and Dr. Radhey Sharma, for kindly agreeing to serve on my committee and their helpful suggestions, comments, and assistance on my dissertation.

I would also like to thank my friends, Dr. Alireza Firoozfar, Dr. Behzad Ghanbarian, Iman Malakpour, and Javad Rahimikollu, for their friendship and support. 


\section{Table of Contents}

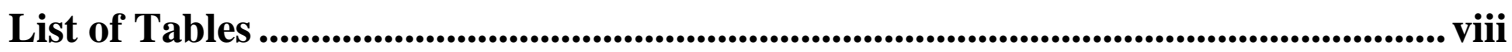

List of Figures............................................................................................................................. $\mathrm{x}$

Chapter 1 Introduction...................................................................................... 1

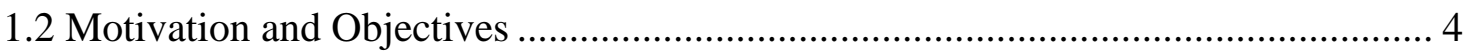

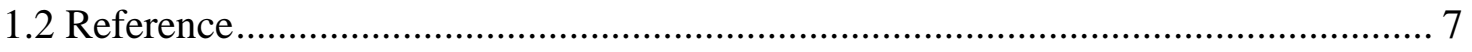

Chapter 2 Downscaling river discharge to assess the effects of climate change on cholera outbreaks in the Bengal Delta .................................................................................... 10

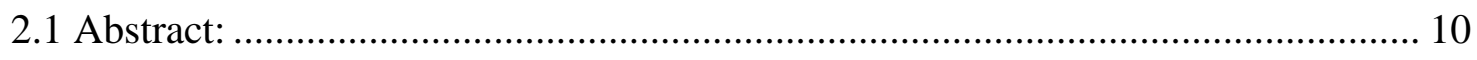

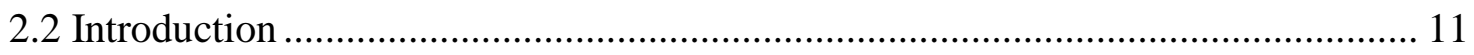

2.3 Geographical Location and Data ...................................................................... 13

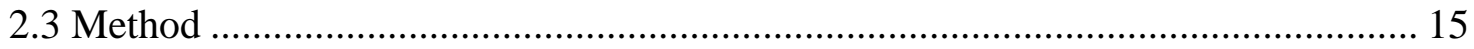

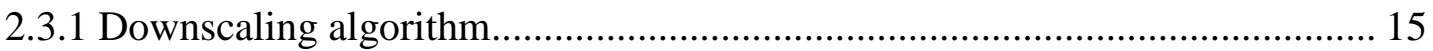

2.3.2 Precipitation-river discharge (P-Q) model................................................... 23

2.3.3 Cholera-river discharge (C-Q) model .......................................................... 24

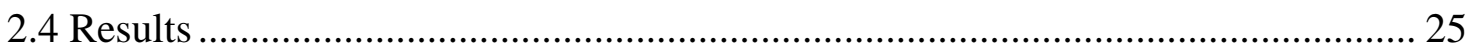

2.4.1 Downscaling precipitation: calibration and validation ..................................... 25

2.4.1 Precipitation-river discharge (P-Q) model..................................................... 29

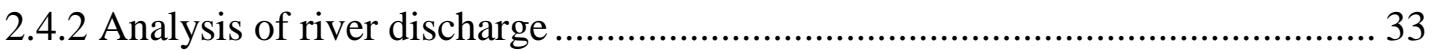

2.4.3 Cholera prevalence under changing climate................................................... 38

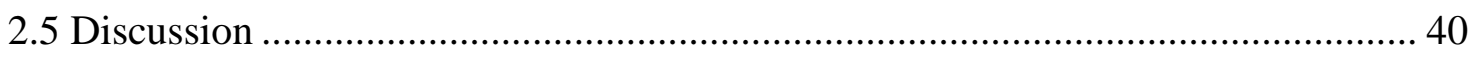

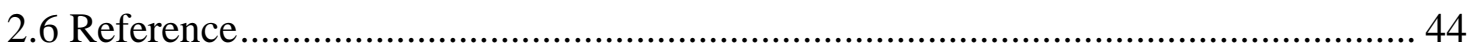

Chapter 3 Hydroclimatic assessment of changing climate on occurrence of endemic cholera outbreaks in Ganges-Brahmaputra Basin .............................................................. 52

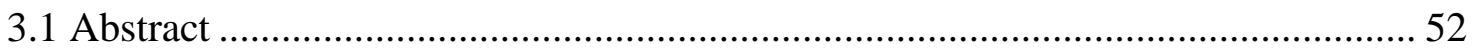

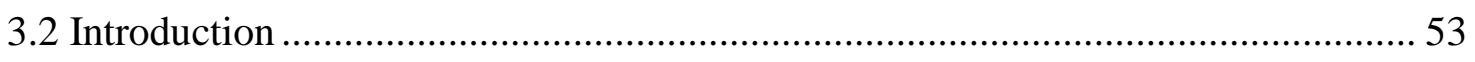

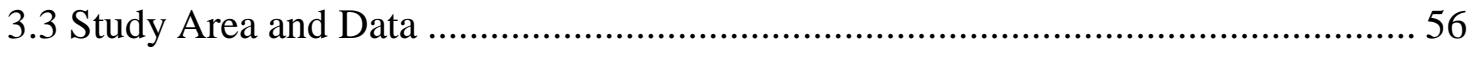

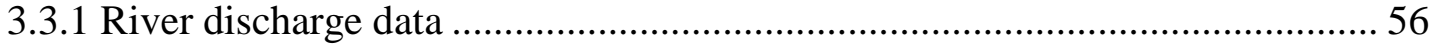

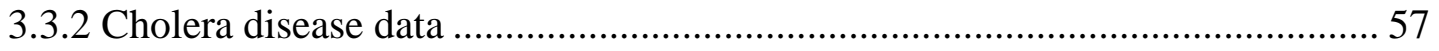

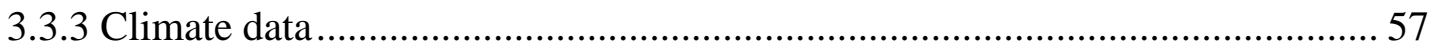

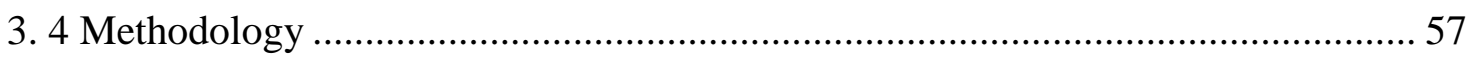

3.4.1 Support Vector Machine (SVM) ………………......................................... 57 


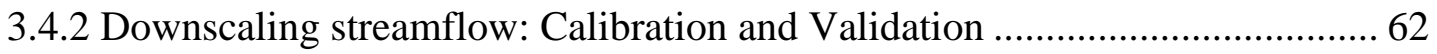

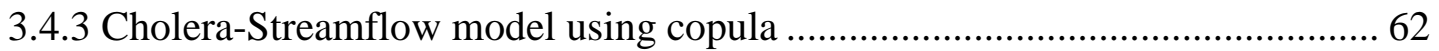

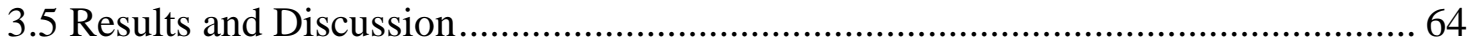

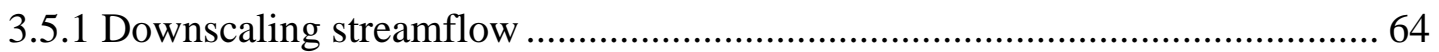

3.5.2 Copula methods for linking cholera and river discharge .............................. 75

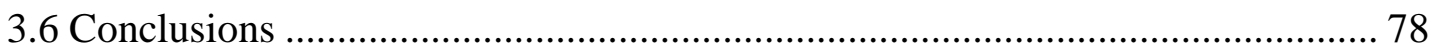

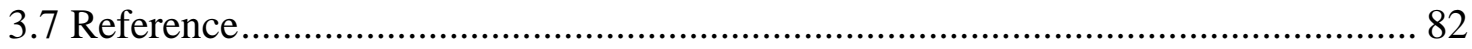

Chapter 4 Summary, discussion and scope of future work ................................... 88

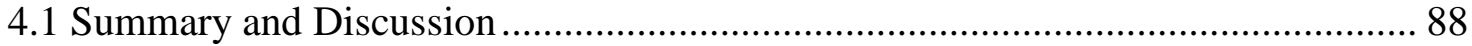

4.2 Scope of future work for development of mechanistic model ............................. 90

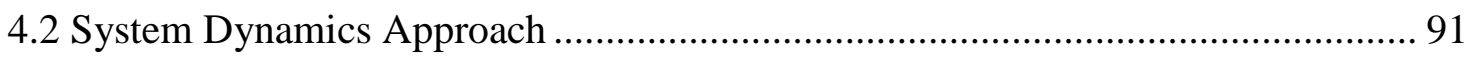

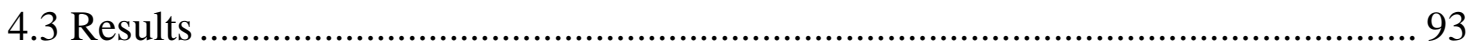

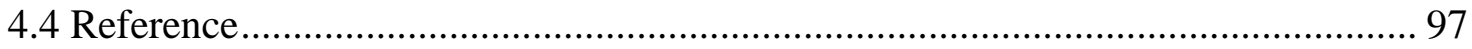




\section{List of Tables}

Table 2-1: Predictors obtained from simulations of 3 global climate change models (GCMs) from the IPCC data center

Table 2-2: Datasets used in this study. PSO-SVR: particle swarm optimization-support vector regression

Table 2-3: Calibration and validation results for downscaling precipitation of HadCM3, ECHAM5 and GDFL

Table 2-4: Variables for HadCM3, ECHAM5 and GDFL. Selected (grey) during calibration of the particle swarm optimization support vector regression (PSO-SVR) algorithm. $\bullet$ HadCM3, • ECHAM5, $\boldsymbol{\Delta}$ GFDL. Cost: Error minimization tradeoff parameter to achieve low training and testing errors. Gamma: Width of RBF kernel defining shape of boundary separation. Variable definitions are given in Table 1-1 ....... 28

Table 2-5: Model performance statistics for the observed river discharge-precipitation model. NSE: Nash Sutcliffe Efficiency

Table 2-6: Bias correction factors for three climate change models.

Table 2-7: Logistic regression model performance statistics for spring and autumn cholera

Table 3-1: Selected variables along with cost and gamma for three GCMs (ECHAM5, GFDL, and HADCM3).

Table 3-2: Calibration and validation results for downscaling Brahmaputra and Ganges streamflow.

Table 3-3: Ensemble uncertainty of combined river discharge under A2 and A1B scenarios based on three GCM models (HADCM3, ECHAM5, and GFDL).

Table 3-4: Selected marginal distribution, based on AD, KS, and CVM criteria, and their parameters 
Table 3-5: Selected copula, based on KS and CVM criteria, and estimated parameter for joint probability distribution of cholera and streamflow for spring and fall respectively 76

Table 3-6: Projected minimum, first quantile, median, third quantile and maximum

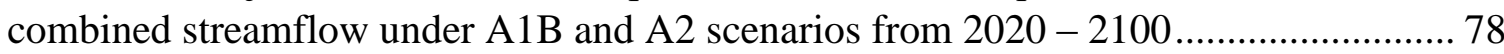




\section{List of Figures}

Figure 1-1: Global research pathway to understand impact of climate change on ecology of pathogenic vibrios. Solid dark lines represent scope of this research.

Figure 2-1: Location of Dhaka City, Bangladesh and Ganges-Brahmaputra-Meghna (GBM) river system

Figure 2-2: Seasonality of precipitation ( $\mathrm{mm} / \mathrm{month}$ ) and discharge of the Ganges, Brahmaputra, and combined rivers $\left(\mathrm{m}^{3} / \mathrm{s}\right)$.

Figure 2-3: Correlation between monthly observed and simulated precipitation using 3 global climate change models (GCMs) over Dhaka, Bangladesh

Figure 2-4: Simulated and observed river discharge for calibration period computed using equation 16 .

Figure 2-5: Simulated and observed river discharge (cusecs) using bias corrected P-Q model.

Figure 2-6: Seasonality of river discharge for $(\mathrm{a}-\mathrm{c})$ A1B and $(\mathrm{d}-\mathrm{f})$ A2 scenarios for $(\mathrm{a}, \mathrm{d})$ ECHAM5, (b, e) GFDL, and (c, f) HaDCM3 models

Figure 2-7: Changes in magnitude of river discharge for each decade under $(\mathrm{a}-\mathrm{c}) \mathrm{A} 2$ and $(\mathrm{d}-\mathrm{f})$ A1B scenarios for (a, d) ECHAM5, (b, e) GFDL, and (c, f) HADCM3 models. Percent change was calculated with respect to control historical data from 1960-1999. 35

Figure 2-8: Ensemble percent change in river discharge for each decade under (a) A1B and (2) A2 scenario. Number on figure indicate percent change

Figure 2-9: Uncertainty in ensemble river discharge for each decade for (a) A1B and (b) A2 scenario. The numbers on the figure shows the percent certainty in changes in river discharge

Figure 2-10: Ensemble mean probabilities for above average cholera for spring season under (a) A1B and (b) A2 scenarios; autumn season under (c) A1B and (d) A2 scenarios. Dashed line is linear trend with Kendall Tau values of (a) 0.31 ( $p<0.001$ ); (b) 0.29 
$(\mathrm{p}<0.001)$; (c) $0.23(\mathrm{p}<0.05)$, and (d) $0.16(\mathrm{p}<0.01)$. Shaded area represent confidence intervals.

Figure 2-11: Exceedence probability of above-average cholera outbreaks

Figure 3-1: Monthly observed vs simulated streamflow of Ganges under three GCM model (ECHAM5, GFDL, and HADCM3)

Figure 3-2: Monthly observed vs simulated streamflow of Brahmaputra under three GCM model (ECHAM5, GFDL, and HADCM3)

Figure 3-3: Simulated vs observed Ganges streamflow $\left(\mathrm{m}^{3} / \mathrm{s}\right)$.

Figure 3-4: Simulated vs observed Brahmaputra streamflow $\left(\mathrm{m}^{3} / \mathrm{s}\right)$

Figure 3-5: Projected ensemble streamflow of Ganges along with confidence interval. The first and second rows show the projected ensemble streamflow under A2 and A1B scenarios as well as the first and second column are associated to low and high flows. The black and red lines are related to projected date and confidence interval at 95\% .... 72

Figure 3-6: Projected ensemble streamflow of Brahmaputra along with confidence interval. The first and second rows show the projected ensemble streamflow under A2 and A1B scenarios as well as the first and second column are associated to low and high flows. The black and red lines are related to projected date and confidence interval at $95 \%$.

Figure 3-7: Cumulative density function of spring and fall cholera given streamflow. The first and second columns present CDF of cholera prevalence related to spring and fall respectively. The first, second and third rows shows CDF of cholera for historical, A1B

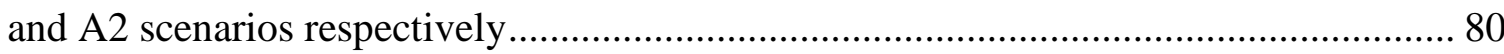

Figure 4-1: Schematic of incorporation of hydroclimate variables with cholera bacteria and trigger

Figure 4-2: Transmission of cholera prevalence in population using SIR model. 94

Figure 4-3: Simulated infected people 95 


\section{Chapter 1 Introduction}

The effects of predicted two to three degree of rise of global temperatures (IPCC 2007) will have uncertain effects on human health. Changing climate is likely to impact local to regional availability of water, thus likely to perturb delicate balance between humans and disease causing pathogens. One of the more serious consequences of climate change is on occurrence of pathogenic vibrios, which are responsible for leading cause of child death worldwide, killing over 1.5 million children annually and infecting millions more (Bartram and Cairncross, 2010). These diseases are not likely to be eradicated since the disease causing agents are always present and adapt to the local environment (Huq et al., 2005); that is further influenced by geophysical processes. Changing climate is likely to have wide-ranging effects on human health (McMichael et al., 1996; Haines et al., 2000). Most of these effects are likely to occur where hydrologic, climatic, and ecological extremes converge with population vulnerability, particularly in the developing world where it poses a severe threat to national security (Costello et al., 2009).

The focus of this research is on cholera a signature diarrheal disease that was first discovered by Pacini in 1854. Vibrio cholerae are comma-shaped gram-negative causative agent of cholera disease and it is contagious but his idea was under doubt and ignored (Howard-Jones, 1984). Thirty years later, Robert Koch rediscovered Vibrio as a

causative agent of cholera and named it $V$. cholerae (Lipp E. K. et al., 2002). John Snow was perhaps one of the first scientists to associate cholera and water drinking source in London in 1854 (Lipp E. K. et al., 2002). 
Since the nineteenth century cholera was spread in the world (pandemic) seven times affecting tens of millions of people (Kelley Lee 2003). The first cholera pandemic (1817-1823) was started from the Bengal region of India and reached to China, Japan, Southeast Asia, Russia, and Middle East at the end of pandemic. The Europe and United States were affected by the second pandemic (1826-1837). The third pandemic started in 1839 and continued till the end of 1856 before reaching South America. The sub-Saharan African region was affected by the fourth pandemic (1863-1875). During the fifth (18811896) and sixth pandemic (1899-1923) the Iran, Egypt, India, and the Philippines were severely affected (McNeil J 2001). The last pandemic originated from Indonesia in 1961 and persists up to day, primarily due to emergence of new strain (Aberth, John 2011). With changing climate, it is equally plausible that a next pandemic of cholera may be at horizon.

Vibrio Cholerae has various species that are categorized into 200 serogroups such as $\mathrm{O} 1, \mathrm{O} 2$ and etc. $\mathrm{O} 1$ and $\mathrm{O} 139$ are recognized to be pathogenic members that are responsible for major pandemics. The O1 serogroups can be divided to into three serotypes which are Inaba, Ogawa, and Hijokima or two biotypes (Classical and El Tor). Studies showed serogroup O1 and O139 are recognized for cholera epidemic (Faruque at al., 1998). For instance, the fifth and sixth pandemics were caused by $V$. cholera classical O1 biotype whereas $V$. cholera $\mathrm{O} 1 \mathrm{El}$ Tor biotype is responsible for the seventh pandemic.

Cholera occurs in three forms - epidemic (sudden or seasonal outbreaks in inland regions e.g., Pakistan, Mozambique, South Sudan, Zimbabwe, and most recently Haiti), 
endemic (recurrence and persistence of the disease for several consecutive years; primarily in coastal regions of the Bengal Delta and Sub-Saharan Africa) with significant spatial and temporal heterogeneity, and pandemic (epidemic occurrence in large region such as multiple countries) (Jutla et al., 2013a). The disease still remains a public health threat in the world, specifically in coastal areas of South Asia, Africa, and Latin America. Distribution of Vibrio cholera in the natural environment is unusually broad and accommodates two distinctive environments: the micro-environment of the human body and the macro-environment of aquatic habitats. Micro- is defined as processes related to bacteria themselves, while macro- refers to hydrological, ecological, and climatic processes affecting the bacteria (Jutla et al., 2010).

Despite a steady accumulation of knowledge on $V$. cholerae, the linkage between the appropriate trigger and transmission mechanisms of cholera and its outbreaks have not yet been established. There is a dire need for assessment of conditions related to when and where the next outbreak will occur, under changing climate. Growth of cholera bacteria has been hypothesized to be related to episodic variability in various macroenvironmental processes such as precipitation (Hashizume et al., 2008), floods (Koelle et al., 2005), peak river level (Schwartz et al., 2006), sea surface temperature (SST) (Lobitz et al., 2000; Pascual, 2000) and sea height (Lobitz et al., 2000), water temperature (Huq et al., 2005), plankton abundance (Worden et al., 2006; Jutla et al., 2013b), and fecal contamination (Islam et al., 2009). 


\subsection{Motivation and Objectives}

Linking climate change with diarrheal disease is challenging, primarily due to scale mismatch between macro and micro-environmental processes. Figure 1-1 shows a

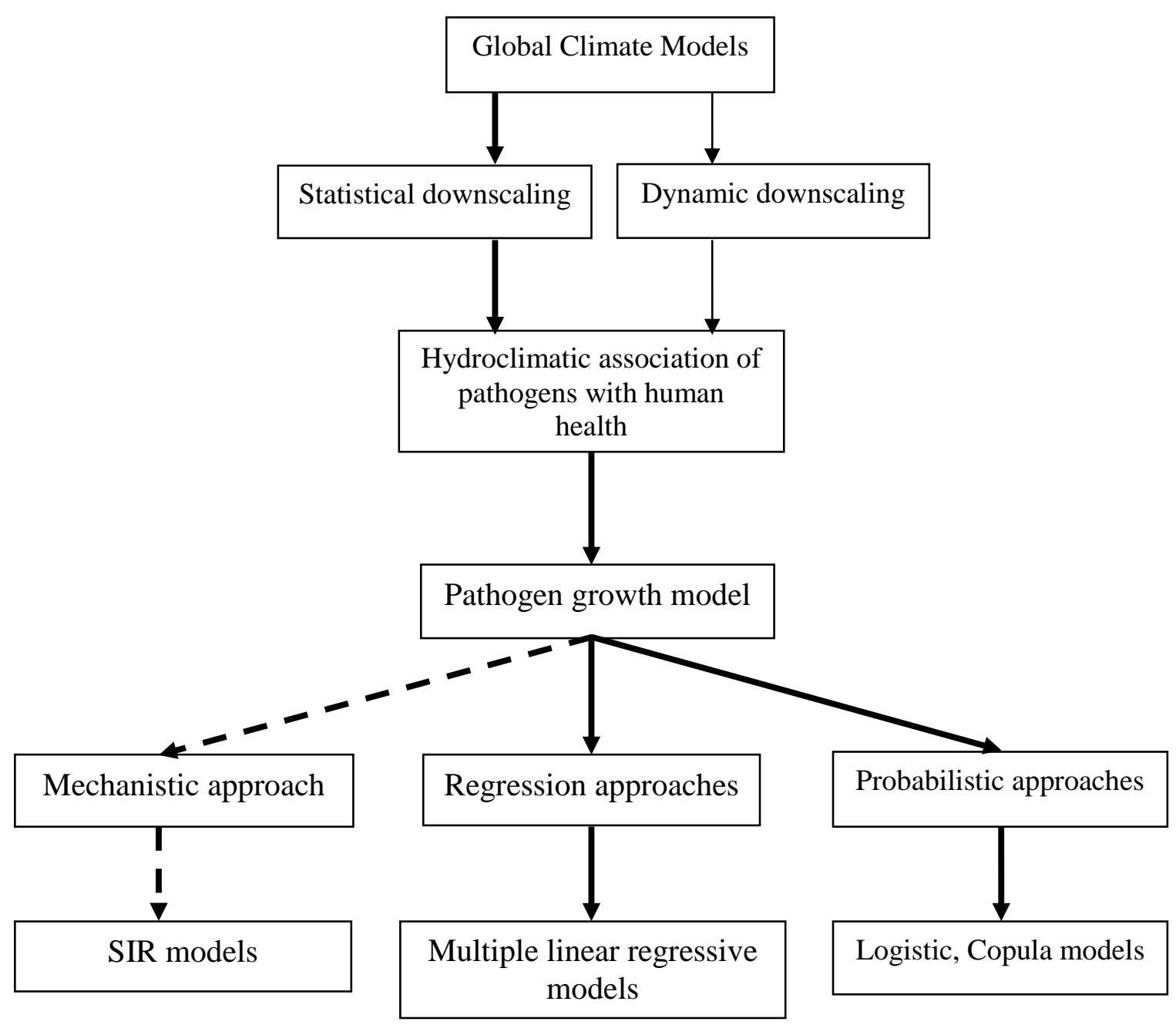

Figure 1-1: Global research pathway to understand impact of climate change on ecology of pathogenic vibrios. Solid dark lines represent scope of this research. Dashed line indicate conceptual model. 
schematics to understand impacts of changing climate on pathogenic vibrios. The solid lines are the scope of this research and will be explained in next chapters. Using cholera as a signature diarrheal disease, three empirical observations provide the motivation to explore effect of climate change on trigger of cholera:

(a) V. cholerae is native to the aquatic environment, with growing evidence of new biotypes/serotypes emerging under different climates (Siddique et al., 2010) (b) macro-environmental and micro-environmental processes have been found to affect different components of the disease transmission cycle (Colwell 1996; Koelle et al. 2005; Jutla et al. 2013a)

(c) Downscaling algorithms shows promises for studying of future hydro climatic variability (Tripathi et al. 2006, Guo et al. 2011).

Even though the linkage between effect of changing climate and infectious diseases have been investigated qualitatively (Patz et al., 2005), there is not yet any framework to quantitatively explore impact of changing climate on diarrhea diseases especially on cholera. The Global Climate Model (GCM) outputs and linkage development between hydroclimate variables and interested disease are two major challenges that are needed to be addressed. The coarse resolution of GCM outputs (100 $300 \mathrm{~km}$ ) are not appropriate for hydrologic studies where variability is usually limited at much fine resolution $(10-50 \mathrm{~km})$. Hence, within this context, three of this research are to: 
I. (i) develop algorithms to traditionally link geophysical processes with cholera and investigate changing patterns of climate on disease occurrence;

II. (ii) develop statistical algorithms to downscale non-traditional geophysical processes and to link with cholera, and compare it with the traditional approach, and

III. provide a conceptual systems approach to mechanistically simulate cholera under changing climate. The results related to the objectives are summarized in the following two papers:

Nasr-Azadani F, Unnikrishnan A, Akanda A, Islam S, Munir Alam, Anwar Huq, Antarpreet Jutla1, Rita Colwell (2015), Downscaling river discharge to assess the effects of climate change on cholera outbreaks in the Bengal Delta. Clim Res $64: 257-274$

Nasr-Azadani F, Unnikrishnan A, Akanda A, Munir Alam, Antarpreet Jutla1, Rita Colwell (2015), Hydroclimatic assessment of changing climate on occurrence of endemic cholera outbreaks in Ganges-Brahmaputra Basin, under review. 


\subsection{Reference}

Aberth, J. (2011). Plagues in World History. Rowman \& Littlefield Publishers.

Bartram, J., \& Cairncross, S. (2010). Hygiene, sanitation, and water: forgotten foundations of health. PLoS Med, 7(11), e1000367.

Colwell, R. R. (1996). Global climate and infectious disease: the cholera paradigm.

Science, 274(5295), 2025-2031.

Costello, A. B. (2009). Getting the most from your analysis. Pan, 12(2), 131-146.

Faruque, S. M., Albert, M. J., \& Mekalanos, J. J. (1998). Epidemiology, Genetics, and Ecology of ToxigenicVibrio cholerae. Microbiology and molecular biology reviews, 62(4), 1301-1314.

Guo J, Zhou JZ, Qin H, Zou Q, Li QQ (2011) Monthly streamflow forecasting based on improved support vector machine model. Expert Syst Appl 38:13073-13081

Haines, A., McMichael, A. J., \& Epstein, P. R. (2000). Environment and health: 2. Global climate change and health. Canadian Medical Association Journal, 163(6), 729-734.

Hashizume, M., Hayakawa, N., \& Mihara, M. (2008). IL-6 trans-signalling directly induces RANKL on fibroblast-like synovial cells and is involved in RANKL induction by TNF- $\alpha$ and IL-17. Rheumatology, 47(11), 1635-1640.

Howard-Jones, N. (1984). Robert Koch and the cholera vibrio: a centenary. BMJ, 288(6414), 379-381.

Huq, Anwar, R. Bradley Sack, Azhar Nizam, Ira M. Longini, G. Balakrish Nair, Afsar Ali, J. Glenn Morris et al. "Critical factors influencing the occurrence of Vibrio cholerae 
in the environment of Bangladesh." Applied and environmental microbiology 71, no. 8 (2005): 4645-4654.

Islam, M. S., Sharker, M. A. Y., Rheman, S., Hossain, S., Mahmud, Z. H., Uddin, A. M. K., ... \& Larson, C. P. (2009). Effects of local climate variability on transmission dynamics of cholera in Matlab, Bangladesh. Transactions of the Royal Society of Tropical Medicine and Hygiene, 103(11), 1165-1170.

Jutla AS, Whitcombe E, Hasan H, Haley B and others (2013a) Environmental factors influencing epidemic cholera response. Am J Trop Med Hyg 89:597-604

Jutla AS, Akanda AS, Islam S (2013b) A framework for predicting endemic cholera using satellite derived environmental determinants. Environ Model Softw 47:148-158

Jutla, A.S., Akanda, A.S. and Islam, S. 2010. Trackingcholera in coastal regions using satellite observations. Journal of American Water Resources Association. 46(4):651-662. Doi: 10.1111/j.1752-1688.2010.00448.x.

Kelley Lee (2003) "Health impacts of globalization: towards global governance". Palgrave Macmillan. p.131. ISBN 0-333-80254-3

Koelle, K., Rodó, X., Pascual, M., Yunus, M., \& Mostafa, G. (2005). Refractory periods and climate forcing in cholera dynamics. Nature, 436(7051), 696-700.

Lipp, E. K., Huq, A., \& Colwell, R. R. (2002). Effects of global climate on infectious disease: the cholera model. Clinical microbiology reviews, 15(4), 757-770.

Lobitz, B., Beck, L., Huq, A., Wood, B., Fuchs, G., Faruque, A. S. G., \& Colwell, R. (2000). Climate and infectious disease: use of remote sensing for detection of Vibrio 
cholerae by indirect measurement. Proceedings of the National Academy of Sciences, 97(4), 1438-1443.

McNeil J. 2000. Something New Under The Sun: An Environmental History of the Twentieth Century World (The Global Century Series).

Pascual, M., \& Ellner, S. P. (2000). Linking ecological patterns to environmental forcing via nonlinear time series models. Ecology, 81(10), 2767-2780.

Siddique, A. K., Nair, G. B., Alam, M., Sack, D. A., Huq, A., Nizam, A., ... \& Ahmed, S. (2010). El Tor cholera with severe disease: a new threat to Asia and beyond. Epidemiology and infection, 138(03), 347-352.

Tripathi S, Srinivas VV, Nanjundiah RS (2006) Downscaling of precipitation for climate change scenarios: a support vector machine approach. J Hydrol (Amst) 330: $621-640$

Worden, A. Z., Seidel, M., Smriga, S., Wick, A., Malfatti, F., Bartlett, D., \& Azam, F. (2006). Trophic regulation of Vibrio cholerae in coastal marine waters. Environmental Microbiology, 8(1), 21-29. 


\section{Chapter 2 Downscaling river discharge to assess the effects of climate change on cholera outbreaks in the Bengal Delta}

\subsection{Abstract:}

Endemic cholera in the Bengal Delta region of South Asia has been associated with asymmetric and episodic variability of river discharge. Spring cholera was found to be related to intrusion of bacteria-laden coastal seawater during low flow seasons. Autumn cholera was hypothesized to result from cross-contamination of water resources when high river discharge causes massive inland inundation. The effect of climate change on diarrheal diseases has not been explored, because of the difficulties in establishing linkages between coarse-resolution global climate model outputs with localized disease outbreaks. Since rivers act as corridors for transport of cholera bacteria, the first step is to understand the discharge variability that may occur with climate change and whether it is linked to cholera. Here, we present a framework for downscaling precipitation from global climate models for river discharge in the Ganges-Brahmaputra-Meghna basin. Using a data-mining method that includes particle swarm optimization-based support vector regression, precipitation was downscaled for a statistical multiple regressive model to estimate river discharge in the basin. Key results from an ensemble of HadCM3, GFDL, and ECHAM5 models indicated 8 and $7.5 \%$ increase in flows for the IPCC A1B and A2 scenarios, respectively. The majority of the changes are attributable to increases in flows from February through August for both scenarios, with little to no change in seasonality of high and low flows during the next century. The probability of spring and autumn cholera is likely to increase steadily in the endemic region of the Bengal Delta. 


\subsection{Introduction}

Cholera, a severe water-borne diarrheal disease, is a major public health concern on a global scale (Collins 2003). The bacterium Vibrio cholerae, the causative agent of the disease, is native to and proliferates in the aquatic environment (Huq et al. 2005). Occurrence of cholera is usually categorized as epidemic (seasonal and sudden outbreak, such as that which occurred in Haiti in 2010) or endemic (persistence of the disease throughout the year at a low rate with seasonal peaks as evidenced in the Bengal Delta) (Jutla et al. 2013a). Endemic cholera shows a strong relationship with coastal ecology and asymmetrical variability with river dynamics (Bertuzzo et al. 2008, Akanda et al. 2011, and Jutla et al. 2013b). Dual peaks of cholera in the Bengal Delta are associated with high and low river discharge of the Ganges and Brahmaputra rivers. The spring cholera peak is related to prevailing low flows, allowing intrusion of bacteria-laden seawater to inland regions, whereas the autumn peak is linked to widespread flooding due to monsoon rainfall, inducing cross-contamination from sanitation system overflow (Bertuzzo, et al. 2008, Akanda et al. 2009).

Climate change is predicted to have wide-ranging effects on human health (McMichael 1997, Haines et al. 2000), mostly where hydrologic, climatic, and ecological extremes converge with population vulnerability, notably in the developing world. The complex nature of environmental processes and socio-economic and cultural practices makes it difficult to interpret and quantify the linkages between climate change and human health. Human diseases have been linked with climate fluctuations and change (Haines et al. 2000, Patz et al. 2005), but for most waterborne pathogens monitoring is 
incomplete, with diagnoses that are not uniform and limited understanding of the effects of climate-related drivers. With a continuously expanding geography of cholera during the seventh pandemic and high mortality rates in newly affected regions of sub-Saharan Africa, effective global cholera prevention strategies are needed (Akanda et al. 2012). Prediction of conditions conducive to cholera is critical for planning the logistics associated with cholera prevention and treatment mechanisms, i.e. oral rehydration, antibiotics, and vaccination. Changing climatic patterns and their impact on cholera dynamics are not directly linked in current global climate change model (GCM) simulations, since these are usually at $100-200 \mathrm{~km}$ spatial resolution. The outputs of climate model simulations ( 100 km; Cooney 2012) cannot be directly applied to study cholera incidence in an area like Dhaka ( $\sim 10 \mathrm{~km}$ spatial resolution) or growth of cholera bacteria in a pond in the rural Matlab ( 1 m) region of Bangladesh. Reliable, long-term records of cholera incidence are not available, nor are observational data for cholera bacteria. Poor coverage, both spatially and temporally, of environmental drivers exacerbates the impediment to understanding and quantifying the climate-cholera connection. A robust and scalable framework is required to translate changes in climatic conditions of a vulnerable region, using scenarios of hydroclimatic and environmental drivers of cholera.

The objective of this study was to determine the effect of climate change on river discharge and thereafter on endemic cholera in the Bengal Delta. The motivations to estimate river discharge under climate change scenarios were as follows. (1) Empirical studies have shown that river discharge is a major contributing hydroclimatic process related to cholera (Pascual et al. 2008, Akanda et al. 2009). (2) Monsoon precipitation has 
been linked to variability in the flow of major Bengal rivers (Mirza 2003, Li et al. 2013).

(3) Downscaling algorithms show promise for study of future hydroclimatic variability (Tripathi et al. 2006, Guo et al. 2011). We developed a statistical data-mining algorithm for downscaling precipitation over the Bengal Delta. A multiple linear regression model using precipitation was then developed to estimate river discharge. A logistical regression model was later calibrated and validated for 2 seasonal peaks of cholera in Bangladesh using river discharge data.

\subsection{Geographical Location and Data}

The Ganges-Brahmaputra-Meghan (GBM) river system (Figure 2-1), located between $22^{\circ} 3.5^{\prime}$ and $31^{\circ} 50^{\prime} \mathrm{N}$ latitudes and $73^{\circ} 10.5^{\prime}$ to $97^{\circ} 53^{\prime}$ E longitudes, receives high precipitation from May through September (Figure 2-2). Bangladesh is the downstream region where the Ganges and Brahmaputra Rivers discharge into the Bay of Bengal. Dhaka City is located near the confluence of the Ganges and Brahmaputra Rivers. Monthly river discharge data, from 1975- 2006, for the Ganges (Hardinge gauge) and Brahmaputra (Bahadurabad gauge) rivers, and observed precipitation data for Dhaka on monthly scales from 1960-2006 were obtained from the Bangladesh University of Engineering and Technology.

The focal region of this study is Bangladesh, where an extensive data set on monthly cholera prevalence is available from 1980 and 2004. The data were collected and 


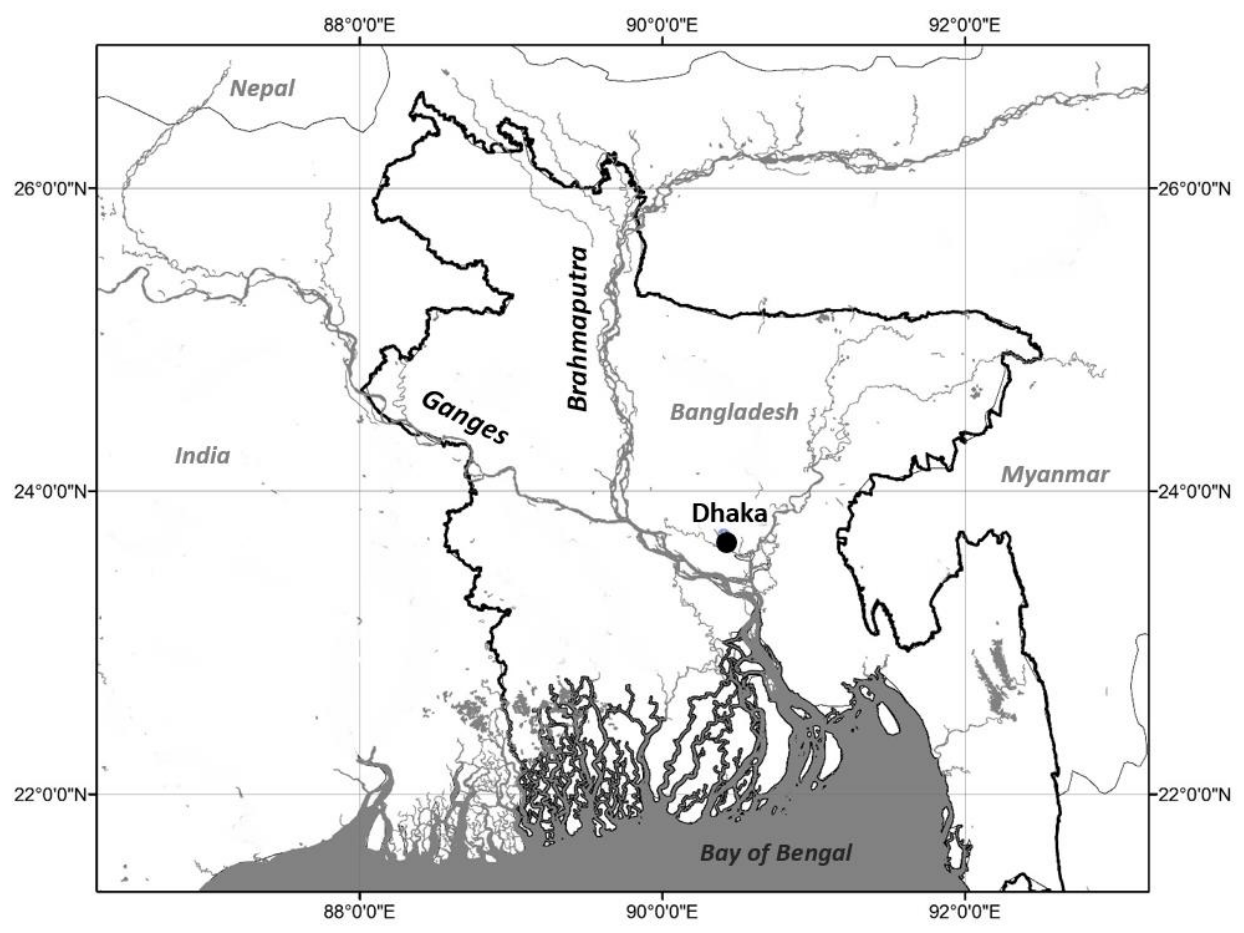

Figure 2-1: Location of Dhaka City, Bangladesh and Ganges-BrahmaputraMeghna (GBM) river system

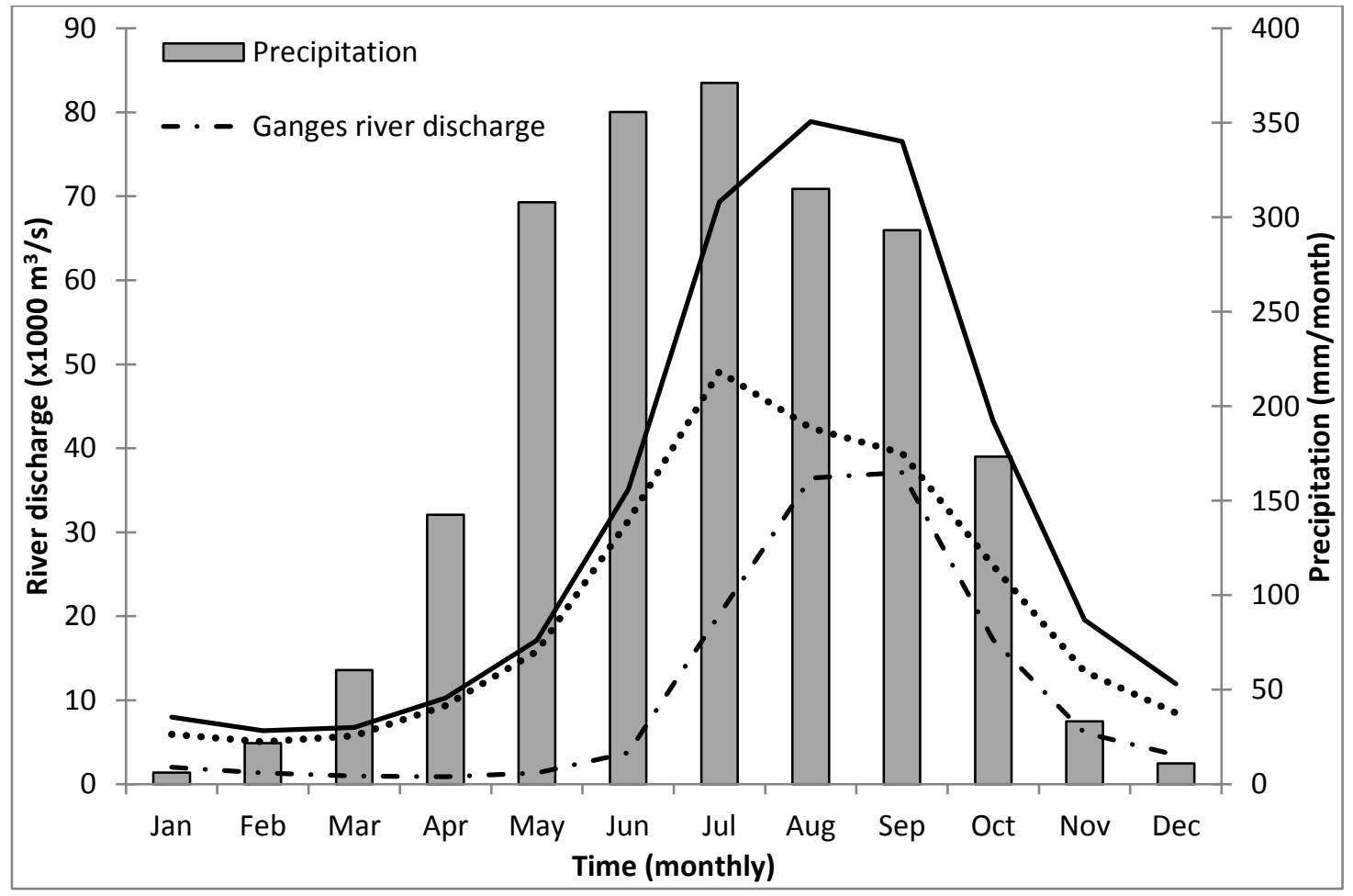

Figure 2-2: Seasonality of precipitation ( $\mathrm{mm} / \mathrm{month}$ ) and discharge of the Ganges, Brahmaputra, and combined rivers $\left(\mathrm{m}^{3} / \mathrm{s}\right)$. 
made available through the International Centre for Diarrhoeal Disease Research, Dhaka, Bangladesh. For the purpose of this study, the variable of primary interest is combined river discharge since it has asymmetrical effects in creating conditions favorable for cholera outbreaks (Akanda et al. 2009). Seasonality of the individual rivers differs, with the Ganges peaking roughly a month after the Brahmaputra River. High flow of the combined river discharge (sum of monthly discharges of the 2 rivers) occurs from June through October and low flow during December through March (Figure 2 - 2).

Simulated data on climate scenarios, on monthly scales from 2000-2100, were obtained from Intergovernmental Panel on Climate Change (IPCC) servers. Two scenarios, A1B and A2, from 3 global climate change models (GFDL, ECHAM5, and HADCM3) were used in this study. The A1B scenario is categorized by rapid economic growth, with a global population of 9 billion in 2050 coupled with efficient technology, while the A2 storyline is categorized by increasing population continually so that economic development is more regionally focused (see www.ipccdata.org/sim/gcm_monthly/ SRES_AR4/index.html). Each of these models produced outputs at coarse spatial scales and monthly time levels from 1960-2100. Table 2-1 lists 24 variables obtained from the $3 \mathrm{GCM}$ s that were used in this study. Table 2-2 provides a summary of datasets, variables used, time scales, and purpose of data.

\subsection{Method}

\subsubsection{Downscaling algorithm}

Statistical downscaling builds empirical relationships between GCM output and 
Table 2-1: Predictors obtained from simulations of 3 global climate change models (GCMs) from the IPCC data center

\begin{tabular}{ll}
\hline Variable & Description \\
\hline Hur200 & Relative humidity at $200 \mathrm{hPa}$ height \\
Hur500 & Relative humidity at $500 \mathrm{hPa}$ height \\
Hur850 & Relative humidity at $850 \mathrm{hPa}$ height \\
Mrso & Total soil moisture content \\
Pr & Total precipitation \\
Prc & Convective precipitation \\
Psl & Sea level pressure \\
Rsds & Surface downwelling shortwave radiation \\
Tas & Near surface air temperature \\
Ta200 & Air temperature at $200 \mathrm{hPa}$ height \\
Ta500 & Air temperature at $500 \mathrm{hPa}$ height \\
Ta850 & Air temperature at $850 \mathrm{hPa}$ height \\
Ts & Surface skin temperature/SST \\
Uas & Zonal surface wind speed \\
Ua200 & Zonal wind component at $200 \mathrm{hPa}$ height \\
Ua500 & Zonal wind component at $500 \mathrm{hPa}$ height \\
Ua850 & Zonal wind component at $850 \mathrm{hPa}$ height \\
Vas & Meridional surface wind speed \\
Va200 & Meridional wind component at $200 \mathrm{hPa}$ height \\
Va500 & Meridional wind component at $500 \mathrm{hPa}$ height \\
Va850 & Meridional wind component at $850 \mathrm{hPa}$ height \\
$Z g 200$ & Geopotential height at $200 \mathrm{hPa}$ \\
$Z g 500$ & Geopotential height at $500 \mathrm{hPa}$ \\
$Z g 850$ & Geopotential height at $850 \mathrm{hPa}$
\end{tabular}


Table 2-2: Datasets used in this study. PSO-SVR: particle swarm optimization-support vector regression

\begin{tabular}{|c|c|c|c|c|}
\hline Dataset & Resolution & Period & Purpose & Source \\
\hline $\begin{array}{l}\text { 20C3M of } \\
\text { GFDL }\end{array}$ & $\begin{array}{l}24 \text { monthly simulated } \\
\text { climate variables, coarse } \\
\text { resolution }\end{array}$ & 1960 to 2000 & $\begin{array}{l}80 \% \text { of the data randomly used for } \\
\text { calibrating and } 20 \% \text { used for validation }\end{array}$ & $\begin{array}{l}\text { IPCC (http://cera-www.dkrz.de/ } \\
\text { WDCC/ui/Compact.jsp?acronym } \\
\text { =GFDL_CM2.0_20C3M_1) }\end{array}$ \\
\hline $\begin{array}{l}20 \mathrm{C} 3 \mathrm{M} \text { of } \\
\text { ECHAM5 }\end{array}$ & $\begin{array}{l}24 \text { monthly simulated } \\
\text { climate variables, coarse } \\
\text { resolution }\end{array}$ & 1960 to 2000 & $\begin{array}{l}80 \% \text { of the data randomly used for } \\
\text { calibrating and } 20 \% \text { used for validation }\end{array}$ & $\begin{array}{l}\text { IPCC (http://cera-www.dkrz.de/ } \\
\text { WDCC/ui/Compact.jsp?acronym } \\
\text { =EH5_MPI_OM_20C3M_1) }\end{array}$ \\
\hline $\begin{array}{l}20 \mathrm{C} 3 \mathrm{M} \text { of } \\
\text { HADCM3 }\end{array}$ & $\begin{array}{l}24 \text { monthly simulated } \\
\text { climate variables, coarse } \\
\text { resolution }\end{array}$ & 1960 to 2000 & $\begin{array}{l}80 \% \text { of the data randomly used for } \\
\text { calibrating and } 20 \% \text { used for validation }\end{array}$ & $\begin{array}{l}\text { IPCC (http://cera-www.dkrz.de/ } \\
\text { WDCC/ui/Compact.jsp?acronym } \\
\text { =UKMO_HadCM3_20C3M_1) }\end{array}$ \\
\hline $\begin{array}{l}\text { River discharge } \\
\text { data }\end{array}$ & $\begin{array}{l}\text { Monthly discharge at } \\
\text { two gages on Ganges } \\
\text { and Brahmaputra Rivers }\end{array}$ & 1975 to 2006 & $\begin{array}{l}80 \% \text { of data used to calibrate the river } \\
\text { discharge - precipitation model; } 20 \% \text { used } \\
\text { for validation }\end{array}$ & $\begin{array}{l}\text { Bangladesh University of } \\
\text { Engineering and Technology }\end{array}$ \\
\hline $\begin{array}{l}\text { Precipitation } \\
\text { data }\end{array}$ & $\begin{array}{l}\text { Monthly data for Dhaka } \\
\text { City. }\end{array}$ & 1960 to 2006 & $\begin{array}{l}80 \% \text { of data used for calibration and } 20 \% \\
\text { used for validation }\end{array}$ & $\begin{array}{l}\text { Bangladesh University of } \\
\text { Engineering and Technology }\end{array}$ \\
\hline Cholera data & Monthly incidence data & 1980 to 2004 & $\begin{array}{l}80 \% \text { of the data used for calibrating the } \\
\text { cholera-river discharge model; } 20 \% \text { of } \\
\text { the dataset used for validation }\end{array}$ & $\begin{array}{l}\text { International Centre for Diarrhoeal } \\
\text { Disease Research, Dhaka, } \\
\text { Bangladesh }\end{array}$ \\
\hline
\end{tabular}


observed regional climatic processes. Statistical downscaling can be further categorized as resampling (Murphy 2000, Palutikof et al. 2002), weather typing (von Storch et al. 1993, Bardossy 1997), stochastic weather generator (Tung \& Haith 1995, Yu et al. 2002), and regression (Busuioc et al. 2001, Hellström et al. 2001, Hanssen-Bauer et al. 2003) methods. The regression method, based on building an empirical function (linearly or nonlinearly) between GCM output and local climatic processes, is reliable and easy to implement (Chen et al. 2010) in regions where observed boundary conditions are not readily available.

The regression function for downscaling can be derived from principal components (Menzel \& Burger 2002, Chu et al. 2008), artificial neural networks (Olsson et al. 2001, Dibike \& Coulibaly 2006), or support vector machine (SVM) (Tripathi et al. 2006, Chen et al. 2010) based algorithms. We used an SVM-based pattern classification algorithm, which is increasingly being used to downscale GCM output to regional scales, since it provides reliable accuracy at low computational costs. Tripathi et al. (2006) and Chen et al. (2010) downscaled precipitation using SVM to project climate change scenarios in Asia with satisfactory accuracy. Guo et al. (2011) and Lin et al. (2006) employed SVM to forecast and predict monthly river discharge in the Changjiang (Yangtze) River Basin and Manwan Hydropower Scheme, respectively. Behzad et al. (2009) concluded that SVM-based classification performed better than neural networks for rainfall-runoff processes. Chen et al. (2010) observed that SVM-based downscaling outperformed multivariate regression methods since SVM characterized non-linearity in the data more efficiently than simple regression. The challenge with SVM-based 
downscaling is selection of feature classes, such as predictor variables, and optimal parameters. We used a particle swarm optimization (PSO) algorithm to determine parameter space and to fine-tune feature class selection of the SVM model (He et al. 2008, 2009, Lin et al. 2008, Chen \& Lin 2009, Behnamian \& Ghomi 2010).

Support vector regression (SVR) utilizes the power of SVM-based classification patterns to minimize overfitting through structural risk minimization (Chen et al. 2010). Consider the training sample data $\left\{\left(x_{i}, y_{i}\right) \mid \forall i=1,2 \ldots, n\right\}$, where $x_{i} \in \mathrm{R}^{m}$ is an input vector and $\mathrm{yi} \in \mathrm{R}$ is the model output or target value. The goal of SVR for linear functional forms is to find a function, $f(x, w)=w^{T}+b$, where $w \in \mathrm{R}^{m}, b \in \mathrm{R}$, so that the model prediction best matches training data target values. In SVR, loss function is the $\varepsilon$ and the intensive loss function, $L[y i, f(x, w)]$, proposed by Vapnik (1995) is:

$$
L\left[y_{i}, f(x, w)\right]=\left\{\begin{array}{lc}
0 & \left|y_{i}-f\left(x_{i}, w\right)\right|<\grave{o} \\
\left|y_{i}-f\left(x_{i}, w\right)\right|-\grave{o} & \text { otherwise }
\end{array}\right.
$$

In the above equation, $\varepsilon$ is a predefined positive constant and can be viewed as a measure of noise or error allowed in the prediction. SVR attempts to obtain model parameters $\mathrm{W}$ and $\mathrm{b}$ by solving the following quadratic minimization formulation:

Minimize $R=C \sum_{i=1}^{n}\left(\xi_{i}^{+}+\xi_{i}^{-}\right)+\frac{1}{2} w^{2}$

Subject to: 


$$
\begin{array}{ll}
y_{i}-\left(w^{T} x_{i}+b\right)<\grave{o}+\xi_{i}^{+} & \forall i=1,2, \ldots . n \\
\left(w^{T} x_{i}+b\right)-y_{i}<\grave{o}+\xi_{i}^{-} & \forall i=1,2, \ldots n \\
\xi_{i}^{+} \geq 0, \xi_{i}^{-} \geq 0 & \forall i=1,2, \ldots n
\end{array}
$$

The SVR objective function has 2 goals: (1) to make the function fitted to the data points as flat as possible by minimizing the norm of $w, w^{2}$ and (2) to minimize error, represented as the amount by which deviations higher or lower than $\grave{o}$ are tolerated. The variable $\xi_{i}^{+}$represents deviation above $\grave{o}$ and $\xi_{i}^{-}$deviations below $\grave{o}$. The constant $C$ represents a tradeoff between minimizing errors and making the function as flat as possible. For nonlinear regression, a nonlinear mapping function $\square(x)$ is used to map input to higher dimensional space. A linear function is generated in the higher dimensional space, $f(x, w)=w^{T} \square(x)+b$, and a similar quadratic minimization problem can be formulated. Constraint (3) can be represented as:

$$
\begin{array}{ll}
y_{i}-\left(w^{T} \phi\left(x_{i}\right)+b\right)<\grave{o}+\xi_{i}^{+} & \forall i=1,2, \ldots . n \\
\left(w^{T} \phi\left(x_{i}\right)+b\right)-y_{i}<\grave{o}+\xi_{i}^{-} & \forall i=1,2, \ldots . n
\end{array}
$$

Using the principle of Lagrangian multipliers, the optimal value for $w$ and the functional form $f(x, w)$ can be obtained as:

$$
w=\sum_{i=1}^{n}\left(\alpha_{i}-\alpha_{i}^{*}\right) \phi\left(x_{i}\right)
$$


$f\left(x, \alpha_{i}, \alpha_{i}^{*}\right)=\sum_{i=1}^{n}\left(\alpha_{i}-\alpha_{i}^{*}\right) K\left(x, x_{i}\right)+b$

In the above equation, $K\left(x, x_{i}\right)=\square(x)^{T} \square\left(x_{i}\right)$ corresponds to a kernel function, any function which satisfies the Mercer Theorem (Mercer 1909). In this study, we used radial basis, sigmoid kernel functions to determine optimal parameter spaces. Also, the value of the Lagrangian multipliers $\square_{i}$ and $\square_{i}{ }^{*}$ can be obtained by solving the dual of the quadratic minimization problem given as:

Maximize $R=-\frac{1}{2} \sum_{i=1}^{n} \sum_{j=1}^{n}\left(\alpha_{i}-\alpha_{i}^{*}\right)\left(\alpha_{j}-\alpha_{j}^{*}\right) K\left(x_{i}, x_{j}\right)+\sum_{i=1}^{n} y_{i}\left(\alpha_{i}-\alpha_{i}^{*}\right)$

- ò $\left(\alpha_{i}+\alpha_{i}^{*}\right)$

Subject to:

$\sum_{i=1}^{n}\left(\alpha_{i}-\alpha_{i}^{*}\right)=0$

$0 \leq \alpha_{i}, \alpha_{i}^{*} \leq \mathrm{C} \quad \forall \mathrm{i}=1,2, \ldots . \mathrm{n}$

The data points corresponding to non-0 Lagrangian multipliers $\square_{i}$ or $\square_{i}{ }^{*}$ are support vectors. The bias-parameter, $b$, can be obtained using the following equation:

$\mathrm{b}=\frac{\sum_{\mathrm{i}=1}^{\mathrm{n}} \mathrm{y}_{\mathrm{d}}^{\mathrm{i}}}{\mathrm{n}}$

$\mathrm{y}_{\mathrm{d}}^{\mathrm{i}}=\mathrm{y}_{\mathrm{i}}-\sum_{\mathrm{i}=1}^{\mathrm{n}}\left(\alpha_{\mathrm{i}}-\alpha_{\mathrm{i}}^{*}\right) \mathrm{K}\left(\mathrm{x}, \mathrm{x}_{\mathrm{i}}\right)-\operatorname{òsign}\left(\alpha_{\mathrm{i}}-\alpha_{\mathrm{i}}^{*}\right) \quad \forall \mathrm{i}=1,2, . ., \mathrm{n}$

Several investigators have recommended using optimization-based meta-heuristic tuning to improve SVR prediction accuracy (Chapelle et al. 2002, He et al. 2008, Lin et al. 
2008). In this study, we fine-tuned and determined optimal values of the error minimization tradeoff parameter $\mathrm{C}$, kernel parameters, and best features (predictors), using the PSO approach adopted from Lin et al. (2008). The meta-heuristic PSO approach was selected to avoid dependencies or relationship between the parameter values and SVR performance metrics (Kennedy \& Eberhart 1995). Each solution (or particle) of PSO will comprise $\mathrm{m}+\mathrm{K}+1$ decision variables corresponding to $\mathrm{m}$ features, $\mathrm{K}$ parameters associated with the kernel selected, and 1 decision variable for the error minimization tradeoff parameter. The values of $m$ decision variables corresponding to $\mathrm{m}$ features range from 0 to 1 . For a variable value $\leq 0.5$, the corresponding feature was not selected, and for a variable with a value $>0.5$, the corresponding feature was selected. An overview of the PSO algorithm is provided below.

Step 1: A population of potential solutions, called particles, is randomly generated over multidimensional search space.

Step 2: The position of each particle is evaluated based on the objective or fitness function. In this study, the fitness function corresponds to deviation (evaluated as $r^{2}$ ) of the model prediction from the validation target value. The current fitness value of the particle is compared with the best recorded fitness. If the current fitness value is better than the best recorded fitness, the particle best recorded fitness is updated. Globally best fitness is obtained by comparing the best recorded fitness value with the current global best fitness value.

Step 3: Particle velocities and positions are updated using the following equations 


$$
\begin{array}{ll}
v_{i}^{h+1}=w v_{i}^{h}+c_{1} U_{1}^{h}\left(p b_{i}^{h}-x_{i}^{h}\right)+c_{2} U_{2}^{h}\left(g b^{h}-x_{i}^{h}\right) & \forall i=1, \ldots, M \\
x_{i}^{h+1}=x_{i}^{h}+v_{i}^{h+1} & \forall i=1, \ldots, M
\end{array}
$$

where $v_{i}^{h}=$ velocity of particle $i$ in iteration $h ; p b_{i}^{h}=$ current best solution of particle $i ; g b^{h}$ is the global best solution at iteration $h ; x_{i}^{h}$ is the position of particle $i$ in iteration $h ; U_{1}^{h}$ and $U_{2}^{h}$ are uniform random numbers in the range [0,1]; and $w, c_{1}$, and $c_{2}$ are inertial, self cognitive, and social cognitive parameters.

Step 4: Determine whether the termination criteria are satisfied, with termination criteria chosen as (1) when the best possible fitness function value does not change over a number of iterations or (2) when the maximum number of iterations is reached. If termination criteria are satisfied, no further step is followed. If termination criteria are not satisfied, step 2 is taken. The PSO-SVR theory has not been employed previously to downscale outputs from GCMs. The PSO-SVR-based machine learning algorithm is free from the assumption that the mean of a time series is constant. Therefore, in all likelihood, it is a robust algorithm for understanding the impact of climate variability under non-stationary hydroclimatic scenarios, as discussed by Milly et al. (2008). Simulated data for the 20th century (20C3M), obtained from IPCC, was used as the predictor data set to develop models with observed precipitation at Dhaka using the PSOSVR algorithm.

\subsubsection{Precipitation-river discharge (P-Q) model}

Linking river discharge to large-scale geophysical processes remains a challenge in the GBM basin. The goal was to develop a model to accurately simulate river discharge 
using the minimum number of parameters. Such a model should have the ability to be linked to GCM outputs to understand variability in streamflow in future decades. Appendix 1 provides an overview of key studies establishing relationships between river discharge and outputs from climate change models. A key observation is that the majority of studies used statistical models to downscale precipitation and temperature, after which hydrological routing models were used to estimate river discharge. Although results of the river discharge analyses appear to be satisfactory, most studies were conducted in geographical regions where detailed hydrological data were available for calibration and validation of a routing model. Due to the lack of availability of detailed hydrological data to develop a routing model for our study, we proceeded with a statistical river discharge estimation procedure. Hence, we developed an empirical statistical relationship between historical precipitation and river discharge. A multiple log linear regression model (Eq. 16) was calibrated and validated for the combined river discharge in the GBM basin:

$\ln \left(Q_{t}\right)=\beta 0+\beta 1 P t+\beta 2 P t-3+\beta 3 \ln (Q t-1)+\beta 4 \ln (Q t-3)+\varepsilon n$

where $\mathrm{Q}_{\mathrm{t}-1}$ and $\mathrm{Q}_{\mathrm{t}-3}$ are the combined river discharge at 1 and 3 mo lag times; $\mathrm{P}_{\mathrm{t}}$ and $\mathrm{P}_{\mathrm{t}-3}$ are precipitation at 1 and 3 mo lag times, and $\varepsilon_{\mathrm{n}}$ is the noise term. Variables in the model were selected after multiple combinations of trial and error runs using linear regression (details in section 4.2).

\subsubsection{Cholera-river discharge (C-Q) model}

A logistical regression approach was used to understand the effects of changing climate on cholera in the Bengal Delta. Binomial logistical regression models were developed to estimate the probabilistic likelihood of above and below average cholera 
levels. Based on our previous studies on the hydroclimatological association of cholera with river discharge (Akanda et al. 2009), separate models were developed for the spring (average of March, April, and May) and autumn (average of October, November, and December) seasons. Outputs were compared (Hosmer et al. 2013) using measures of association (Goodman-Kruskal Gamma) as well as goodness of fit (Hosmer-Lemeshow tests). Measures of association established relationships between the response variable (above-average cholera incidence) and predicted probabilities of the variables, showing the effect of predictors (river discharge) on seasonal cholera. Goodman-Kruskal Gamma is a non-parametric rank correlation that ranges between -1 and 1 , with 1 representing a perfect association. Hosmer-Lemeshow is a chi-squared test that assesses whether observed events match the expected output event in subgroups of a model population (Hosmer et al. 2013).

\subsection{Results}

\subsubsection{Downscaling precipitation: calibration and validation}

Monthly data simulated for the 20th century (20C3M) from 3 GCMs (HADCM3, GFDL, and ECHAM5) were used to develop a model for down scaling precipitation at Dhaka in Bangladesh. The datasets, from 1960-2000, were randomly divided into 2 separate sets for calibration and validation in the ratio of 80 to $20 \%$, respectively. Three statistical measures were used to determine the adequacy of model performance and include the coefficient of determination (referred to as the correlation coefficient, $\mathrm{r}^{2}$, hereafter), bias, and root mean square error (RMSE) on monthly scales. Table 2-3 shows the performance of the HadCM3, ECHAM5, and GFDL models during calibration and validation using the PSO-SVM algorithm. On average, a value of 0.86 , 
0.84 , and 0.83 for $\mathrm{r}^{2}$ during calibration and $0.71,0.68$, and 0.61 for validation was achieved for HadCM3, ECHAM5, and GFDL models, respectively. Similarly, RMSE values of $36.33,40.49$, and $43.58 \mathrm{~mm} \mathrm{mo}^{-1}$ for calibration and $76.31,57.02$, and 67.28 $\mathrm{mm} \mathrm{mo}^{-1}$ for validation were obtained for HadCM3, ECHAM4, and GFDL models, respectively. High RMSE values were noted for high river discharge months, partly due to the fact that the variability in precipitation is high during the same months. Average bias $\left(\mathrm{mm} \mathrm{mo}^{-1}\right)$ was recorded as $-3.78,-0.11$, and 0.38 during calibration; and 17.00, 0.71, and -14.81 during validation for HadCM3, ECHAM5, and GFDL models, respectively.

SVR is a machine learning statistical technique that identifies patterns in the data and then relates them to the output (in this case precipitation); it is therefore important to document model parameters. During development of the models, a radial basis function kernel function was used with 2 calibration parameters optimized using the PSO technique. The Gamma parameter was assigned a value of unity, and Table 2-4 lists the cost function parameter used for simulation of the models for 3 GCMs. Figure 2-3 shows coefficients of determination between simulated downscaled and observed precipitation from 1960-2000, obtained using data from all 3 GCMs. This figure along with other 
Table 2-3: Calibration and validation results for downscaling precipitation of HadCM3, ECHAM5 and GDFL

\begin{tabular}{|c|c|c|c|c|c|c|c|c|c|c|c|c|c|}
\hline \multirow{3}{*}{$\begin{array}{l}\text { Mean } \\
\text { SD } \\
\end{array}$} & & Jan & Feb & Mar & Apr & May & Jun & Jul & Aug & Sep & Oct & Nov & Dec \\
\hline & & 6.59 & 22.5 & 60.91 & 157.03 & 309.88 & 358.15 & 385.53 & 315.88 & 296.21 & 162.47 & 32.88 & 10.03 \\
\hline & & 10.64 & 19.55 & 54.1 & 82.84 & 147.08 & 159.08 & 142.51 & 124.2 & 131.54 & 108.3 & 50.15 & 23.92 \\
\hline \multicolumn{14}{|c|}{ HadCM3 } \\
\hline \multirow{2}{*}{$\mathrm{R}^{2}$} & Calibration & 0.98 & 0.73 & 0.98 & 0.81 & 0.9 & 0.78 & 0.66 & 0.78 & 0.82 & 0.98 & 0.67 & 0.98 \\
\hline & Validation & 0.72 & 0.66 & 0.68 & 0.67 & 0.58 & 0.62 & 0.63 & 0.68 & 0.58 & 0.74 & 0.85 & 0.81 \\
\hline \multirow{2}{*}{ RMSE } & Calibration & 0.15 & 14.19 & 6.19 & 36.56 & 49.61 & 75.67 & 87.98 & 64.08 & 68.35 & 12.65 & 38.8 & 0.78 \\
\hline & Validation & 13.93 & 10.74 & 28.98 & 65.59 & 77.53 & 97.07 & 91.89 & 53.59 & 98.14 & 72.28 & 27.21 & 45.33 \\
\hline \multirow{2}{*}{ Bias } & Calibration & -0.03 & 1.79 & -1.11 & -0.56 & -5.76 & -6.62 & 0.14 & -7.97 & 9.35 & 3.17 & -13.14 & 0.15 \\
\hline & Validation & -11.17 & -0.83 & 5.69 & -30.78 & 14.72 & -77.33 & 10.63 & 19.42 & 67.22 & 44.81 & -11.69 & -8.81 \\
\hline \multicolumn{14}{|c|}{ ECHAM5 } \\
\hline \multirow{2}{*}{$\mathrm{R}^{2}$} & Calibration & 0.98 & 0.98 & 0.73 & 0.77 & 0.97 & 0.69 & 0.77 & 0.78 & 0.81 & 0.94 & 0.73 & 0.98 \\
\hline & Validation & 0.85 & 0.78 & 0.69 & 0.66 & 0.7 & 0.72 & 0.53 & 0.64 & 0.54 & 0.74 & 0.53 & 0.73 \\
\hline \multirow{2}{*}{ RMSE } & Calibration & 0.16 & 0.17 & 31.5 & 50.6 & 27.5 & 89.5 & 87.2 & 62.24 & 64.79 & 31.89 & 37.51 & 2.84 \\
\hline & Validation & 20.38 & 13.4 & 34.36 & 66.97 & 80.08 & 118.97 & 60.32 & 106.17 & 79.43 & 63.18 & 26.57 & 14.48 \\
\hline \multirow{2}{*}{ Bias } & Calibration & -0.04 & 0.003 & 3.36 & 8.81 & 6.53 & -10.43 & -9.17 & -1.34 & 15.6 & -1.67 & -13.43 & 0.45 \\
\hline & Validation & 6.55 & -9.66 & 10.57 & 1.52 & 32.89 & -29.67 & -14.81 & 58.2 & 26.18 & -42.89 & -20.73 & -9.65 \\
\hline \multicolumn{14}{|l|}{ GDFL } \\
\hline \multirow{2}{*}{$\mathrm{R}^{2}$} & Calibration & 0.98 & 0.98 & 0.98 & 0.74 & 0.78 & 0.82 & 0.64 & 0.75 & 0.87 & 0.72 & 0.98 & 0.98 \\
\hline & Validation & 0.86 & 0.66 & 0.76 & 0.58 & 0.54 & 0.47 & 0.61 & 0.55 & 0.5 & 0.59 & 0.65 & 0.73 \\
\hline \multirow{2}{*}{ RMSE } & Calibration & 1.08 & 0.16 & 0.18 & 47.55 & 68.15 & 98.12 & 81.58 & 70.81 & 40.38 & 76.71 & 0.14 & 0.18 \\
\hline & Validation & 22.16 & 20.1 & 24.1 & 66.32 & 130.4 & 114.7 & 122.31 & 96.96 & 91.1 & 64.76 & 25.08 & 8.94 \\
\hline \multirow{2}{*}{ Bias } & Calibration & 0.16 & 0.03 & 0 & -0.22 & -6.06 & 13.07 & 6.21 & -10.59 & -0.1 & 14.98 & 0 & -0.02 \\
\hline & Validation & -18.13 & -5.15 & 20.48 & -34.11 & -23.67 & -96.16 & 39.06 & -38.67 & 39.31 & -8.99 & -1.73 & -6.74 \\
\hline
\end{tabular}


Table 2-4: Variables for HadCM3, ECHAM5 and GDFL. Selected (grey) during calibration of the particle swarm optimization support vector regression (PSO-SVR) algorithm. $\bullet$ HadCM3, • ECHAM5, $\boldsymbol{\Delta}$ GFDL. Cost: Error minimization tradeoff parameter to achieve low training and testing errors. Gamma: Width of RBF kernel defining shape of boundary separation. Variable definitions are given in

Table 1-1

\begin{tabular}{|c|c|c|c|c|c|c|c|c|c|c|c|c|}
\hline Variable & Jan & Feb & Mar & Apr & May & Jun & Jul & Aug & Sep & Oct & Nov & Dec \\
\hline Hur200 & 口 & 口 $\Delta$ & $\square \Delta$ & & $\bullet$ & $\Delta$ & 口० & $\bullet$ & $\bullet \Delta$ & $\bullet \Delta$ & $\square \Delta$ & n० \\
\hline Hur500 & $\Delta$ & घ० & "n & 口 & $\square \Delta$ & $\bullet \Delta$ & $\square \bullet \Delta$ & & $m \Delta$ & 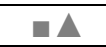 & $\cdot \Delta$ & $\overline{\Delta \Delta}$ \\
\hline Hur850 & $\Delta$ & $\Delta$ & $\Delta$ & $\bullet \Delta$ & & 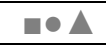 & 口० $\Delta$ & 무 & 口A & $n \Delta$ & $\Delta$ & $\square \Delta$ \\
\hline Mrso & $\because \bullet \Delta$ & $\Delta$ & & $\Delta$ & 口 & $\square \Delta$ & $\square \bullet \Delta$ & $\bullet$ & & & $\bullet$ & $\Delta$ \\
\hline$P r$ & 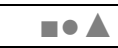 & 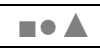 & n० & $\bullet$ & घ० & $\bullet$ & घ๑ & $\square \Delta$ & $\square \Delta$ & $\square$ & घ० & $\Delta$ \\
\hline Prc & n๑ & 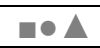 & $\bullet$ & "०A & 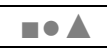 & 口A & $\pm \Delta$ & $\bullet \Delta$ & $\bullet$ & $\bullet$ & & 口A \\
\hline$P s l$ & $\square \Delta$ & & $\square \bullet \Delta$ & $\Delta$ & $\bullet \triangle$ & $\bullet$ & & $\bullet$ & $\bullet$ & घ० & & $\Delta$ \\
\hline$R s d s$ & घ० & $\square \bullet \Delta$ & $\square \bullet \Delta$ & $\bullet \Delta$ & घ॰ & $\bullet$ & & $\bullet \Delta$ & $\bullet \Delta$ & $n \Delta$ & $\bullet$ & \\
\hline Ta200 & 무임 & 口 & $\bullet \Delta$ & 모 & 口० $\Delta$ & 口 & $\bullet \Delta$ & 口・A & $\bullet$ & 口A & & $\Delta$ \\
\hline Ta500 & & $\bullet$ & घ० & $\Delta$ & & 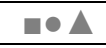 & a & $n \Delta$ & $\bullet \triangle$ & E・A & & $\bullet \Delta$ \\
\hline Ta850 & $\square$ & 뭉 & $m \bullet \Delta$ & $\square \Delta$ & & $\Delta$ & & ! & $\because \bullet \Delta$ & n० & $n \Delta$ & \\
\hline Tas & 口曰 & n曰 & $\bullet \Delta$ & n॰ & $\Delta$ & $\Delta$ & & $\Delta$ & & $\bullet \Delta$ & 口० $\Delta$ & 口 \\
\hline$T s$ & $\Delta$ & $\Delta$ & $\bullet$ & ! & $\bullet \Delta$ & $\Delta$ & $\bullet \Delta$ & $\Delta$ & 口० & $\circ \Delta$ & $\square \bullet \Delta$ & $\Delta$ \\
\hline Ua200 & $\square \Delta$ & $\Delta$ & $\Delta$ & $\cdot \Delta$ & घ० & $\Delta$ & $\Delta$ & $\bullet \Delta$ & $\square \Delta$ & $\bullet$ & $\bullet$ & घ॰ \\
\hline Ua500 & 口 & $\bullet \Delta$ & $\Delta$ & 口 & 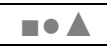 & $\square$ & & 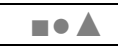 & $\Delta$ & 口० & 口 & $\square \Delta$ \\
\hline Ua850 & & घ! & $\bullet$ & $\square \bullet \Delta$ & $\bullet$ & $\bullet \Delta$ & 口A & ne & $\square \bullet \Delta$ & 口० & 무 & $\bullet$ \\
\hline Uas & 口 & $\Delta$ & 口 & $\square \Delta$ & $\bullet \Delta$ & घ० & n॰ & $\Delta$ & घ॰ & $n \Delta$ & & 口० \\
\hline Va200 & घ० & & $\square \Delta$ & & 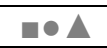 & 口 & 口A & 口 & $\bullet \Delta$ & $\square \Delta$ & $\square \Delta$ & $\bullet$ \\
\hline Va500 & 무 & $\square \Delta$ & ㅁ. & 口10 & 口० $\Delta$ & $\bullet$ & $\bullet \triangle$ & $\bullet \Delta$ & 口A & n॰ & $\square \Delta$ & \\
\hline Va850 & & $\square \Delta$ & & $\bullet$ & $\Delta$ & $\Delta$ & $\Delta$ & $\Delta$ & $\bullet \Delta$ & $\square \bullet \Delta$ & $\square \bullet \Delta$ & $\square$ \\
\hline Vas & nA & ㅁ. & $\bullet$ & $\bullet$ & $\Delta$ & 口 & 口A & 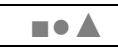 & ! & 口 & 口・A & $\bullet$ \\
\hline $\mathrm{Zg} 200$ & n० & & 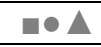 & $\Delta$ & 口. & $n \Delta$ & 口 & $\Delta$ & $\bullet \Delta$ & $\bullet$ & $\bullet \Delta$ & $\bullet$ \\
\hline $\mathrm{Zg} 500$ & 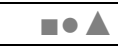 & & n๑ & 口० $\triangle$ & घ॰ & $\square \bullet \Delta$ & $\square \bullet \Delta$ & $\square \bullet \Delta$ & $\bullet$ & $\Delta$ & 口 & $\square \Delta$ \\
\hline $\mathrm{Zg} 850$ & & 口० $\Delta$ & $\square \Delta$ & 口० & $\bullet \Delta$ & 口 & 口० $\Delta$ & $\square \Delta$ & 口 & $\bullet$ & 口० $\Delta$ & $\square \Delta$ \\
\hline Cost HadCM3) & 2 & 0.66 & 3.89 & 2.74 & 5.58 & 1.7 & 3.75 & 49.88 & 27.49 & 6.86 & 1.41 & 3.84 \\
\hline Cost (ECHAM5) & 6.83 & 7.79 & 1.29 & 1.39 & 4.96 & 1.51 & 1.67 & 2 & 5 & 4.81 & 1.44 & 4.17 \\
\hline $\operatorname{Cost}(G F D L)$ & 4.8 & 7 & 3.9 & 2.72 & 5 & 1.58 & 4.6 & 9.65 & 6.89 & 1.73 & 1.28 & 0.97 \\
\hline Gamma & 1 & 1 & 1 & 1 & 1 & 1 & 1 & 1 & 1 & 1 & 1 & 1 \\
\hline
\end{tabular}


statistical measures indicate that the PSO-SVR algorithm satisfactorily captured variability between observed Dhaka precipitation and GCM output of HADCM3, ECHAM5, and GFDL models.

\subsubsection{Precipitation-river discharge (P-Q) model}

A multiple log-linear regression model was calibrated and validated for estimating river discharge. Historical river discharge and precipitation data from 1975-2000 (about $80 \%$ of the data) were used to develop the model while the remaining data from 2001-2006 were used to test the developed model. With reference to basins like GBM, where reliable rainfall runoff routing models cannot be developed due to unavailability of geophysical data, Miller et al. (1981) suggested that inclusion of precipitation to forecast river discharge may yield satisfactory results, since precipitation provides nonlinearity components of variability in discharge. Such modeling approaches have been used where geophysical data were not available (e.g. Yazicigil et al. 1982, Kottegoda et al. 2000, Mirza 2003) for development of mechanistic rainfall-runoff models. The model in Eq. (16) provided the highest $r^{2}(0.95)$, adjusted $r^{2}(0.94)$, and predicted $r^{2}(0.94)$ during the calibration process. Residuals showed a statistically insignificant autocorrelation (0.01 at Lag 1). Values of 4.590 (95\% CI: $4.136-5.045), \quad 0.00428 \quad(95 \% \quad$ CI: $0.000184-$ $0.000671), 0.000773$ (95\% CI: $0.000541-0.00100), 1.050$ (95\% CI: 0.9404-1.159), and 2.237 (95\% CI: $2.131-2.342)$ were obtained from $\beta 0, \beta 1, \beta 2, \beta 3$, and $\beta 4$, respectively, with $\mathrm{p}<0.05$, indicating statistical significance of all the parameters. Variance inflation factors ranged between 1.5 and 2.2, suggesting the absence of multicollinearity between 


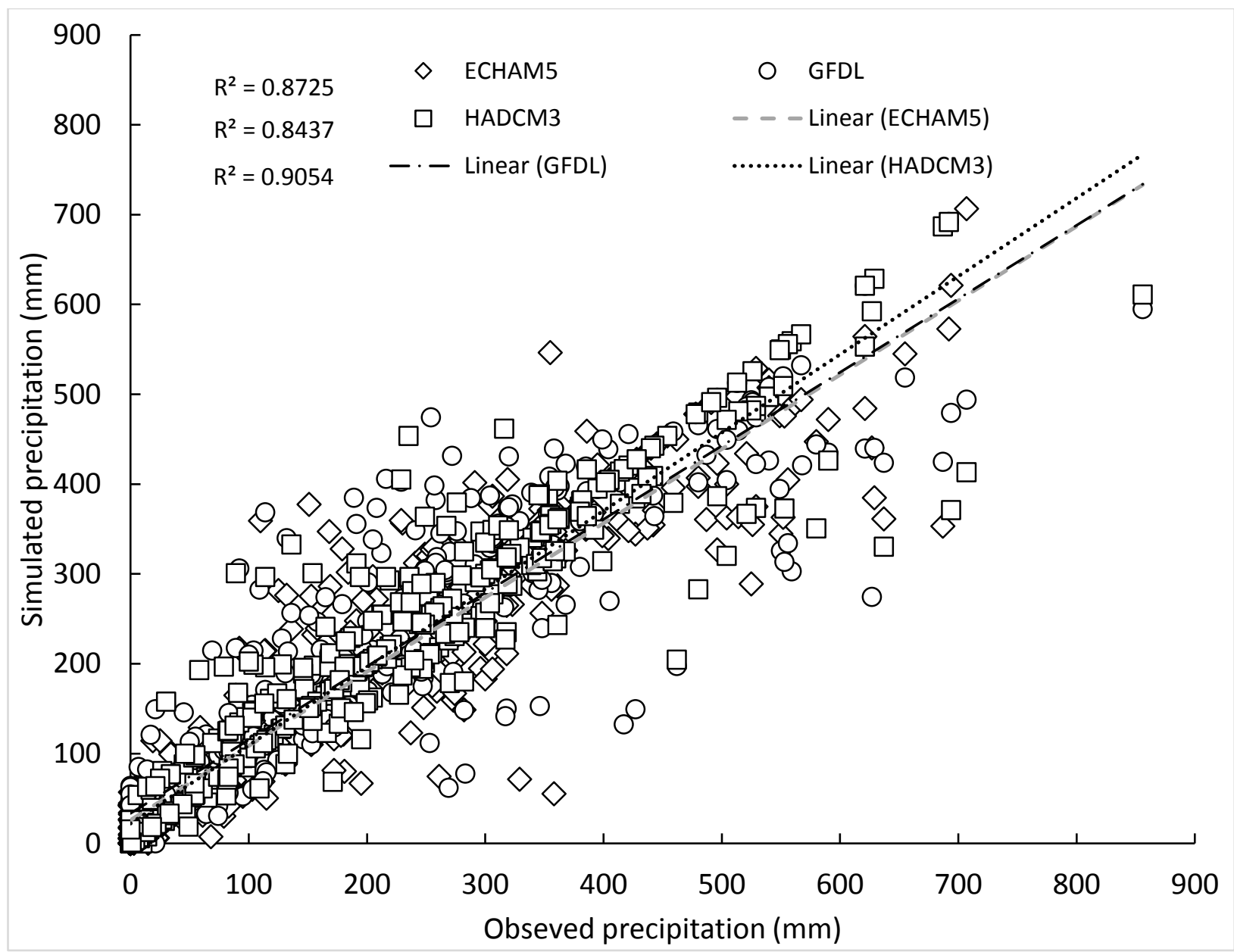

Figure 2-3: Correlation between monthly observed and simulated precipitation using 3 global climate change models (GCMs) over Dhaka, Bangladesh

Table 2-5: Model performance statistics for the observed river discharge-precipitation model. NSE: Nash Sutcliffe Efficiency

\begin{tabular}{|lcccc|}
\hline & $\mathrm{R}^{2}$ & Bias (cusecs) & $\begin{array}{c}\text { RMSE } \\
\text { (cusecs) }\end{array}$ & NSE \\
\hline Calibration & 0.863 & 1.525 .615 & 15295.6 & 0.730 \\
Validation & 0.830 & 1.010 .258 & 16900 & 0.680 \\
\hline
\end{tabular}




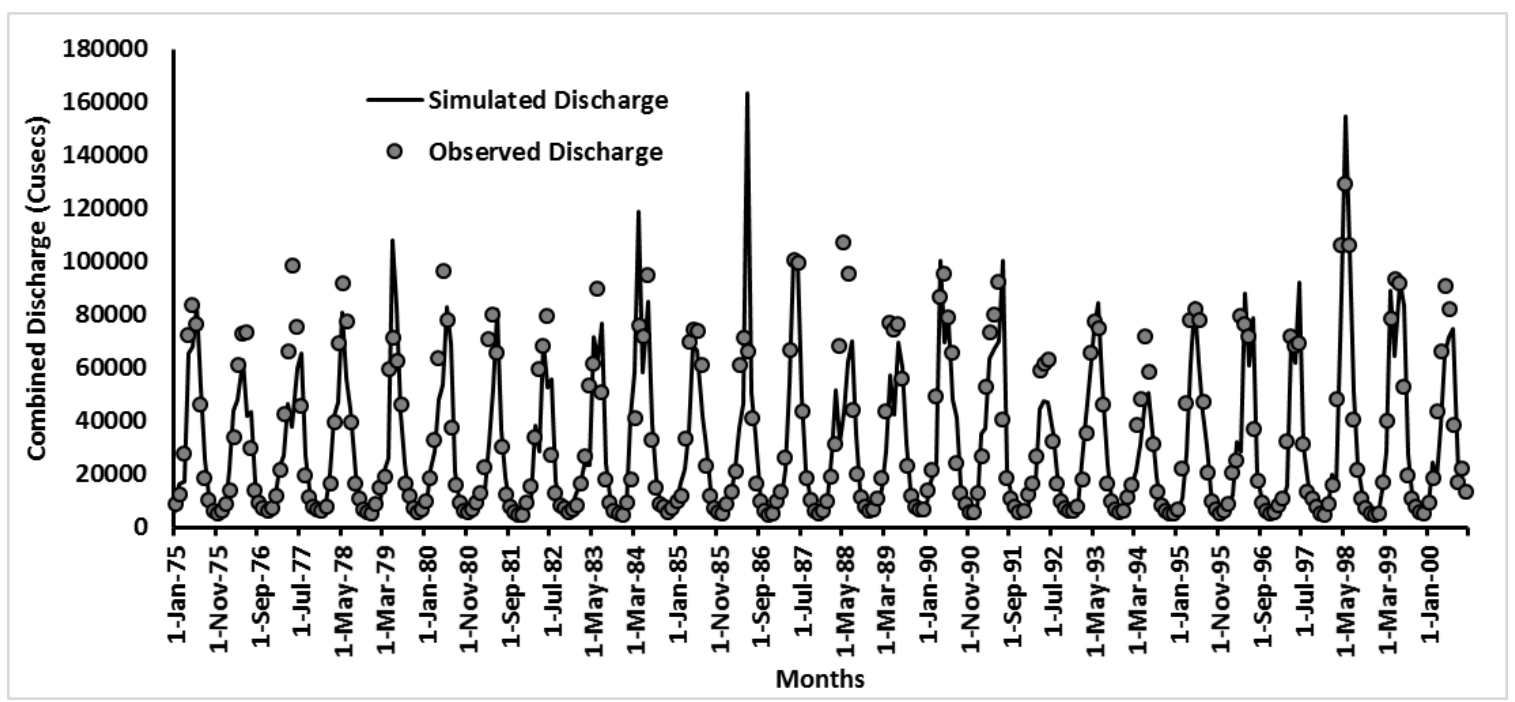

Figure 2-4: Simulated and observed river discharge for calibration period computed using equation 16

variables used to construct the model. The performance of the model was tested using $\mathrm{r}^{2}$, RMSE, bias, and Nash Sutcliffe Efficiency. Table 2-5 and Figure 2-4 show that the model was able to capture variability in the river discharge, during both the calibration and validation processes. The correlation between high and low river discharge months was 0.80 and 0.92 , respectively, further suggesting that the P-Q model was able to capture variability in both spectrums of streamflow. A complementary analysis was performed to determine whether the P-Q model adequately simulated river discharge using precipitation downscaled using 20C3M scenarios for 3 GCMs. Considerable bias was noted in river discharge, and hence, a monthly bias correction factor was computed as the ratio of $20 \mathrm{C} 3 \mathrm{M}$ simulated and observed river discharge (Table 2-6). Figure 2-5 shows simulated and observed river discharge, and the 1:1 line with $r^{2}$ values suggests a minimal bias in the P-Q model after applying correction factors. 
Table 2-6: Bias correction factors for three climate change models.

\begin{tabular}{cccc}
\hline & ECHAM5 & GFDL & HADCM3 \\
\hline January & 0.80 & 0.78 & 0.77 \\
February & 0.77 & 0.76 & 0.77 \\
March & 0.77 & 0.76 & 0.78 \\
April & 0.92 & 0.90 & 0.94 \\
May & 0.96 & 0.95 & 0.98 \\
June & 1.20 & 1.16 & 1.19 \\
July & 1.53 & 1.53 & 1.54 \\
August & 1.50 & 1.52 & 1.49 \\
September & 1.52 & 1.50 & 1.46 \\
October & 1.12 & 1.11 & 1.05 \\
November & 0.79 & 0.78 & 0.75 \\
December & 0.80 & 0.79 & 0.76 \\
\hline
\end{tabular}

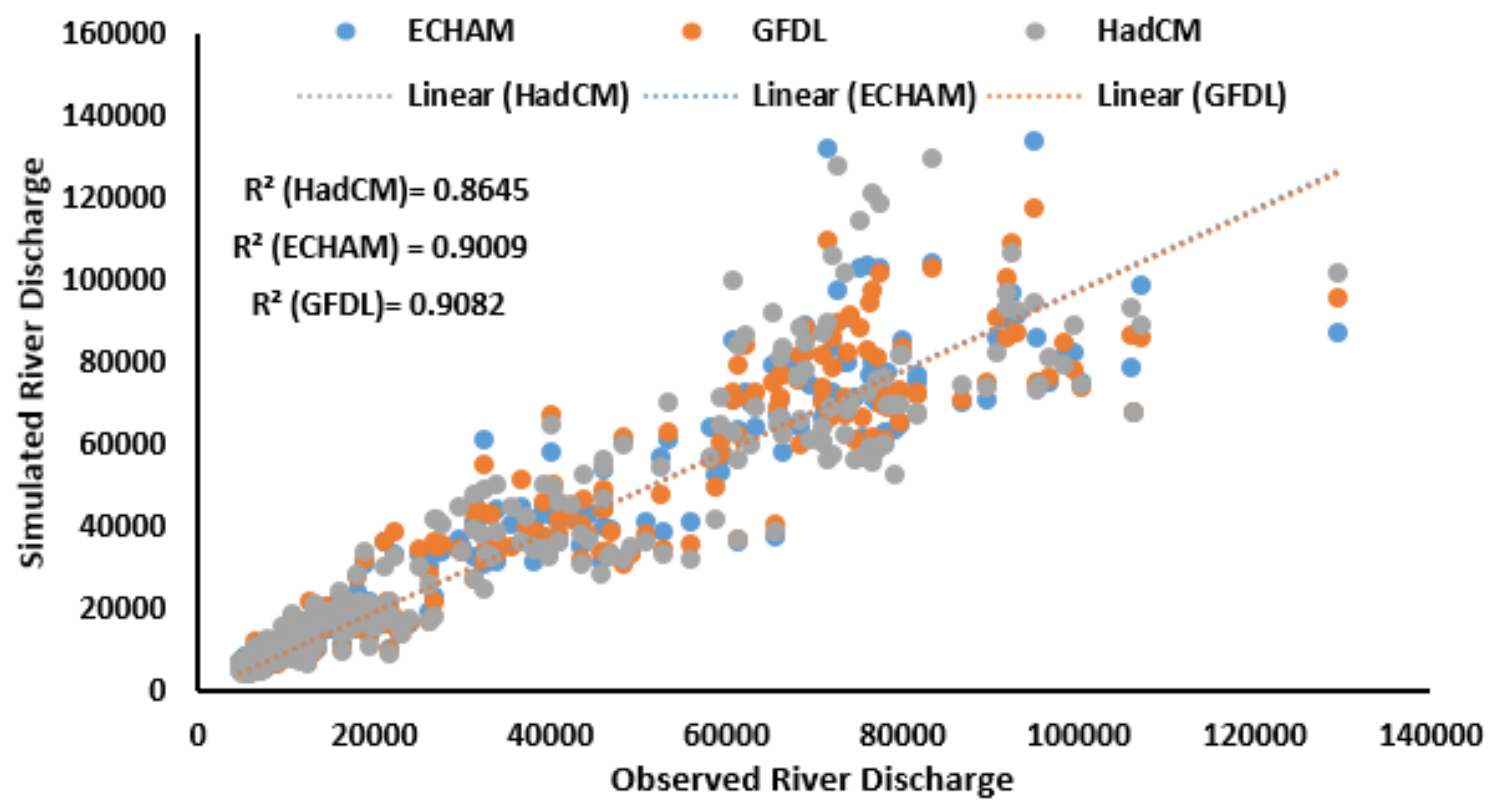

Figure 2-5: Simulated and observed river discharge (cusecs) using bias corrected P-Q model 


\subsubsection{Analysis of river discharge}

Using the calibrated P-Q model, combined river discharge was computed for 2 climate change scenarios, A1B and A2, with downscaled precipitation obtained from 3 GCMs. Since long-term changes in hydroclimatological processes are generally observable on longer temporal scales (Immerzeel 2008, Gain et al. 2011, Kamal et al. 2013), combined discharge for both climate change scenarios was averaged for $10 \mathrm{yr}$ to evaluate the possible changes. Historically, the highest and lowest combined river discharges are observed in the months of August and February, respectively. Figure 2-6 indicates that there are no shifts in the seasonality of discharge. Figure $2-7 \mathrm{a}-\mathrm{c}$ was plotted to show the percent change in monthly combined river discharge in the A1B scenario using the P-Q model with precipitation downscaled from 3 GCMs. The percentage change was calculated by subtracting historical monthly combined river discharge from 1975-2006 from values obtained using P-Q models with downscaled precipitation. Historically, low flow months were from December to March, while June through October are considered high flow months. A decrease in flow during December and January was noted, while March and April showed an increase in discharge for ECHAM5 (Figure $2-7$ a) and GFDL (Figure $2-7$ b) under the A2 scenario. The simulation using HADCM3 (Figure $2-7 \mathrm{c}$ ), on the other hand, showed little to no change in the dry season flows. Discharge outputs from GFDL (Figure $2-7$ b) and HADCM3 (Figure $2-7$ c) showed increases in the high flows during June through August, while in September and October, discharge decreased. ECHAM5 (Figure $2-7$ a) indicated no noticeable changes in the high flows during the next century. A similar observation is true for flows under A1B scenarios for 3 models (Figure $2-7 \mathrm{~d}-\mathrm{f}$ ). In 

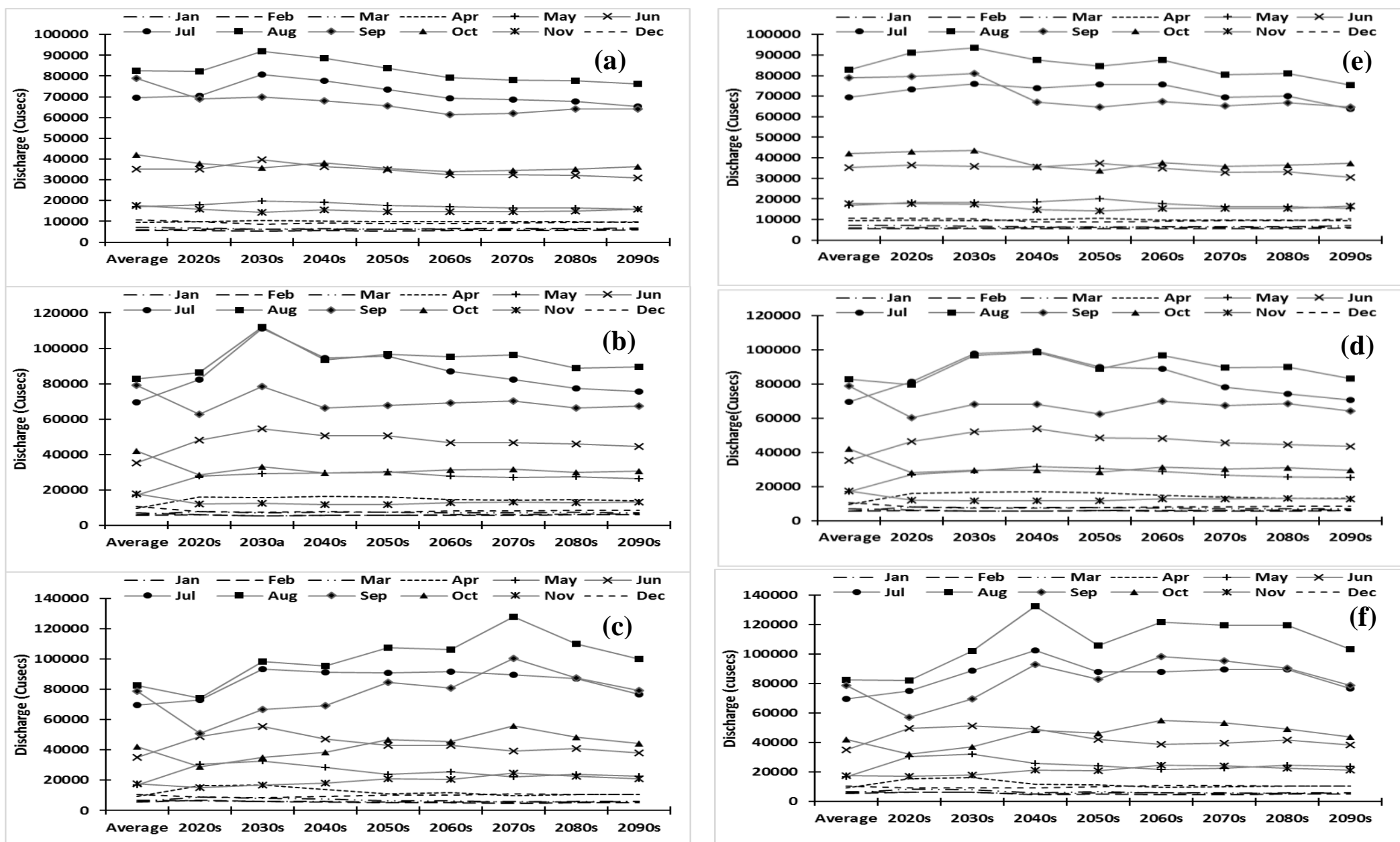

Figure 2-6: Seasonality of river discharge for $(a-c)$ A1B and $(d-f)$ A2 scenarios for (a, d) ECHAM5, (b, e) GFDL, and (c, f) HaDCM3 models 

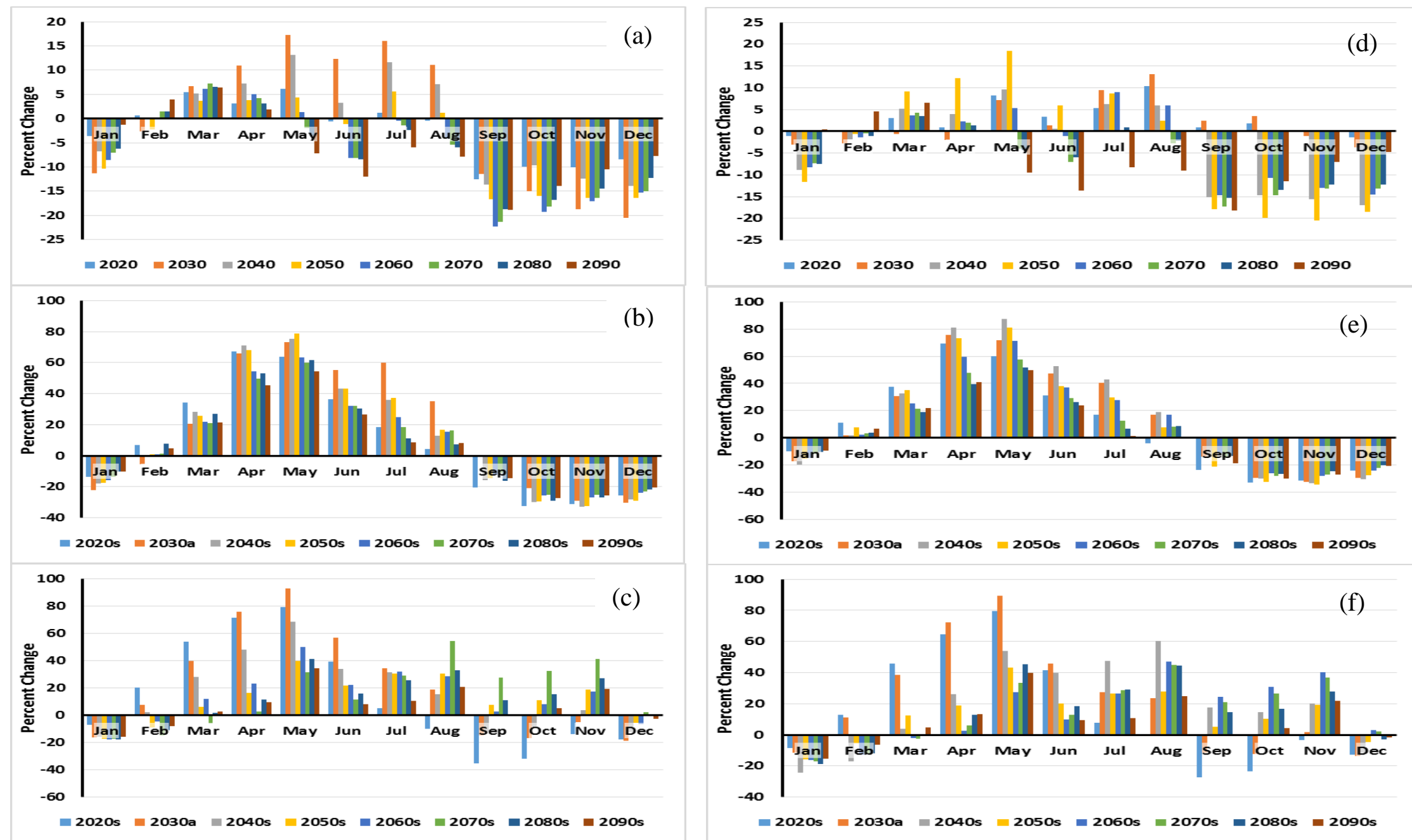

Figure 2-7: Changes in magnitude of river discharge for each decade under $(a-c)$ A2 and (d-f) A1B scenarios for (a, d) ECHAM5, (b, e) GFDL, and (c, f) HADCM3 models. Percent change was calculated with respect to control historical data from 1960-1999 

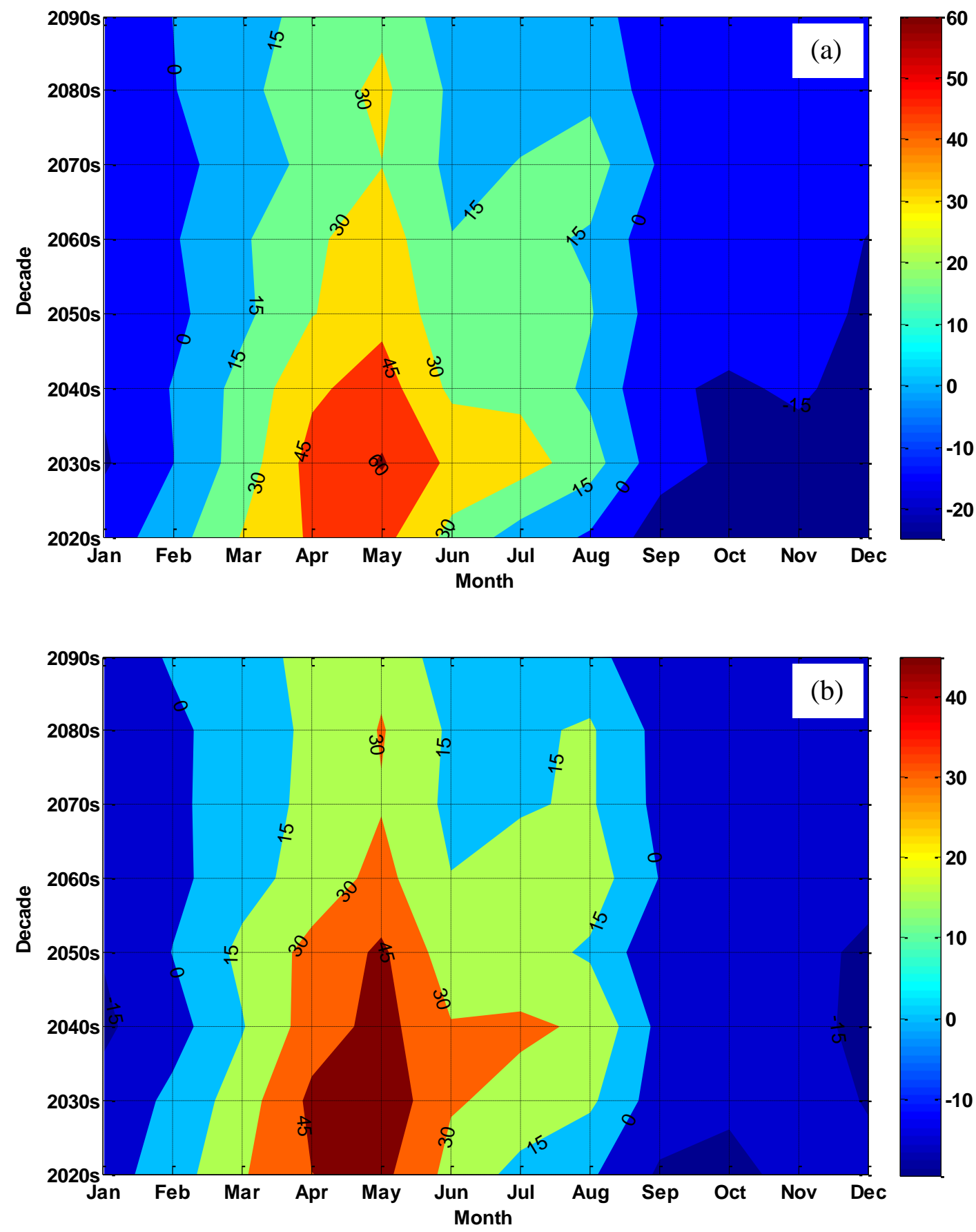

Figure 2-8: Ensemble percent change in river discharge for each decade under (a) A1B and (2) A2 scenario. Number on figure indicate percent change 

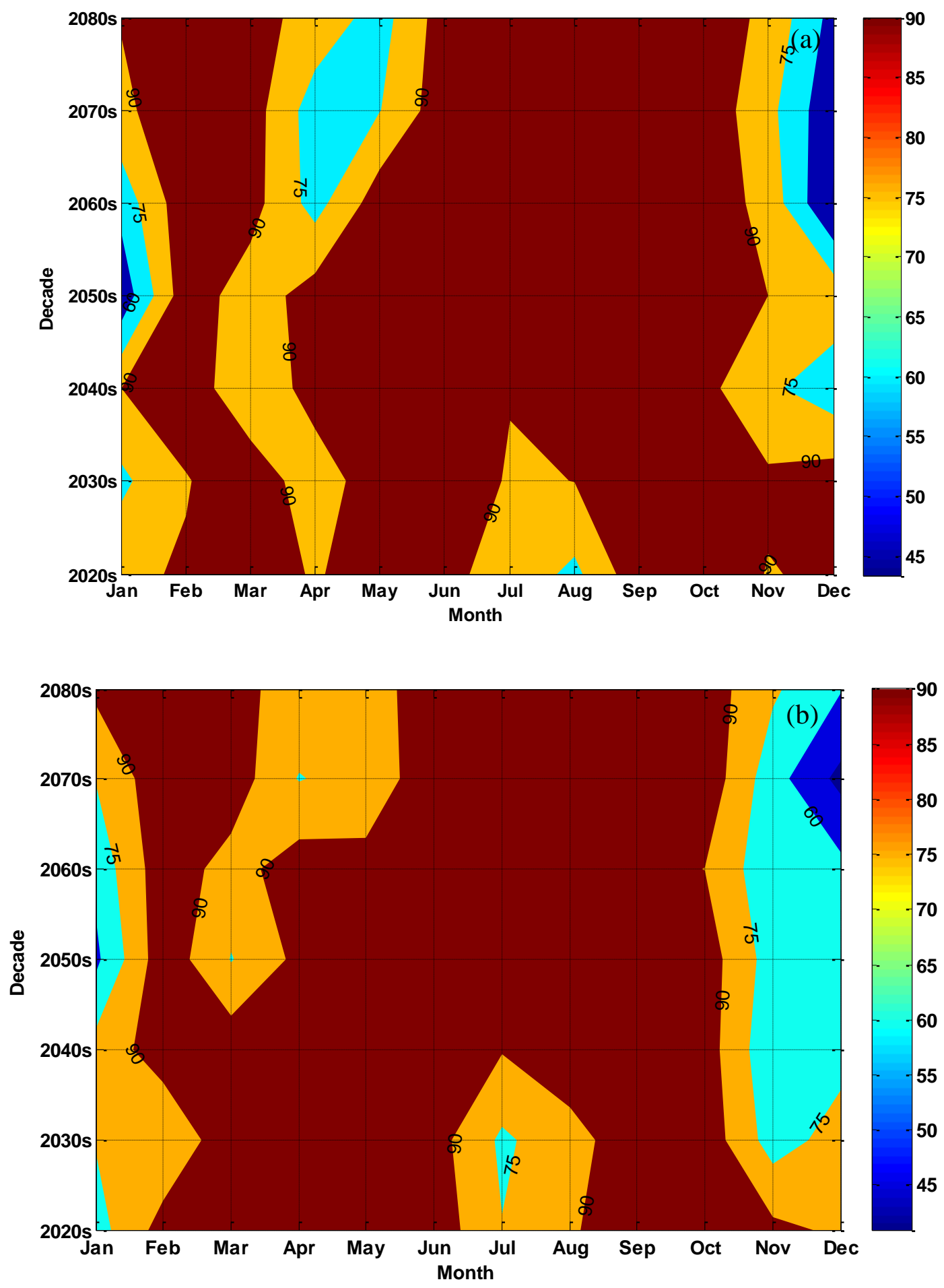

Figure 2-9: Uncertainty in ensemble river discharge for each decade for (a) A1B and (b) A2 scenario. The numbers on the figure shows the percent certainty in changes in river discharge 
order to quantitatively assess the likelihood of changes in magnitude in river discharge, the percent ensemble change was calculated and plotted (Figure 2-8) after averaging river discharge obtained using P-Q models. River discharge generally increased from February through July for both scenarios, while the remaining months were likely to experience decreases in flow values (Figure 2-8).

Uncertainty in projected river discharge under climate change was calculated using unequal variance of a 2-tailed t-test following the methodology proposed by Maurer \& Duffy (2005). Hovmöller plots in Figure 2-9 show confidence levels in changes in river discharge compared with historical data. Most of the months show $>90 \%$ confidence in changes in river discharge over the next decade. November and December are the transition months, when river flows start to decrease substantially, and thus have higher uncertainty than low or high flow months.

\subsubsection{Cholera prevalence under changing climate}

Two separate models are required to simulate cholera dynamics in the deltaic region (Jutla et al. 2013). Hence, 2 binary logistical (C-Q hereafter) models were calibrated and validated for spring and autumn cholera. The models were set up to provide likelihood probabilities of above-average cholera based on historical data from 1980-1999. Validation was conducted using data from 2000 - 2004. Based on our previous study (Akanda et al. 2009), the spring cholera model was developed using the average of river discharge for February and March. The autumn cholera model was constructed using the average of August and September flow values. Similarly, spring cholera was defined as the average of March, April, and May and autumn cholera was the average of October, November, and December. Table 2-7 shows model performance statistics and indicates that the 2 models capture association as well as fit to 
simulate cholera in both seasons. The Hosmer-Lemeshow p values and the Goodman-Kruskal Gamma values indicate a high degree of association between river discharge and the cholera time series (Hosmer et al. 2013). A negative sign in the coefficient (Table 2-7) for spring cholera suggests an inverse relationship with river discharge. Since the model is a binary logistical regression, it is not possible to calculate the correlation $\left(\mathrm{r}^{2}\right)$ between observed and simulated values. For validation, both models were used with limited data from 2000-2004. Spring and autumn cholera for the year 2004 were recorded to be above average, and the model-simulated probabilities of spring and autumn cholera were 0.96 and 0.91 , respectively. For the other 3 years, probabilities were $<0.03$, thus indicating that both models are able to capture cholera-river discharge dynamics sufficiently and can be used for simulating cholera probabilities. C-Q models for spring and autumn cholera were forced with ensemble averages of combined river discharge obtained by using P-Q models with downscaled precipitation of 3 GCMs. Figure 2-10 shows the plots for probabilities of above-average cholera for spring and autumn seasons. An empirical probability distribution plot (Figure 2-11) provides an indication of exceedance values when the likelihood of above-average cholera is $>50 \%$. Probability of

Table 2-7: Logistic regression model performance statistics for spring and autumn cholera

\begin{tabular}{|c|c|c|}
\hline & Spring Cholera & Autumn Cholera \\
\hline$\alpha$ & $22.38(\mathrm{p}<0.001)$ & $15.26(\mathrm{p}<0.001)$ \\
\hline$\beta$ & $-0.004(\mathrm{p}<0.001$ & $0.0018(\mathrm{p}<0.001)$ \\
\hline H-L & 0.910 & 0.902 \\
\hline GKG & 0.831 & 0.801 \\
\hline $\begin{array}{l}\text { H-L: Hosmer-Lemeshow p value }, \text { GKG: Goodman Kruskal Gamma } \\
\text { coefficient; } P(\text { cholera })=\frac{e^{\alpha+\beta Q}}{1+e^{\alpha+\beta Q}} ; \text { Q }=\text { river discharge }\end{array}$ \\
\hline
\end{tabular}


above-average cholera with a value of 0.5 has an exceedance probability of $70 \%, 72 \%, 80 \%$, and 85\% for Autumn A2, Autumn A1B, Spring A2, and Spring A1B cholera, respectively. Under A1B (Figure $2-10$ a) and A2 (Figure $2-10$ b), spring and autumn cholera are expected to increase over next $80 \mathrm{yr}$, assuming that social determinants (such as availability of water and sanitation facilities) either remain the same or worsen over time.

\subsection{Discussion}

The objective of this study was to establish a framework for downscaling river discharge in order to understand the impact of climate change on the occurrence of cholera in the Bengal Delta. Results obtained from the data-mining-based PSO-SVM method reinforces advantages of statistical downscaling in terms of faster computational speeds and yielding results comparable to physical regional climate models that require complex analysis and parameters that are not yet being monitored in developing regions of the world. The uniqueness of the proposed framework for estimating river discharge lies in both its simplicity and applicability to regions where detailed hydroclimatological information on processes is either limited or not available. Similar methods to determine river discharge from precipitation were applied in developed countries in the early 1980s, which motivated us to develop this method over the GBM delta (e.g. Miller et al. 1981). IPCC (2007) reported a temperature increase between 2.4 and $3.4^{\circ} \mathrm{C}$ under A1B and A2 scenarios. A decrease in fresh water availability in South Asia by the 2050s is documented in the latest IPCC report. Yet only limited studies on the effects of climate change on regional river discharge in the Bengal Delta are available. On the GCM grid scale (200-300 km2), Arnell \& Gosling (2013) showed an increase in river discharge in these regions of South Asia to be 

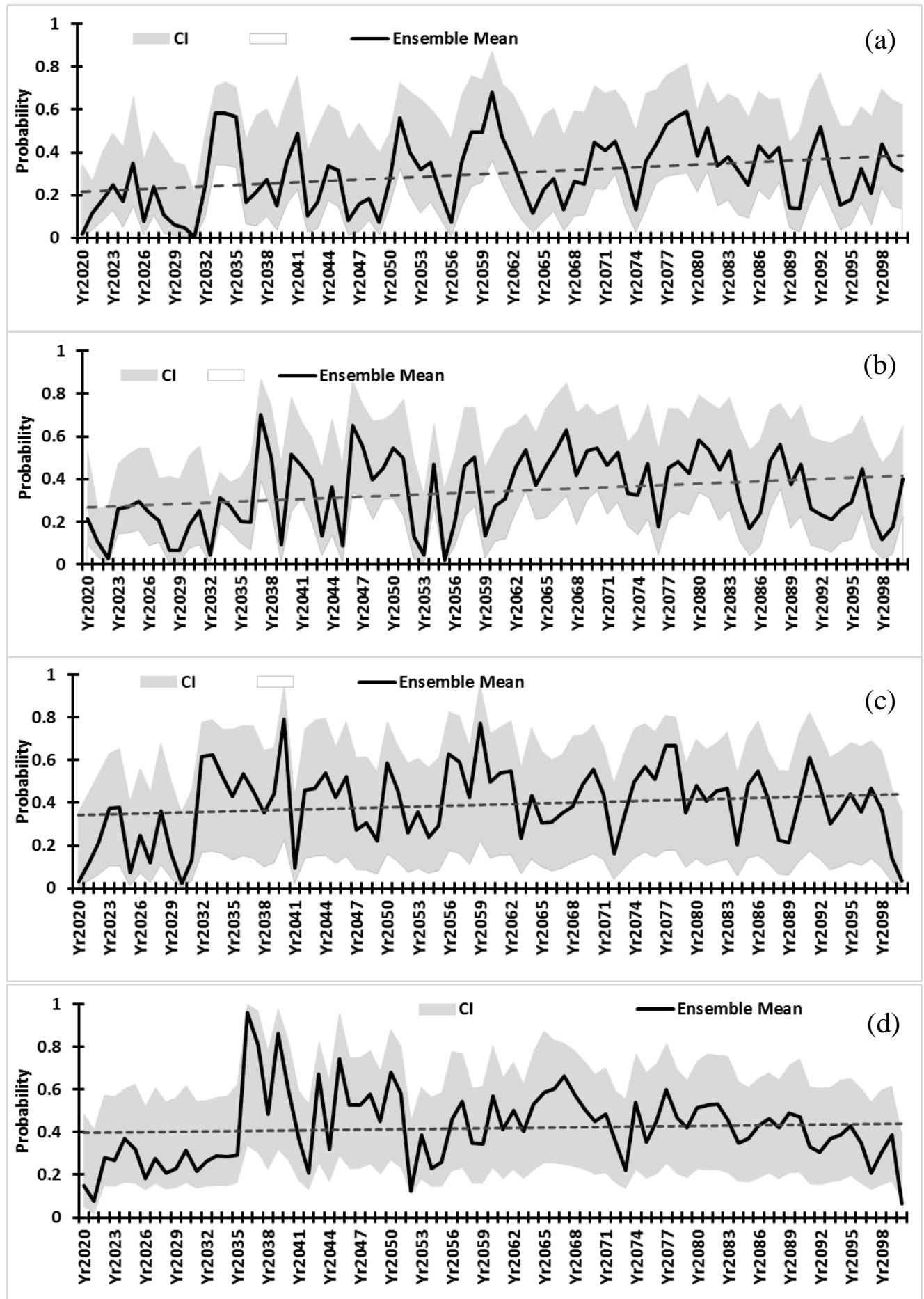

Figure 2-10: Ensemble mean probabilities for above average cholera for spring season under (a) A1B and (b) A2 scenarios; autumn season under (c) A1B and (d) A2 scenarios. Dashed line is linear trend with Kendall Tau values of (a) 0.31 (p<0.001); (b) 0.29 (p<0.001); (c) 0.23 ( $p<0.05$ ), and $(d) 0.16(p<0.01)$. Shaded area represent confidence intervals. 
between 10\% and 65\% during the months of December through January, with runoff from rivers decreasing (15\% and 75\%, region-wise) during June through August. Similarly, Gain et al. (2011) showed a regional increase in river discharge on an annual scale, results consistent with findings reported here, but with a different proportion of change. The uncertainty in determining changes in the South Asian monsoon and the related interannual variability that can be translated into river discharge calculations is recognized (Annamalai et al. 2007, Yang et al. 2008). Nevertheless, an annual increase in river discharge will have significant intra-annual variability, with low flows likely to increase while high combined river discharges decrease. On an annual scale, river discharge is expected to increase by $8 \%$ and $7.5 \%$ for A1B and $\mathrm{A} 2$ scenarios, respectively, which is consistent with published literature (Gain et al. 2011). The majority of the changes are attributable to increases in flows from February through August. Our results indicate no changes or shifts in seasonality of high and low flows during the next century. Diarrheal

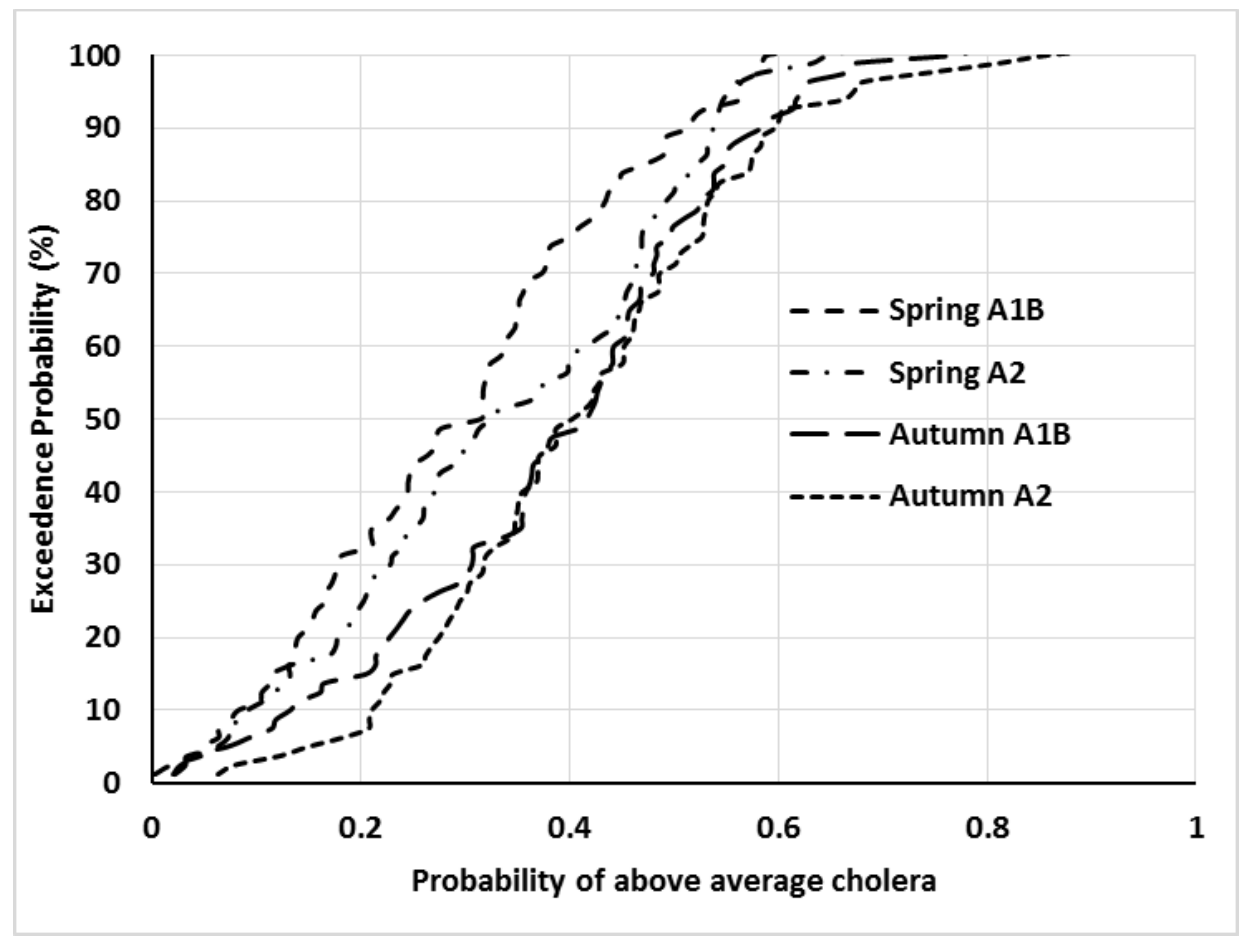

Figure 2-11: Exceedence probability of above-average cholera outbreaks 
diseases are expected to increase as a result of the projected changes in hydrological cycles (Patz et al. 2005). The challenge is to quantitatively link observations of diseases with hydroclimatological processes, so that projected effects can also be quantified. Results from logistical regression-based probabilities of cholera indicate a steady increase in both spring and autumn cholera, provided societal settings (availability of water and sanitation facilities) are preserved or worsen. However, cholera outbreaks are likely to be below average, as evidenced from the high empirical probability of occurrence (Figure 2-11), and perhaps due to increases in the river discharge during the months of February and March. Increases in the flows in these low discharge months will likely limit intrusion of bacteria-laden waters to inland water systems, thereby lowering the probability of occurrence of extreme cholera outbreaks. Discharge during the months of August and September was marginally decreased (ca. 2.8\%), resulting in severe above-average cholera outbreaks in the autumn season. 


\subsection{Reference}

Akanda AS, Jutla AS, Islam S (2009) Dual peak cholera transmission in Bengal Delta: a hydroclimatological explanation. Geophys Res Lett 36:L19401, doi:10.1029/ 2009GL039312

Akanda AS, Jutla AS, Alam M, de Magny GC and others (2011) Hydroclimatic influences on seasonal and spatial cholera transmission cycles: implications for public health intervention in the Bengal Delta. Water Resour Res 47:W00H07, doi:10.1029/2010WR009914

Akanda AS, Jutla AS, Gute DM, Evans T, Islam S (2012) Reinforcing cholera intervention through predictionaided prevention. Bull WHO 90:243-244

Annamalai H, Hamilton K, Sperber KR (2007) The South Asian summer monsoon and its relationship with ENSO in the IPCC AR4 simulations. J Clim 20:1071-1092

Arnell NW, Gosling SN (2013) The impacts of climate change on river flow regimes at the global scale. J Hydrol (Amst) 486:351-364

Bardossy A (1997) Downscaling from GCMs to local climate through stochastic linkages. J Environ Manag 49:7-17 Behnamian J, Ghomi S (2010) Development of a PSO-SA hybrid metaheuristic for a new comprehensive regression model to time-series forecasting. Expert Syst Appl 37:974-984

Behzad M, Asghari K, Eazi M, Palhang M (2009) General- ization performance of support vector machines and neural networks in runoff modeling. Expert Syst Appl 36: 7624-7629

Bertuzzo E, Azaele S, Maritan A, Gatto M, Rodriguez-Iturbe I, Rinaldo A (2008) On the spacetime evolution of a cholera epidemic. Water Resour Res 44:W01424, doi:10. 1029/2010WR009914 
Boyer C, Chaumont D, Chartier I, Roy AG (2010) Impact of climate change on the hydrology of St. Lawrence tributaries. J Hydrol (Amst) 384:65-83

Busuioc A, Chen DL, Hellström C (2001) Performance of sta- tistical downscaling models in GCM validation and regional climate change estimates: application for Swedish precipitation. Int J Climatol 21:557-578

Chapelle O, Vapnik V, Bousquet O, Mukherjee S (2002) Choosing multiple parameters for support vector machines. Mach Learn 46:131-159

Chen YY, Lin JT (2009) A modified particle swarm optimiza- tion for production planning problems in the TFT Array process. Expert Syst Appl 36:12264-12271

Chen ST, Yu PS, Tang YH (2010) Statistical downscaling of daily precipitation using support vector machines and multivariate analysis. J Hydrol (Amst) 385:13-22

Chen H, Xu CY, Guo SL (2012) Comparison and evaluation of multiple GCMs, statistical downscaling and hydrological models in the study of climate change impacts on runoff. J Hydrol (Amst) 434-435:36-45

Chiew FHS, Whetton PH, McMahon TA, Pittock AB (1995) Simulation of the impacts of climate change on runoff and soil moisture in Australian catchments. J Hydrol (Amst) $167: 121-147$

Chu JL, Kang HW, Tam CY, Park CK, Chen CT (2008) Seasonal forecast for local precipitation over northern Taiwan using statistical downscaling. J Geophys Res 113: D12118, doi:10.1029/2007JD009424

Collins AE (2003) Vulnerability to coastal cholera ecology. Soc Sci Med 57:1397-1407 
Cooney CM (2012) Downscaling climate models: sharpening the focus on local-level changes. Environ Health Perspect 120:a22-a28

Cunderlik JM, Simonovic SP (2005) Hydrological extremes in a southwestern Ontario river basin under future climate conditions. Hydrol Sci J 50:631-654

Dibike YB, Coulibaly P (2005) Hydrologic impact of climate change in the Saguenay watershed: comparison of downscaling methods and hydrologic models. J Hydrol (Amst) 307:145-163

Dibike YB, Coulibaly P (2006) Temporal neural networks for downscaling climate variability and extremes. Neural Netw 19:135-144

Evans J, Schreider S (2002) Hydrological impacts of climate change on inflows to Perth, Australia. Clim Change 55: 361-393

Gain AK, Immerzeel WW, Weiland FCS, Bierkens MFP (2011) Impact of climate change on the stream flow of the lower Brahmaputra: trends in high and low flows based on dischargeweighted ensemble modelling. Hydrol Earth Syst Sci 15:1537-1545

Ghosh S, Mujumdar PP (2008) Statistical downscaling of GCM simulations to streamflow using relevance vector machine. Adv Water Resour 31:132-146

Guo J, Zhou JZ, Qin H, Zou Q, Li QQ (2011) Monthly streamflow forecasting based on improved support vector machine model. Expert Syst Appl 38:13073-13081

Haines A, McMichael AJ, Epstein PR (2000) Environment and health: 2. Global climate change and health. CMAJ 163:729-734 
Hanssen-Bauer I, Førland EJ, Haugen JE, Tveito OE (2003) Temperature and precipitation scenarios for Norway: comparison of results from dynamical and empirical downscaling. Clim Res 25:15-27

He WW, Wang ZZ, Jiang H (2008) Model optimizing and feature selecting for support vector regression in time series forecasting. Neurocomputing 72:600-611

He YY, Zhou JZ, Xiang XQ, Chen H, Qin H (2009) Com- parison of different chaotic maps in particle swarm optimization algorithm for long-term cascaded hydroelectric system scheduling. Chaos Solitons Fractals 42: 3169-3176

Hellström C, Chen D, Achberger C, Räisänen J (2001) Com- parison of climate change scenarios for Sweden based on statistical and dynamical downscaling of monthly precipitation. Clim Res $19: 45-55$

Hosmer DW Jr, Lemeshow S, Sturdivant RX (2013) Applied logistic regression, Vol 398. John Wiley \& Sons, Hoboken, NJ

Huq A, Sack RB, Nizam A, Longini IM and others (2005) Critical factors influencing the occurrence of Vibrio cholerae in the environment of Bangladesh. Appl Environ Microbiol $71: 4645-4654$

Immerzeel W (2008) Historical trends and future predictions of climate variability in the Brahmaputra basin. Int J Climatol 28:243-254

IPPC (Intergovernmental Panel on Climate Change) (2007) Climate change 2007: synthesis report. Available at www. ipcc.ch/publications_and_data/ar4/syr/en/spms3.html 
Jasper K, Calanca P, Gyalistras D, Fuhrer J (2004) Differen- tial impacts of climate change on the hydrology of two alpine river basins. Clim Res 26:113-129

Jutla AS, Akanda AS, Islam S (2010) Tracking cholera in coastal regions using satellite observations. J Am Water Resour Assoc 46:651-662

Jutla AS, Whitcombe E, Hasan H, Haley B and others (2013a) Environmental factors influencing epidemic cholera response. Am J Trop Med Hyg 89:597-604

Jutla AS, Akanda AS, Islam S (2013b) A framework for pre- dicting endemic cholera using satellite derived environmental determinants. Environ Model Softw 47:148-158

Kamal R, Matin MA, Nasreen S (2013) Response of river flow regime to various climate change scenarios in Ganges-Brahmaputra-Meghna Basin. J Water Resour Ocean Sci 2:15-24

Kennedy J, Eberhart R (1995) Particle swarm optimization. In: Proceedings of the IEEE International Conference on Neural Networks Vol 4. IEEE, New York, NY, p 1942-1948

Kottegoda NT, Natale L, Raiteri E (2000) Statistical model- ling of daily streamflows using rainfall input and curve number technique. J Hydrol (Amst) 234:170-186

Leander R, Buishand A, Aalders P, De Wit M (2005) Estima- tion of extreme floods of the River Meuse using a stochastic weather generator and a rainfall-runoff model. Hydrol Sci J 50:1089-1103

Li F, Zhang Y, Xu Z, Teng J, Liu C, Liu W, Mpelasoka F (2013) The impact of climate change on runoff in the southeastern Tibetan Plateau. J Hydrol 505:188-201

Lin JY, Cheng CT, Chau KW (2006) Using support vector machines for long-term discharge prediction. Hydrol Sci J 51:599-612 
Lin SW, Ying KC, Chen SC, Lee ZJ (2008) Particle swarm optimization for parameter determination and feature selection of support vector machines. Expert Syst Appl 35:1817-1824

Maurer EP, Duffy PB (2005) Uncertainty in projections of streamflow changes due to climate change in California. Geophys Res Lett 32:L03704, doi:10.1029/2004GL021462

McMichael AJ (1997) Global environmental change and human health. Ecosyst Health $3: 200-210$

Menzel L, Burger G (2002) Climate change scenarios and runoff response in the Mulde catchment (Southern Elbe, Germany). J Hydrol (Amst) 267:53-64

Mercer J (1909) Functions of positive and negative type, and their connection with the theory of integral equations. Philos Trans R Soc Lond A 209:415-446

Miller RB, Bell W, Ferreiro O, Wang RYY (1981) Modeling daily river flows with precipitation input. Water Resour Res 17:209-215

Milly PCD, Betancourt J, Falkenmark M, Hirsch RM, Kundzewicz ZW, Lettenmaier DP, Stouffer RJ (2008) Climate change: stationarity is dead — whither water management? Science 319:573-574

Minville M, Brissette F, Leconte R (2008) Uncertainty of the impact of climate change on the hydrology of a Nordic watershed. J Hydrol (Amst) 358:70-83

Mirza MMQ (2003) Three recent extreme floods in Bang- ladesh: a hydro-meteorological analysis. Nat Hazards 28: 35-64

Murphy J (2000) Predictions of climate change over Europe using statistical and dynamical downscaling techniques. Int J Climatol 20:489-501 
Olsson J, Uvo CB, Jinno K (2001) Statistical atmospheric downscaling of short-term extreme rainfall by neural networks. Phys Chem Earth B Hydrol Oceans Atmos 26: 695-700

Palutikof JP, Goodess CM, Watkins SJ, Holt T (2002) Gener- ating rainfall and temperature scenarios at multiple sites: examples from the Mediterranean. J Clim 15:3529-3548 Pascual M, Chaves LF, Cash B, Rodó X, Yunus M (2008) Predicting endemic cholera: the role of climate variability and disease dynamics. Clim Res 36:131-140

Patz JA, Campbell-Lendrum D, Holloway T, Foley JA (2005) Impact of regional climate change on human health. Nature 438:310-317

Pilling CG, Jones JAA (2002) The impact of future climate change on seasonal discharge, hydrological processes and extreme flows in the Upper Wye experimental catchment, midWales. Hydrol Process 16:1201-1213

Prudhomme C, Wilby RL, Crooks S, Kay AL, Reynard NS (2010) Scenario-neutral approach to climate change impact studies: application to flood risk. J Hydrol (Amst) 390:198-209

Tripathi S, Srinivas VV, Nanjundiah RS (2006) Downscaling of precipitation for climate change scenarios: a support vector machine approach. J Hydrol (Amst) 330: 621-640

Tung CP, Haith DA (1995) Global-warming effects on New York streamflows. J Water Resour Plan Manag 121:216-225

Vapnik V (1995) The nature of statistical learning theory. Springer, New York, NY von Storch H, Zorita E, Cubasch U (1993) Downscaling of global climate change estimates to regional scales: an application to Iberian rainfall in wintertime. J Clim 6: 1161-1171 
Wilby RL, Hay LE, Leavesley GH (1999) A comparison of downscaled and raw GCM output: implications for climate change scenarios in the San Juan River basin, Colorado. J Hydrol (Amst) 225: 67-91

Wilby RL, Whitehead PG, Wade AJ, Butterfield D, Davis RJ, Watts G (2006) Integrated modelling of climate change impacts on water resources and quality in a lowland catchment: River Kennet, UK. J Hydrol (Amst) 330: 204-220

Willems P, Vrac M (2011) Statistical precipitation downscaling for small-scale hydrological impact investigations of climate change. J Hydrol (Amst) 402: 193-205

Yang S, Zhang Z, Kousky VE, Higgins RW, Yoo SH, Liang J,Fan Y (2008) Simulations and seasonal prediction of the Asian summer monsoon in the NCEP Climate Forecast System. J Clim 21: $3755-3775$

Yazicigil H, Rao AR, Toebes GH (1982) Investigation of daily flow forecasting models. J Water Resour Plan Manag Div 108: 67-85

Yu PS, Yang TC, Wu CK (2002) Impact of climate change on water resources in southern Taiwan. J Hydrol (Amst) 260: 161-175 


\section{Chapter 3 Hydroclimatic assessment of changing climate on occurrence of endemic cholera outbreaks in Ganges-Brahmaputra Basin}

\subsection{Abstract}

Even though relationship between cholera and climate have been well explored, evaluation of changing climate on cholera disease is still difficult. The difference between minimum and maximum combined streamflow of Ganges and Brahmaputra rivers, about 70,000 - 100,000 $\mathrm{m}^{3} / \mathrm{s}$, has significant effect on endemic cholera in the Bengal Delta region, which has been associated to unique biannual cholera outbreaks in the world. Spring cholera was found to be related to intrusion of bacteria laden coastal seawater during low flow seasons, while autumn cholera is hypothesized to result from cross-contamination of water resources when high streamflow causes flooding. Course resolution of General Circulate Models (GCM) output, about $100-300 \mathrm{~km}$, cannot be used to evaluate local scale variables $(10-20 \mathrm{~km})$ such as precipitation, streamflow, etc. To explore the effect of climate change on cholera, variability of streamflow need to be recognized under climate change. Here we present a framework to bridge the gap between global climate output and streamflow in the Ganges-Brahmaputra-Meghna basin as well as cholera disease in Dhaka, Bangladesh. In this study Particle Swarm Optimization basedSupport Vector Regression (PSO-SVR) in statistical model was used to downscale streamflow of Ganges and Brahmaputra rivers respectively $\left(\mathrm{R}^{2}=0.89\right.$ and $\left.\mathrm{R}^{2}=0.91\right)$. Key results, using models from ECHAM5, GFDL, and HADCM3 models for A1B and A2 scenarios -- which cover main demographic, economic, and technological driving forces of future greenhouse gas and Sulphur emission -- show that combined low flow season of Ganges and Brahmaputra will be increased while during high flow season it will be increased a little and then decreased in 
comparison with historical period of 1957 - 2000. By increasing combined low flow season and decreasing combined high flow season, likelihood of extreme and low prevalence cholera may decrease up to $20 \%$ at both spring and fall outbreaks.

\subsection{Introduction}

Streamflow as an important component of watershed has significant impacts on environment, economy, and human health. Anthropogenic factors such as reservoir constructions, increased irrigated area and consumptive use have effected streamflow (Kamalet al. 2013). Climate change is another factor, which can have profound effects on magnitude and pattern of streamflow. Policy and decision makers are interested to know the effect of climate change on streamflow due to its impacts on socio-economic, environmental, and human health. The General Circulation Models (GCMs) are advanced tools to investigate effect of climate change on streamflow by simulation time series of future climate variables (Anandhi et al., 2008; Ghosh and Mujumdar 2008). Although GCMs are used at coarse spatial resolution (100-300km), their implementation at finer spatial resolutions, required for hydrologic studies, are not suitable. Downscaling techniques have been developed, as a solution, to bridge the gaps between GCM outputs at large scale and interested surface climatic variables such as precipitation, temperature, and streamflow at local scale (Tisseuil et al., 2010).

There are two classified downscaling methods, which are dynamic and statistic. Dynamic downscaling uses the Regional Climate Model (RCM), nested in a GCM, which is a physical atmospheric model so that the boundary conditions are provided by GCM outputs. The dynamic downscaling have some disadvantages such as high computation cost and complexity (Wilby and Wigley, 1997; Fowler, H. J. et al. 2007; Anandhi et al., 2008, Teutschbein and Seibert, 2010; 
Raje and Mujumdar, 2011; Sachindra et al. 2011) and propagation of systematic bias from GCM to RCM (Giorgi et al., 2001; Crane and Herwitson 1998). Statistical downscaling builds empirical (statistical) relationships between GCM outputs (predictors) and observed regional climatic process (predictand) (Chen et al., 20110). The statistical downscaling has less computational cost and few assumptions in which relationships between predictors and predictand under future climatic condition are valid and GCMs are well described predictor variables: as picture of climate change signal, and their changes (Ghosh and Mujumdar 2008; Wilby and Wigly 2000; Herwitson and Crane 1992).

Downscaling precipitation, temperature, and evapotranspiration at local scale and using them as inputs to hydrological models is one of the ways to explore impact of changing climate on streamflow, which have been widely applied in hydroclimatology (Wilby et al. 2006; Cunderlik, \& Simonovic 2005; Dibike \& Coulibaly 2005; Leander et al. 2005; Jasper et al. 2004, Pilling \& Jones 2002). The drawback of this way is related to propagation and accumulation of uncertainties from input data, e.g. precipitation, temperature, through calibration and validation of data, e.g. streamflow, and model parameters and construction (McMillan et al., 2010; Baldassarre and Montanari 2009). One of the best possible solutions to reduce above mentioned uncertainties could be to downscale GCMs directly to streamflow. Even though nonlinear data-driven models such as arterial neural networks (ANNs) and support vector mechanin (SVM), used to explicitly characterize and quantify physical properties and conditions (Behzad et al., 2009), can be used for downscaling. However, only a few studies have used downscaling GCMs directly to streamflow in downscaling literature. Guo et al. (2011) and Lin et al. (2006) employed SVM to forecast and predict monthly river discharge in the Changjinang (Yangteze) River Basin and Manwan Hydropower Scheme, respectively. Tisseuil et al (2010) developed 
generalized linear (GLM) and additive (GAM) models, aggregated boosted trees (ABT) and multi-layer perceptron neural networks (ANN) to downscale daily streamflow in the southwest of France. Cannon and Whitfield (2002) used ensemble neural network to downscale GCMs to watershed streamflow in British Columbia. Ghosh and Mujumdar (2008) applied Support Vector Machine (SVM) and Relevance Vector Machine (RVM) to downscale monthly streamflow at India.

Different statistical downscaling methods, e.g. resampling (Murphy 2000), weather typing (Von Storch et al. 1993), stochastic weather generator (Tung and Haith, 1995) and regression (Hanssen-Bauer et al. 2003), have been used widely in hydroclimatology studies. But SVM and support vector regression (SVR), based on regression function, in downscaling has been getting increase attention due to its ability to solve nonlinear problem with reliable accuracy at low computational costs (Wu and Jin 2011). Although challenge with SVR based downscaling is a selection of feature classes, such as predictor variables, and optimal parameters of kernel function.

The objective of this study was to downscale GCMs directly to streamflow of Ganges and Brahmaputra, separately at local scale to quantify projected streamflow in future with less uncertainty. Combined streamflow of Ganges and Brahmaputra is defined as one of the largest streamflow in world (Kamal et al., 2013). In this study, we used a particle swarm optimization (PSO) algorithm to determine parameter space and to fine tune feature class selection of the SVR model (Nasr Azadani et al. 2015; Behnamian and Ghomi, 2010; Chen and Lin, 2009). The applications of this framework (SVR-PSO) could be used at water resources planning and management, protection of socio-economic and human health. To show this applications, we 
used this approach to estimate probability of endemic cholera, one of the major public health concern on global scale (Collins, 2003), in future in the Bengal Delta region using copula method. In the rest of paper we describe the data and study area in the first section. We introduce the SVR-PSO and copula methods applied in this study in the second section. We then show and discuss the results in the third section and conclude major findings in the final section.

\subsection{Study Area and Data}

The Ganges-Brahmaputra-Meghna (GBM) river system, which is a transboundary river basin (Figure 2-1) is located between of $22^{0} 3.5^{\prime} \mathrm{N}$ and $31^{0} 50^{\prime} \mathrm{N}$ latitudes and of $73^{0} 10.5^{\prime}$ and 97 $53^{\prime}$ longitudes. After the Amazon and the Congo River systems, the GBM is the third largest river outlet to the world's oceans (Chowdhury and Ward, 2004). The GBM Rivers reach peak flow levels during the months of August and September due to four monsoon months (Jun-Sep) and reach the lowest amount between January and April, which are typically between one-tenth and one-twentieth of the average peak flows in the respective rivers (Figure 2-2). By decreeing water amount spring, the streamflow height could be dropped so that the saltwater from the Bengal cost, containing $V$. cholera, intrude to inland. While increasing water amount in summer, could inundate land area of Bangladesh about 20\% - 60\%, during extreme floods, and contaminate water by mixing with sewer and spread it.

\subsubsection{River discharge data}

Monthly streamflow data for Ganges and Brahmaputra rivers, which is between January 1957 and December 2000 was obtained from the Bangladesh University of Engineering and Technology. The Ganges and Brahmaputra gauges are located at Hardinge Bridge and Bahadurabad city respectively. At this study the combined streamflow is primary interested since 
the flood and drought occurrences have significant impact on disease incidence (Akanda et al. 2009). Figure 2-2 shows the seasonality of Ganges, Brahmaputra, and combined rivers differs so that Brahmaputra peak has one month lag in comparison with Ganges.

\subsubsection{Cholera disease data}

Monthly endemic cholera data in the Bengal delta region, which is from January 1980 through December 2007 was obtained from International Centre for Diarrhoeal Disease Research (IICDDR), Dhaka, Bangladesh.

\subsubsection{Climate data}

Gridded simulated and projected climate data at monthly time scale were obtained from Intergovernmental Panel on Climate Change (IPCC) website for GFDL, ECHAM5, and HADCM3 models, http://www.ipccdata.org/sim/gcm_monthly/ SRES_AR4/ index.html, respectively, Table 2-1. The simulated, 20CM, and projected data (based on three emission scenarios $\mathrm{A} 1 \mathrm{~B}, \mathrm{~A} 2$ and $\mathrm{B} 2)$ on the website of IPCC which are at course resolution generally are from 1860 to 2000 and from 2001 to 2200 respectively. Between three emission scenarios (A1B, A2, and B2) only two emission scenarios, A1B and A2, were selected for this study because B2 scenario does not have all 24 projected climate variables.

\section{4 Methodology}

\subsubsection{Support Vector Machine (SVM)}

The fundamental of Support Vector Machines (SVMs) is based on the statistical learning theory and method of structural risk minimization (Haykin, 2003). Support Vector Regression (SVR) employs ability of structural risk minimization to minimize overfitting (Chen et al. 2010) 
and reach guaranteed global optimum solution (Haykin, 2003). Let the training sample data be $\left\{\left(\mathrm{x}_{\mathrm{i}}, \mathrm{y}_{\mathrm{i}}\right) \mid \forall \mathrm{i}=1,2 \ldots, \mathrm{n}\right\}$, where $\mathrm{x}_{\mathrm{i}} \in \mathrm{R}^{\mathrm{m}}$ and $\mathrm{y}_{\mathrm{i}} \in \mathrm{R}$ are input and output data respectively. The idea of SVR is to find a function, $f(x, w)=w^{T} x+b$ where $w \in R^{m}, b \in R$, for linear functional forms to have minimum deviation from training data and to be as flat as possible (He et al., 2008). To measure and allow error in prediction, Vapnik (1995) proposed the $\epsilon$ intensive loss function, $L\left[y_{i}, f(x, w)\right]$ which is a predefined positive constant:

$$
L\left[y_{i}, f(x, w)\right]=\left\{\begin{array}{lr}
0 & \left|y_{i}-f\left(x_{i}, w\right)\right|<\epsilon \\
\left|y_{i}-f\left(x_{i}, w\right)\right|-\epsilon & \text { otherwise }
\end{array}\right.
$$

The parameters $w$, flatness of function, and $b$, bias parameter, can be calculated by minimizing the below cost function:

Minimize $R=C \sum_{i=1}^{n}\left(\xi_{i}^{+}+\xi_{i}^{-}\right)+\frac{1}{2}\|w\|^{2}$

Subject to:

$$
\begin{array}{lc}
y_{i}-\left(w^{T} x_{i}+b\right)<\epsilon+\xi_{i}^{+} & \forall i=1,2, \ldots . n \\
\left(w^{T} x_{i}+b\right)-y_{i}<\epsilon+\xi_{i}^{-} & \forall i=1,2, \ldots . n \\
\xi_{i}^{+} \geq 0, \xi_{i}^{-} \geq 0 & \forall i=1,2, \ldots . n
\end{array}
$$

Where $\xi_{i}^{+}$and $\xi_{i}^{-}$are slack variables, the amount by which deviations are higher or lower than $\epsilon$ is tolerated, and $\mathrm{C}$ is regularized constant, represents tradeoff between minimizing errors and making the function as flat as possible. The equation (1) is used for linear form so for nonlinear forms a nonlinear mapping function, $\phi(x)$, is used to map input data to higher 
dimensional space to generate linear function, $f(x, w)=w^{T} \phi(x)+b$. By introducing Lagrange multipliers and substituting constraints (4) and (5) as:

$$
\begin{array}{ll}
y_{i}-\left(w^{T} \phi\left(x_{i}\right)+b\right)<\epsilon+\xi_{i}^{+} & \forall i=1,2, \ldots . n \\
\left(w^{T} \phi\left(x_{i}\right)+b\right)-y_{i}<\epsilon+\xi_{i}^{-} & \forall i=1,2, \ldots . n
\end{array}
$$

the optimal value for $w$ and the functional form $f(x, w)$ can be obtained as:

$$
\begin{aligned}
& w=\sum_{i=1}^{n}\left(\alpha_{i}-\alpha_{i}^{*}\right) \phi\left(x_{i}\right) \\
& f\left(x, \alpha_{i}, \alpha_{i}^{*}\right)=\sum_{i=1}^{n}\left(\alpha_{i}-\alpha_{i}^{*}\right) K\left(x, x_{i}\right)+b
\end{aligned}
$$

Where $K$ can be any kernel function, $\mathrm{K}\left(\mathrm{x}, \mathrm{x}_{\mathrm{i}}\right)=\phi(\mathrm{x})^{\mathrm{T}} \phi\left(\mathrm{x}_{\mathrm{i}}\right)$, that satisfies the Mercer Theorem (Mercer, 1909). The common kernel functions are linear, polynomial and Gaussian kernel (RBF). The dual of the quadratic minimization problem can be used to obtain the value of the Lagrangean multipliers $\alpha_{\mathrm{i}}$ and $\alpha_{\mathrm{i}}^{*}$ as below:

Maximize $\mathrm{R}=-\frac{1}{2} \sum_{\mathrm{i}=1}^{\mathrm{n}} \sum_{\mathrm{j}=1}^{\mathrm{n}}\left(\alpha_{\mathrm{i}}-\alpha_{\mathrm{i}}^{*}\right)\left(\alpha_{\mathrm{j}}-\alpha_{\mathrm{j}}^{*}\right) \mathrm{K}\left(\mathrm{x}_{\mathrm{i}}, \mathrm{x}_{\mathrm{j}}\right)+\sum_{\mathrm{i}=1}^{\mathrm{n}} \mathrm{y}_{\mathrm{i}}\left(\alpha_{\mathrm{i}}-\alpha_{\mathrm{i}}^{*}\right)$

$$
-\epsilon\left(\alpha_{i}+\alpha_{i}^{*}\right)
$$

Subject to:

$$
\sum_{i=1}^{n}\left(\alpha_{i}-\alpha_{i}^{*}\right)=0 \quad 0 \leq \alpha_{i}, \alpha_{i}^{*} \leq \mathrm{C} \forall i=1,2, \ldots . n
$$


Based on the KKT conditions (Vapnik 1998), some part of the Lagrangean multipliers $\left(\alpha_{i}\right.$ or $\alpha_{i}^{*}$ ) are nonzero which are called support vectors. Bias parameter, $b$, can be calculated as:

$$
\begin{aligned}
& \mathrm{b}=\frac{\sum_{\mathrm{i}=1}^{\mathrm{n}} \mathrm{y}_{\mathrm{d}}^{\mathrm{i}}}{\mathrm{n}} \\
& \mathrm{y}_{\mathrm{d}}^{\mathrm{i}}=\mathrm{y}_{\mathrm{i}}-\sum_{\mathrm{i}=1}^{\mathrm{n}}\left(\alpha_{\mathrm{i}}-\alpha_{\mathrm{i}}^{*}\right) \mathrm{K}\left(\mathrm{x}, \mathrm{x}_{\mathrm{i}}\right)-\epsilon \operatorname{sign}\left(\alpha_{\mathrm{i}}-\alpha_{\mathrm{i}}^{*}\right) \quad \forall \mathrm{i}=1,2, \ldots, \mathrm{n}
\end{aligned}
$$

Performance of SVR can be improved by meta-heuristic tuning optimization methods (Chapelle et al. 2002; He et al. 2008; Lin et al. 2008). One of the heuristic algorithms for optimization is Particle Swarm Optimization (PSO) method, which is introduced by Kennedy and Eberhart (1995).

In this study, we fine-tuned and determined optimal values of the error minimization tradeoff parameter C, kernel parameters, and best features (predictors), using the PSO approach adopted from Lin et al. (2008). The meta-heuristic PSO approach was selected to avoid dependencies or relationship between the parameter values and SVR performance metrics (Kennedy and Eberhart 1995). Each solution (or particle) of PSO will comprise $\mathrm{m}+\mathrm{K}+1$ decision variables corresponding to $\mathrm{m}$ features, $\mathrm{K}$ parameters associated with the kernel selected, and one decision variable for the error minimization tradeoff parameter. The value of $\mathrm{m}$ decision variables corresponding to $\mathrm{m}$ features range from 0 to 1 . For a variable value less than or equal to 0.5, the corresponding feature will not be selected and for a variable with a value greater than 0.5, the corresponding feature is selected. An overview of the PSO algorithm is provided below. 
Step 1: Population of potential solutions, called particles, are randomly generated over multi-dimensional search space $\mathrm{S}$.

Step 2: The position of each particle is evaluated based on the objective or fitness function. In this study, the fitness function corresponds to deviation (evaluated as $R^{2}$ ) of the model prediction from the validation target value. Current fitness value of the particle is compared with the best recorded fitness. If the current fitness value is better than the best recorded fitness, the particle best recorded fitness is updated. Globally best fitness is obtained by comparing best recorded fitness value with the current global best fitness value.

Step 3: Particle velocities and positions are updated using the following equation.

$$
\begin{array}{ll}
v_{i}^{h+1}=w v_{i}^{h}+c_{1} U_{1}^{h}\left(p b_{i}^{h}-x_{i}^{h}\right)+c_{2} U_{2}^{h}\left(g b^{h}-x_{i}^{h}\right) & \forall i=1, \ldots, M \\
x_{i}^{h+1}=x_{i}^{h}+v_{i}^{h+1} & \forall i=1, \ldots, M
\end{array}
$$

Where $v_{i}^{h}=$ velocity of particle $i$ in iteration $h ; p b_{i}^{h}=$ current best solution of particle $i ; g b^{h}$ is the global best solution at iteration $h ; x_{i}^{h}$ is the position of particle $i$ in iteration $h ; U_{1}^{h}$ and $U_{2}^{h}$ are uniform random numbers in the range 0,1$]$; and $w, c_{1}$, and $c_{2}$ are inertial, self cognitive, and social cognitive parameters

Step 4: Determine if the termination criteria are satisfied, with termination criteria chosen as (i) when the best possible fitness function value does not change over a number of iterations or (ii) when the maximum number of iterations is reached. If termination criteria are satisfied, no further step is followed. If termination criteria are not satisfied, step 2 is taken. Interestingly, PSO-based SVR theory apparently has not been employed previously to downscale GCM output, with the advantage that the PSO-SVR based machine learning algorithm is freed from the assumption that the mean of a time series is constant, hence is a robust algorithm for 
understanding the impact of climate variability under non-stationary hydroclimatic scenarios, as discussed by Milly et al. (2008).

\subsubsection{Downscaling streamflow: Calibration and Validation}

Monthly simulated climate variables data, the twentieth century (20C3M), obtained from IPCC for three GCMs (HADCM3, GFDL, and ECHAM) as predictors and observed streamflow of Ganges and Brahmaputra as a predictand were used for SVR-PSO development. To better capture variability of seasonal streamflow due to changes in atmospheric circulation, total data were divided to two seasons. The first and second season were defined from Nov to Mar and from Apr to Oct, respectively. For each streamflow and GCMs two SVR-PSO were developed, for each season. To develop SVR-PSO for each, the seasonal data were randomly divided to calibration set, about $80 \%$, and validation set, about $20 \%$. The calibration and validation set were normalized between -1 and $1, x_{\text {normalized }}=2 *\left(\frac{x-x_{\min }}{x_{\max }-x_{\min }}\right)-1$.

The above normalized calibration was used to perform SVR-PSO model. The optimum cost value, and selected potential climate variables from calibration process were used at validation step to check performance of the model using $\mathrm{r}^{2}$, bias, and RMSE measurement. These calibration and validation development were repeated for each season of each GCM. So for each of the GCMs and each streamflow two SVR-PSO models were developed.

\subsubsection{Cholera-Streamflow model using copula}

Copula method was utilized to model dependence structure between cholera and streamflow in the Bengal Delta region. Sklar's theorem (Sklar 1959), fundamental theory of copulas, states that if there are two random variables, namely $\mathrm{X}$ and $\mathrm{Y}$ with contentious marginal distribution of 
$F_{X}(x)$ and $F_{Y}(y)$ and $H(x, y)$ is a joint distribution of random variables, then there is unique copula that couple joint distribution function to marginal distribution functions:

$$
H(x, y)=C\left[F_{X}(x), F_{Y}(y)\right] \quad x, y \in R
$$

Where $C:[0,1]^{2} \rightarrow[0,1]$ is a copula which confines the dependence structure between random variable $X$ and $Y$ (Schweizer and Sklar 1983). The conditional distribution can be expressed as:

$$
\begin{aligned}
P(X \leq x \mid Y= & y)=\frac{P(X \leq x, Y=y)}{P(Y=y)}=\frac{\frac{\partial}{\partial v} C(F(x), F(y)) \cdot F(y)}{F(y)} \\
= & \frac{\partial}{\partial v} C(F(x), F(y))
\end{aligned}
$$

Various copula families with one and two parameters are available and developed for different applications (Joe 1997 and Nelsen 2006). In this study, copula families with one parameter are investigated to find the best fitted copula model.

Copula parameter can be estimated using several methods including nonparametric, inference function for marginal distribution (IFM), and maximum likelihood estimation (MLE) methods. Here, MLE was used to estimate copula parameter, $\theta$. If the univariate marginal distributions of cholera $(X)$ and streamflow $(Y)$ random variable was defined as $F_{X}(x)$ and $F_{Y}(y)$, then the maximum log-likelihood function can be used to estimate copula parameter as:

$$
l(\theta)=\sum_{i=1}^{n} \log \left(c_{\theta}\left(u_{i}, v_{i}\right)\right)=\sum_{i=1}^{n} \log \left(c_{\theta}\left(F_{X}\left(x_{i}\right), F_{Y}\left(y_{i}\right)\right)\right)
$$

Where $\theta$ is the copula parameter, $\mathrm{n}$ is the number of observation, and $c_{\theta}(u, v)$ is the copula density function as: 


$$
c_{\theta}(u, v)=\frac{\partial^{2} C_{\theta}(u, v)}{\partial u \partial v}=\frac{\partial^{2} C_{\theta}(u, v)}{\partial F_{X}(x) F_{Y}(y)}
$$

The Cramer-von Mises (CVM) (Cramer 1928 and Von Miese 1929) and KolmogorovSmirnov (KS) test statistics were used to select the best copula. Chosen copula then used to drive conditional distribution function of cholera given streamflow to investigate effect of streamflow and changing climate on cholera.

\subsection{Results and Discussion}

\subsubsection{Downscaling streamflow}

Monthly simulated climate data from three GCMs (HADCM3, ECHAM5, and GFDL) were used to develop SVR-PSO model to downscale streamflow of Ganges and Brahmaputra at the Bengal Delta region. The available dataset for calibration and validation is from 1957 to 2000. To capture variability of each streamflow, the dataset was divided in to two seasons, from Nov to Mar, and Apr to Oct. Each seasonal data was randomly separated to calibration set, about $80 \%$, and validation set, about $20 \%$. The Radial Basis Function (RBF) kernel function was used

for SVR and selected potential climate variables and cost were optimized using PSO method. Table 3-1 shows the selected potential climate variables and optimized cost (range 0.14-1) for each SVR-PSO model. The performance of each SVR-PSO were monitored using three statistical measurement, bias, RMSE, and correlation coefficient $\left(\mathrm{r}^{2}\right)$. Table 3-2 shows the implementation of SVR-PSO during calibration and validation process for each season and each of GCMs. $\mathrm{R}^{2}$, RMSE, and bias are respectively ranged $0.73-0.89,1513-15101$, and $75-1130$ for calibration and $0.72-0.85,1900$ - 14550, and -1606 - 2229 for validation. Figures 3-1 and 32 show scatter plots of observed vs simulated Ganges and Brahmaputra rivers respectively. The 
Table 3-1: Selected variables along with cost and gamma for three GCMs (ECHAM5, GFDL, and HADCM3). $\mathrm{X}$ implies selected variables during calibration of PSO-SVR algorithm

\begin{tabular}{|c|c|c|c|c|c|c|c|c|c|c|c|c|}
\hline \multirow[t]{3}{*}{ Variables } & \multicolumn{4}{|c|}{ ЕСНАM5 } & \multicolumn{4}{|c|}{ GFDL } & \multicolumn{4}{|c|}{ HADCM3 } \\
\hline & \multicolumn{2}{|c|}{ Brahmaputra } & \multicolumn{2}{|c|}{ Ganges } & \multicolumn{2}{|c|}{ Brahmaputra } & \multicolumn{2}{|c|}{ Ganges } & \multicolumn{2}{|c|}{ Brahmaputra } & \multicolumn{2}{|c|}{ Ganges } \\
\hline & LF & $\mathrm{HF}$ & LF & $\mathrm{HF}$ & LF & $\mathrm{HF}$ & LF & $\mathrm{HF}$ & LF & $\mathrm{HF}$ & LF & $\mathrm{HF}$ \\
\hline Hur200 & $\mathrm{X}$ & 0 & 0 & $\mathrm{X}$ & $\mathrm{X}$ & 0 & $\mathrm{X}$ & 0 & $\mathrm{X}$ & $\mathrm{X}$ & $\mathrm{X}$ & 0 \\
\hline Hur200 & 0 & 0 & $\mathrm{X}$ & 0 & $\mathrm{X}$ & 0 & 0 & 0 & 0 & $\mathrm{X}$ & 0 & 0 \\
\hline Hur500 & 0 & $\mathrm{X}$ & $\mathrm{X}$ & $\mathrm{X}$ & 0 & $X$ & $\mathrm{X}$ & 0 & 0 & 0 & $\mathrm{X}$ & 0 \\
\hline Hur850 & $\mathrm{X}$ & 0 & 0 & $\mathrm{X}$ & $\mathrm{X}$ & 0 & $\mathrm{X}$ & $\mathrm{X}$ & $\mathrm{X}$ & 0 & $\mathrm{X}$ & $\mathrm{X}$ \\
\hline Mrso & $\mathrm{X}$ & $\mathrm{X}$ & 0 & 0 & 0 & 0 & $\mathrm{X}$ & 0 & $\mathrm{X}$ & $\mathrm{X}$ & 0 & $\mathrm{X}$ \\
\hline$P r$ & $X$ & $X$ & 0 & 0 & $X$ & $X$ & $X$ & 0 & $X$ & 0 & 0 & $X$ \\
\hline Prc & $\mathrm{X}$ & $\mathrm{X}$ & $\mathrm{X}$ & $\mathrm{X}$ & $\mathrm{X}$ & $\mathrm{X}$ & $\mathrm{X}$ & 0 & $\mathrm{X}$ & $\mathrm{X}$ & $\mathrm{X}$ & $\mathrm{X}$ \\
\hline Psl & $\mathrm{X}$ & 0 & $\mathrm{X}$ & $\mathrm{X}$ & 0 & $\mathrm{X}$ & $\mathrm{X}$ & $\mathrm{X}$ & 0 & $\mathrm{X}$ & $\mathrm{X}$ & $X$ \\
\hline$R s d s$ & 0 & 0 & 0 & 0 & 0 & $X$ & 0 & 0 & 0 & $X$ & $X$ & $X$ \\
\hline Ta200 & 0 & $X$ & $X$ & 0 & $X$ & $\mathrm{X}$ & 0 & $X$ & $X$ & 0 & $X$ & $X$ \\
\hline Ta500 & 0 & $X$ & $X$ & 0 & $X$ & 0 & $X$ & $X$ & 0 & 0 & $X$ & $X$ \\
\hline Ta850 & 0 & 0 & 0 & $X$ & $X$ & 0 & 0 & 0 & $X$ & 0 & 0 & $X$ \\
\hline Tas & $X$ & $X$ & $X$ & 0 & 0 & 0 & 0 & $X$ & 0 & 0 & $X$ & $X$ \\
\hline$T S$ & 0 & $X$ & $X$ & $X$ & 0 & 0 & 0 & $X$ & 0 & 0 & 0 & 0 \\
\hline Ua200 & $X$ & $X$ & $X$ & 0 & 0 & $X$ & 0 & 0 & $X$ & 0 & $X$ & $X$ \\
\hline Ua500 & 0 & $X$ & 0 & $X$ & 0 & 0 & $X$ & $X$ & 0 & $X$ & $X$ & 0 \\
\hline Ua850 & $X$ & 0 & 0 & $X$ & 0 & $X$ & $X$ & $X$ & $X$ & 0 & $X$ & 0 \\
\hline Uas & 0 & $X$ & $X$ & $X$ & 0 & 0 & 0 & 0 & $X$ & 0 & 0 & 0 \\
\hline Va200 & 0 & 0 & $X$ & 0 & 0 & 0 & 0 & 0 & 0 & 0 & 0 & 0 \\
\hline Va500 & 0 & $\mathrm{X}$ & $X$ & $\mathrm{X}$ & $\mathrm{X}$ & $\mathrm{X}$ & $\mathrm{X}$ & $X$ & $\mathrm{X}$ & $X$ & $X$ & $X$ \\
\hline Va850 & $X$ & $\mathrm{X}$ & 0 & $\mathrm{X}$ & $X$ & $X$ & 0 & $\mathrm{X}$ & $X$ & 0 & $X$ & 0 \\
\hline Vas & 0 & 0 & 0 & 0 & $X$ & 0 & 0 & $X$ & 0 & 0 & 0 & $X$ \\
\hline Zg200 & $X$ & $X$ & 0 & $X$ & 0 & $X$ & $X$ & 0 & 0 & $X$ & 0 & $X$ \\
\hline Zg500 & 0 & $X$ & 0 & 0 & 0 & $X$ & $X$ & $X$ & 0 & $X$ & 0 & $X$ \\
\hline Zg850 & $\mathrm{X}$ & 0 & 0 & $X$ & $X$ & 0 & $\mathrm{X}$ & 0 & $\mathrm{X}$ & $\mathrm{X}$ & $\mathrm{X}$ & 0 \\
\hline Cost & 0.34 & 1 & 0.25 & 0.92 & 0.2 & 0.52 & 0.35 & 0.29 & 0.36 & 0.98 & 0.14 & 0.92 \\
\hline Gama & 1 & 1 & 1 & 1 & 1 & 1 & 1 & 1 & 1 & 1 & 1 & 1 \\
\hline
\end{tabular}


Table 3-2: Calibration and validation results for downscaling Brahmaputra and Ganges streamflow

\begin{tabular}{|c|c|c|c|c|c|c|c|c|c|c|}
\hline Model & River & Season & Mean & STD & \multicolumn{2}{|c|}{$\mathbf{R 2}$} & \multicolumn{2}{|c|}{ RMSE } & \multicolumn{2}{|c|}{ Bias } \\
\hline & & & & & Calib. & Valid. & Calib. & Valid. & Calib. & Valid. \\
\hline \multirow{4}{*}{ ЕСНАM5 } & \multirow{2}{*}{ Brahmaputra } & $\mathrm{LF}$ & 9597.71 & 4692.87 & 0.80 & 0.76 & 2329.94 & 1900.84 & 279.94 & -55.94 \\
\hline & & $\mathrm{HF}$ & 47064.13 & 28264.05 & 0.85 & 0.79 & 10078.41 & 13094.47 & 459.92 & 2229.21 \\
\hline & \multirow{2}{*}{ Ganges } & LF & 9597.71 & 4692.87 & 0.73 & 0.72 & 2801.43 & 2815.85 & 347.54 & -988.68 \\
\hline & & $\mathrm{HF}$ & 47064.13 & 28264.05 & 0.86 & 0.78 & 12738.74 & 17550.73 & 1074.38 & -1606.37 \\
\hline \multirow{4}{*}{ GFDL } & \multirow{2}{*}{ Brahmaputra } & $\mathrm{LF}$ & 9597.71 & 4692.87 & 0.81 & 0.79 & 2344.78 & 2148.54 & 331.89 & 553.22 \\
\hline & & $\mathrm{HF}$ & 47064.13 & 28264.05 & 0.86 & 0.85 & 9943.54 & 10444.11 & 213.41 & 1548.75 \\
\hline & \multirow{2}{*}{ Ganges } & $\mathrm{LF}$ & 9597.71 & 4692.87 & 0.75 & 0.73 & 2456.27 & 3470.75 & 367.72 & 1688.8 \\
\hline & & $\mathrm{HF}$ & 47064.13 & 28264.05 & 0.82 & 0.83 & 15101.22 & 14327.57 & 1033.07 & -142.75 \\
\hline \multirow{4}{*}{ HADCMЗ } & \multirow{2}{*}{ Brahmaputra } & LF & 9597.71 & 4692.87 & 0.89 & 0.84 & 1513.99 & 2034.90 & 144.52 & 549.72 \\
\hline & & $\mathrm{HF}$ & 47064.13 & 28264.05 & 0.84 & 0.81 & 10759.14 & 10792.91 & 439.59 & -1365.54 \\
\hline & \multirow{2}{*}{ Ganges } & LF & 9597.71 & 4692.87 & 0.83 & 0.78 & 1924.54 & 2091.06 & 75.01 & -186.22 \\
\hline & & $\mathrm{HF}$ & 47064.13 & 28264.05 & 0.85 & 0.85 & 13456.59 & 13808.71 & 1130.13 & 883.25 \\
\hline
\end{tabular}

Abbreviation used: Calib. $=$ Calibration, Valid. $=$ Validation. 


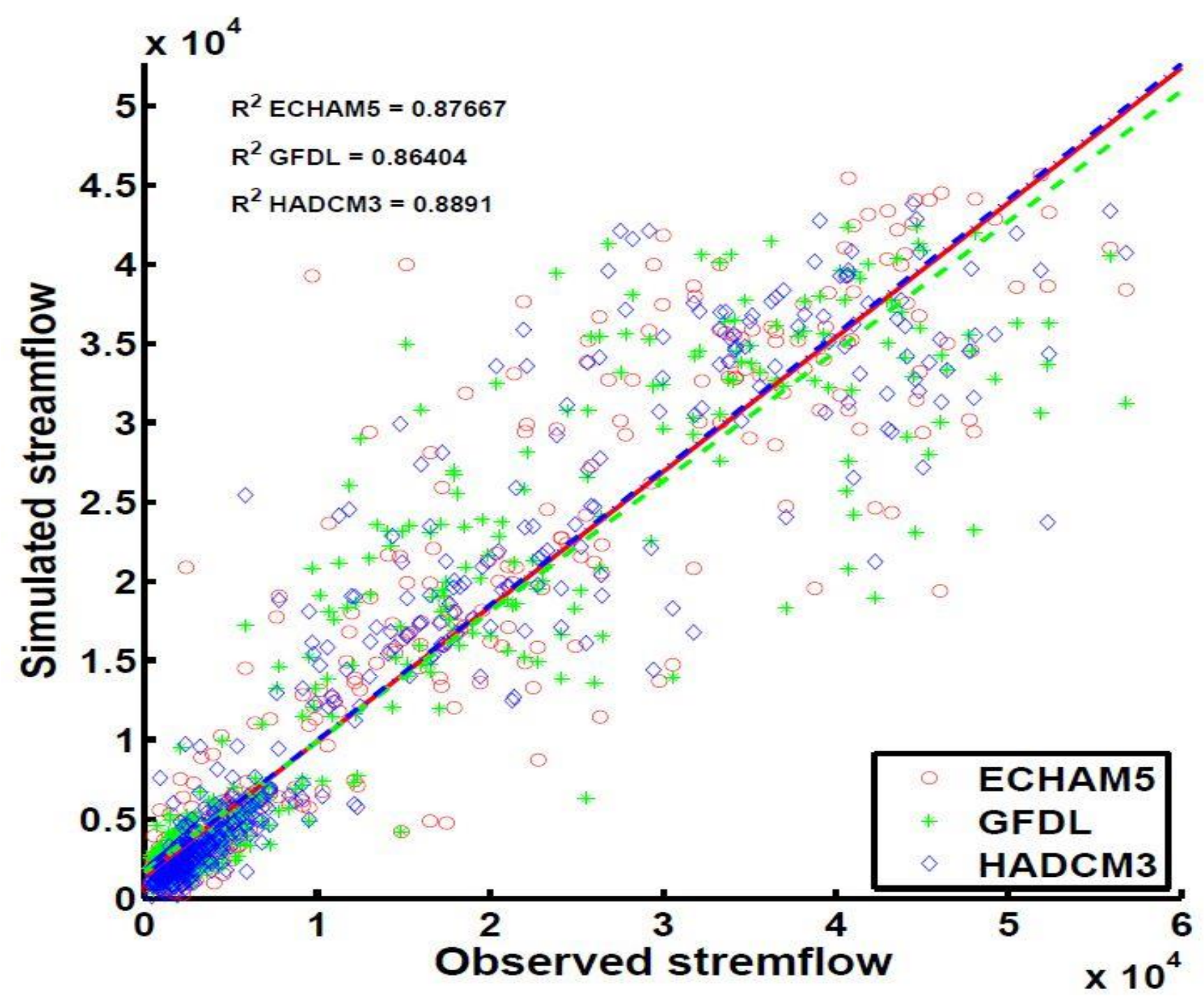

Figure 3-1: Monthly observed vs simulated streamflow of Ganges under three GCM model (ECHAM5, GFDL, and HADCM3) 


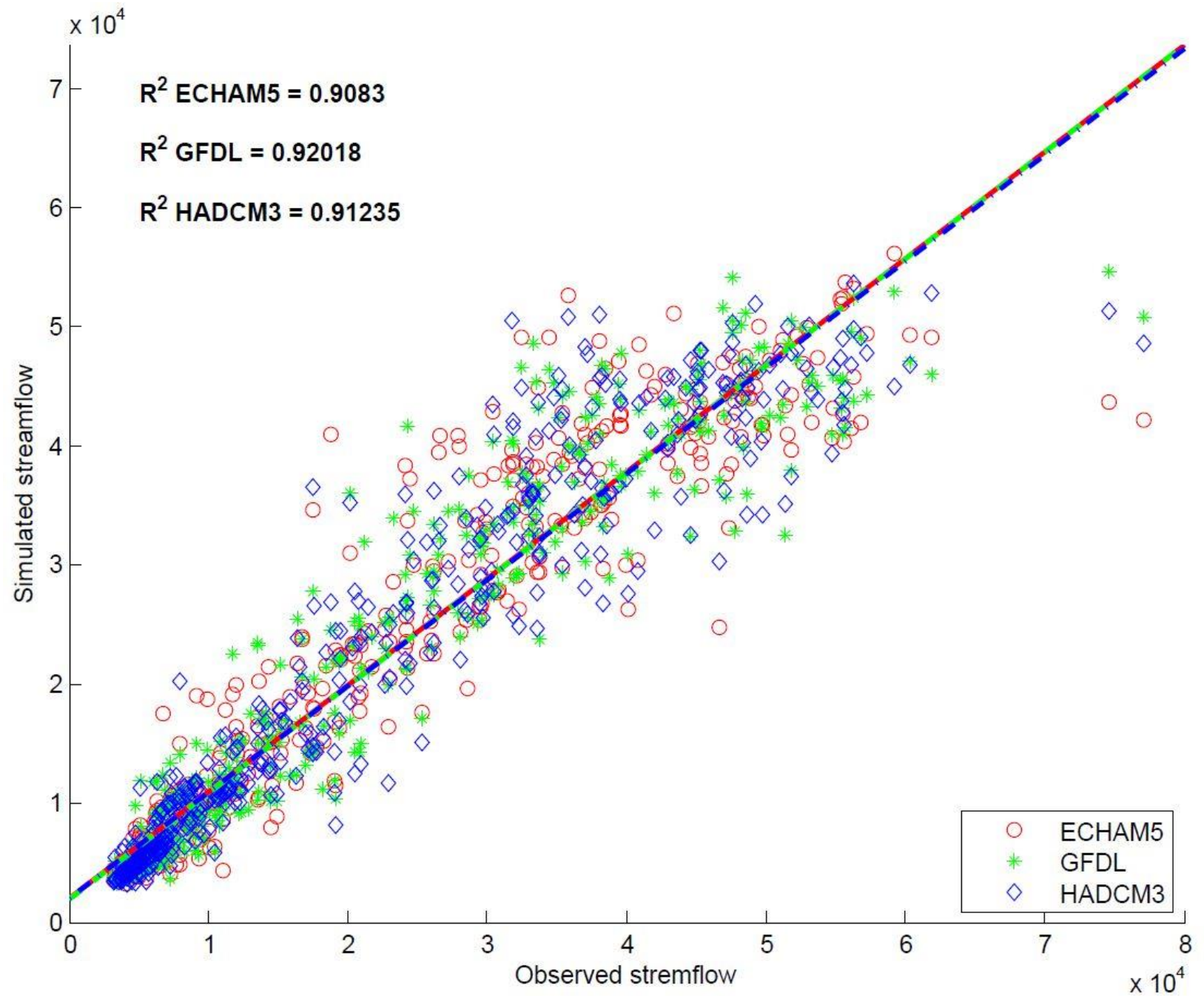

Figure 3-2: Monthly observed vs simulated streamflow of Brahmaputra under three GCM model (ECHAM5, GFDL, and HADCM3) 


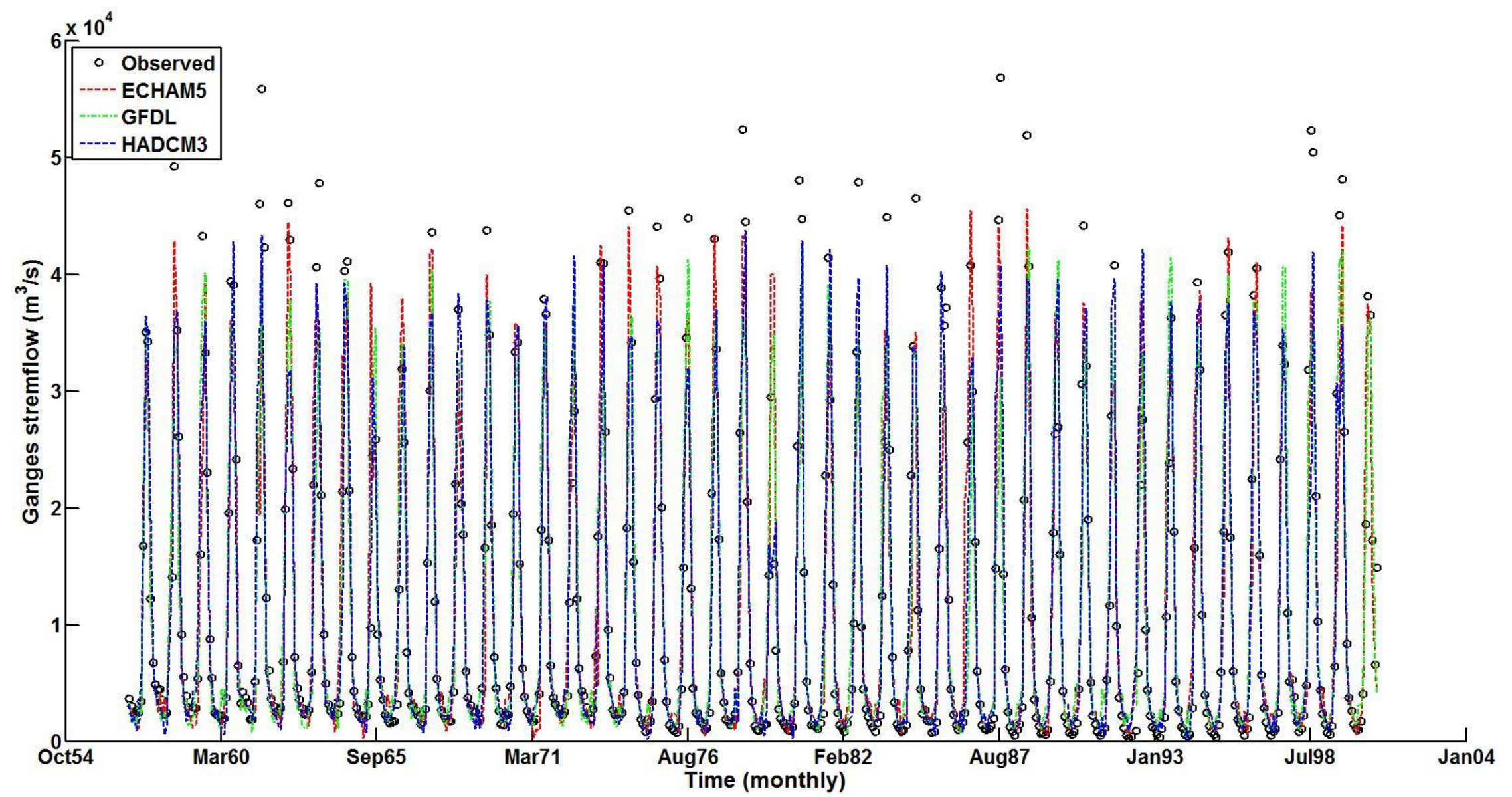

Figure 3-3: Simulated vs observed Ganges streamflow $\left(\mathrm{m}^{3} / \mathrm{s}\right)$. 


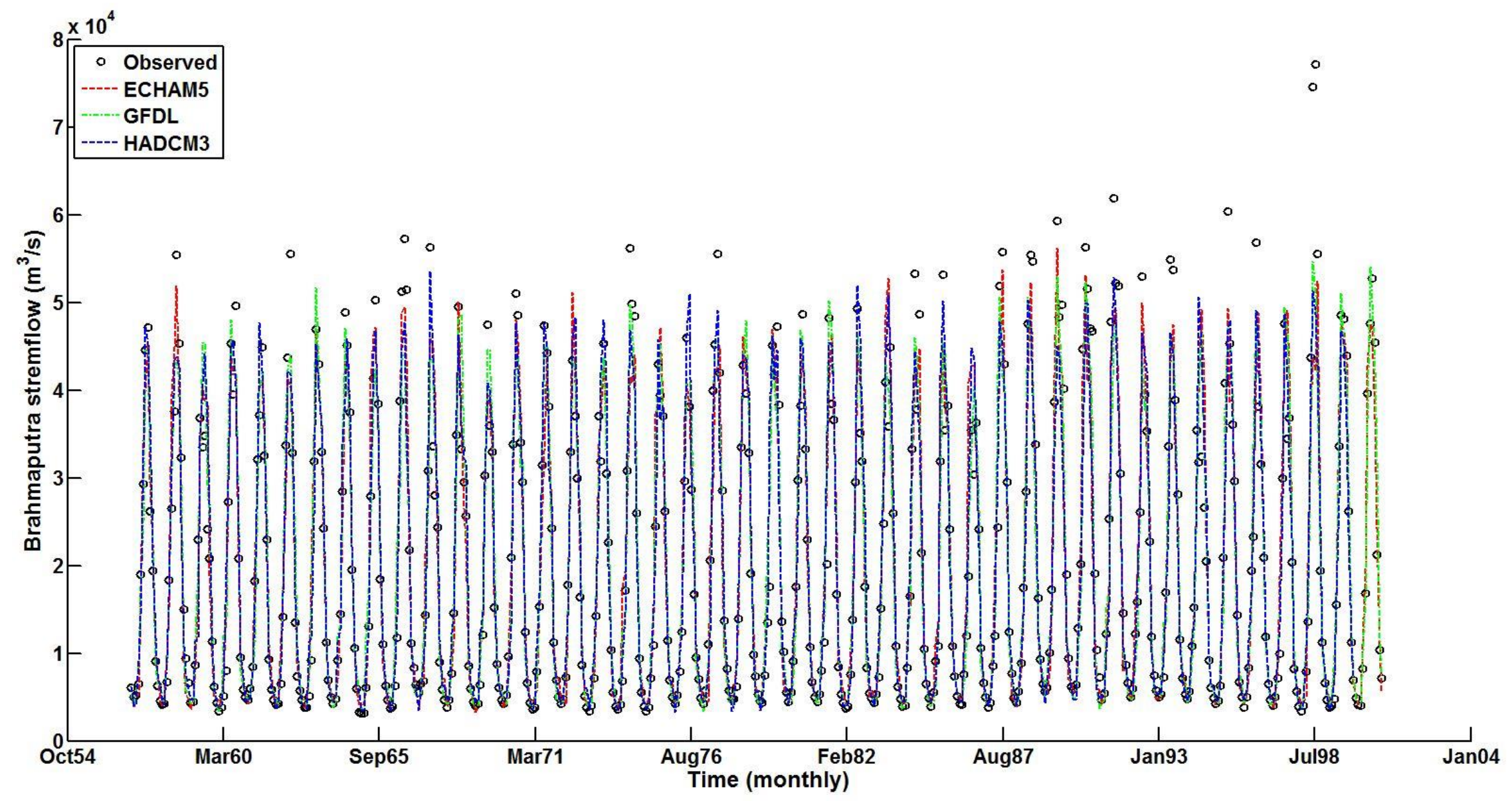

Figure 3-4: Simulated vs observed Brahmaputra streamflow $\left(\mathrm{m}^{3} / \mathrm{s}\right)$ 
simulated streamflow using SVR-PSO were aggregated for each of GCMs to produce continuous time series to camper with observed streamflow (Figures 3-3 and 3-4). Figures 3-1, 3-2, 3-3, and 3-4 as well as Table 3-2 show that the SVR-PSO's ability to capture variability of streamflow which is very good.

To explore impact of climate change on cholera occurrence, streamflow variability under climate change should be quantified. Future streamflow variability was projected by forcing climate change scenarios, A1B and A2, by calibrated and validated SVR-PSO model (section 3). Based on previous studies, outbreaks cholera in the Bengal Delta regions are related to low and high flows. To understand the impact of changing climate on streamflow and then on cholera outbreaks, two time series, low flow season (Dec-Mar) and high flow (Jul-Oct), were generated.

In this study, seasonality of projected low and high flow were aggregated to decades to show the difference with respect to control scenario, historical seasonality of low and high flow from 1957 to 2000 (Figure 3-5 and 3-6). Figures 3-5 and 3-6 show projected ensemble models of HADCM3, GFDL, and ECHAM5 for Ganges and Brahmaputra, respectively. The first and second rows of two figures are related to A2 and A1B scenarios as well as the first and second columns are associated with low and high flow time series. While amount of low flow, Dec-Mar, will be increasing under A2 and A1B for both of Ganges and Brahmaputra, high flow will be increasing a little for three decades (2020s-2040s) and then decreasing for the other decades in comparison with control scenario (Figure 3-5 and 3-6).

Projected streamflow has some uncertainty and estimation of which could be useful for policy and decision makers to interpret the results. Uncertainty has been calculated using unequal 

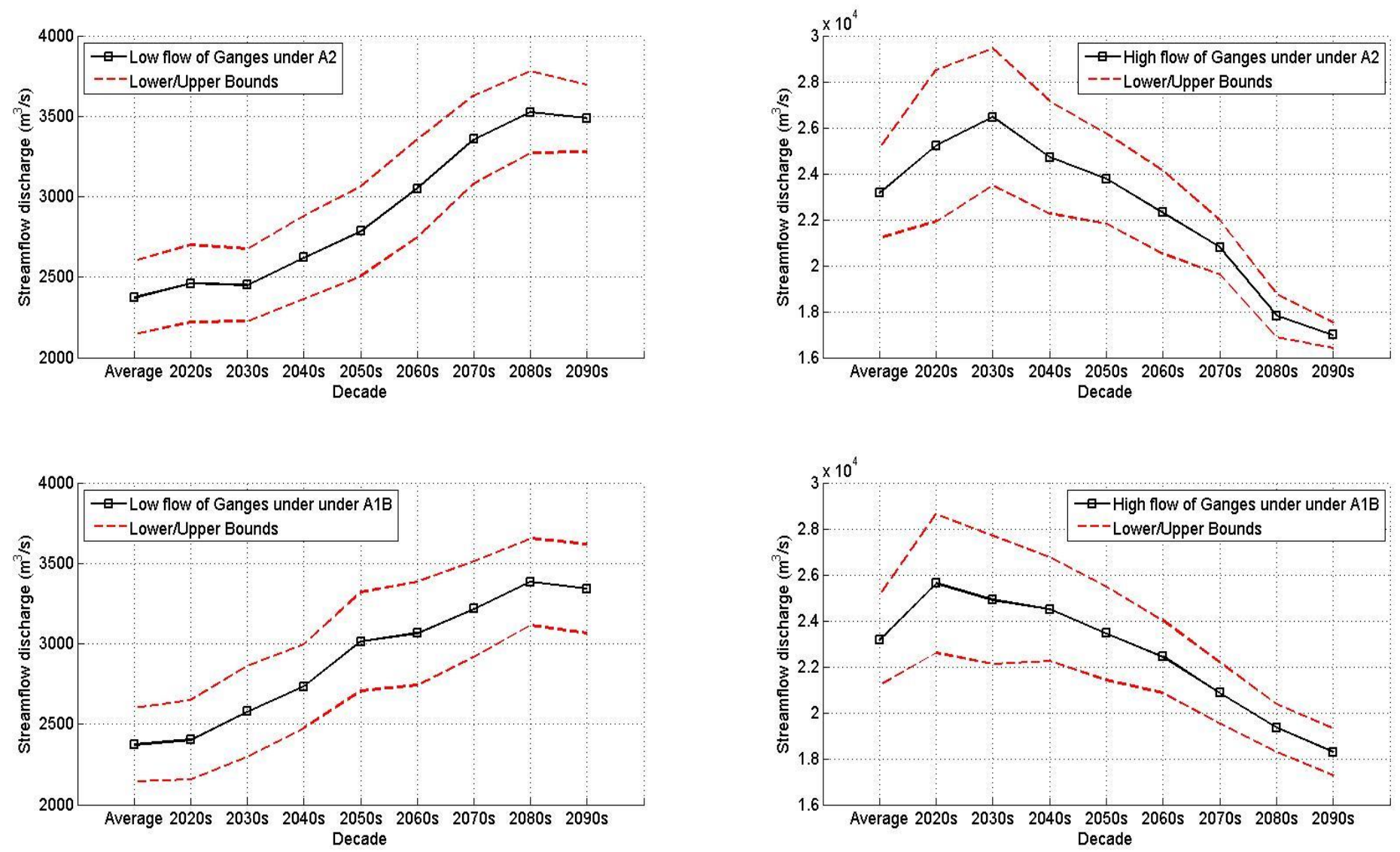

Figure 3-5: Projected ensemble streamflow of Ganges along with confidence interval. The first and second rows show the projected ensemble streamflow under A2 and A1B scenarios as well as the first and second column are associated to low and high flows. The black and red lines are related to projected date and confidence interval at $95 \%$. 

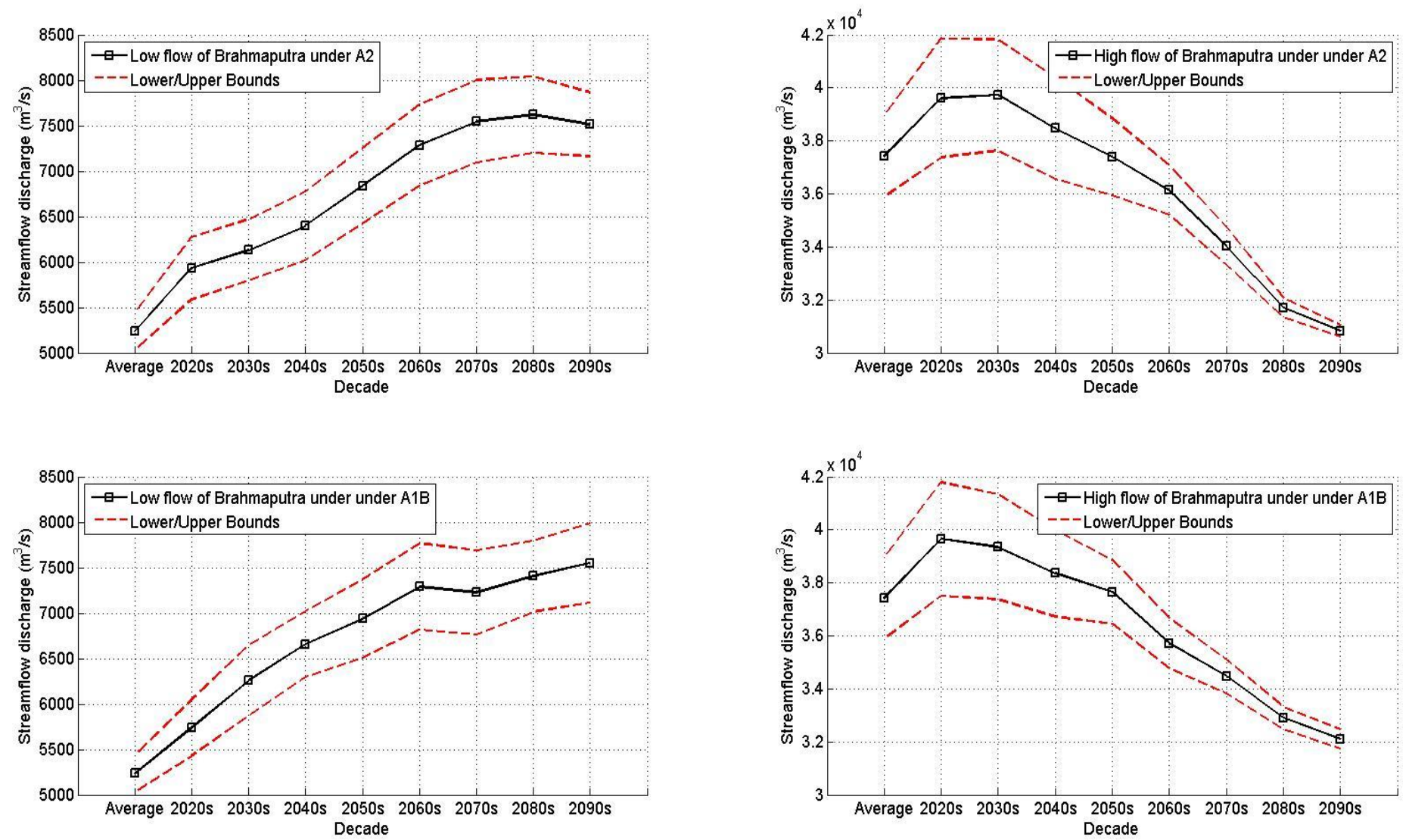

Figure 3-6: Projected ensemble streamflow of Brahmaputra along with confidence interval. The first and second rows show the projected ensemble streamflow under A2 and A1B scenarios as well as the first and second column are associated to low and high flows. The black and red lines are related to projected date and confidence interval at $95 \%$. 
Table 3-3: Ensemble uncertainty of combined river discharge under A2 and A1B scenarios based on three GCM models (HADCM3, ECHAM5, and GFDL)

\begin{tabular}{|c|c|c|c|c|c|c|c|c|c|c|c|c|c|}
\hline Decade & Scenario & Jan & Feb & Mar & Apr & May & Jun & Jul & Aug & Sep & Oct & Nov & Dec \\
\hline \multirow{2}{*}{$2020 s$} & $\mathrm{~A} 2$ & 96.65 & 97.49 & 87.50 & 98.32 & 99.84 & 99.90 & 85.25 & 81.78 & 51.02 & 71.07 & 82.30 & 54.10 \\
\hline & A1B & 73.98 & 95.84 & 52.65 & 99.93 & 99.32 & 99.67 & 95.21 & 74.18 & 54.53 & 57.78 & 66.73 & 24.69 \\
\hline \multirow{2}{*}{$2030 s$} & $\mathrm{~A} 2$ & 91.47 & 98.68 & 72.22 & 96.66 & 99.99 & 99.88 & 91.81 & 84.38 & 59.04 & 58.44 & 85.31 & 82.32 \\
\hline & A1B & 85.50 & 98.41 & 69.86 & 99.88 & 99.99 & 99.61 & 62.73 & 72.90 & 73.75 & 61.23 & 55.92 & 94.52 \\
\hline \multirow{2}{*}{ 2040s } & $\mathrm{A} 2$ & 90.79 & 92.03 & 87.47 & 99.93 & 99.94 & 99.99 & 63.20 & 90.19 & 45.46 & 42.46 & 98.44 & 88.93 \\
\hline & A1B & 99.86 & 99.19 & 95.15 & 99.99 & 99.99 & 99.96 & 70.03 & 95.20 & 56.68 & 64.38 & 96.99 & 96.69 \\
\hline \multirow{2}{*}{$2050 s$} & $\mathrm{~A} 2$ & 99.91 & 99.83 & 93.47 & 99.98 & 99.99 & 99.99 & 95.25 & 69.38 & 71.13 & 88.82 & 96.15 & 97.57 \\
\hline & A1B & 99.99 & 99.30 & 99.99 & 99.99 & 99.99 & 99.99 & 97.53 & 74.36 & 74.41 & 99.26 & 88.10 & 99.81 \\
\hline \multirow{2}{*}{$2060 s$} & A2 & 99.96 & 99.98 & 99.93 & 99.99 & 99.99 & 99.98 & 99.36 & 71.06 & 83.17 & 84.57 & 97.47 & 99.89 \\
\hline & A1B & 99.79 & 99.91 & 97.84 & 99.99 & 99.99 & 99.79 & 90.82 & 71.65 & 84.08 & 98.81 & 99.97 & 99.98 \\
\hline \multirow{2}{*}{$2070 s$} & $\mathrm{~A} 2$ & 99.99 & 99.95 & 99.99 & 99.99 & 99.99 & 99.98 & 96.57 & 84.53 & 93.36 & 98.81 & 99.97 & 99.99 \\
\hline & A1B & 99.99 & 99.82 & 99.99 & 99.99 & 99.99 & 99.98 & 99.36 & 93.57 & 86.99 & 96.23 & 99.97 & 99.56 \\
\hline \multirow{2}{*}{$2080 s$} & $\mathrm{~A} 2$ & 99.99 & 99.99 & 99.99 & 99.99 & 99.99 & 99.97 & 98.81 & 99.99 & 99.99 & 74.28 & 99.99 & 99.92 \\
\hline & A1B & 99.99 & 99.99 & 99.99 & 99.99 & 99.99 & 99.99 & 71.17 & 99.99 & 99.99 & 94.81 & 99.99 & 99.99 \\
\hline
\end{tabular}


variance of two tail t-test following methodology proposed by Maurer and Duffy (2005) for each decade. Table 3-3 shows confidence level in changes of projected streamflow over next decades.

While confidence of changes in streamflow is more than $90 \%$ in majority of months over next decades, months of August through December have more uncertainty. The range of uncertainties for Aug, Sep, Oct, Nov and Dec are between about $50-85 \%$. Although part of time period in 2020s and 2040s of Dec and Sep respectively are less than $50 \%$ in which are statistically insignificant confidence in changes in combined streamflow. The reason could be that the months of August and September as well as months of October and November are transitioning months related to Brahmaputra and Ganges respectively when those start to decrease.

\subsubsection{Copula methods for linking cholera and river discharge}

Cholera in the Bengal Delta shows two seasonal peaks where spring season peak is associated with low flows based intrusion of coastal water containing bacteria to inland water systems and the autumn season peak is associated with inundation as a result of high river flows, leading to massive cross contamination of water systems with sewerage (Akanda et al., 2009). Our previous studies indicated that two separate models were required to simulate cholera dynamics in the deltaic region (Jutla et al., 2013). Hence, two copula models, spring and autumn, were developed for two cholera outbreaks. For spring copula, two time series of spring cholera and streamflow were developed by taking average of March-April-May and average of February and March respectively. Two time series of autumn cholera and streamflow also were created by taking average of September and October and average of July and August respectively to 
Table 3-4: Selected marginal distribution, based on AD, KS, and CVM criteria, and their parameters

\begin{tabular}{|l|c|c|c|c|c|c|c|}
\hline Variables & Marginal & AD & KS & CVM & Location & Shape & Scale \\
\hline Spring streamflow & Lognormal & 0.33 & 0.14 & 0.05 & 8.64381 & & 0.10112 \\
\hline Fall streamflow & Logistic & 0.27 & 0.12 & .02 & 75012.62 & & 7505.14 \\
\hline Spring cholera & Logistic & 0.36 & 0.14 & 0.04 & 14.13303 & & 4.18319 \\
\hline Fall cholera & Weibull & 0.38 & 0.16 & 0.05 & & 2.44012 & 20.85972 \\
\hline
\end{tabular}

Table 3-5: Selected copula, based on KS and CVM criteria, and estimated parameter for joint probability distribution of cholera and streamflow for spring and fall respectively

\begin{tabular}{|l|c|c|c|}
\hline Copula family & KS & CVM & Estimate parameter \\
\hline Frank & 1.54 & 0.6 & -5.575501 \\
\hline Joe & 0.62 & 0.08 & 2.284156 \\
\hline
\end{tabular}


to construct fall copula.

Marginal distributions are the first and important step of copula construction. To select distributions for spring and fall cholera as well as spring and fall streamflow 14 distributions, including normal, 2 and 3-parameter lognormal, 1 and 2-parameter exponential, 2 and 3parameter Weibull, smallest and largest extreme value, 2 and 3-parameter gamma, logistic, and loglogistic distributions were considered. Based on KS, CVM, and Anderson-Darling (AD) statistic, lognormal and logistic distributions were selected for spring and fall streamflow as well as logistic and Weibull for spring and fall cholera respectively (Table 3-4). Table 3-4 shows the parameters of selected marginal distributions along with parameters. The defined distributions using MLE were used to estimate copula parameter, $\theta$, and select the best fitted copula based on KS and CVM statistic (Table 3-5). The Frank and Joe copulas are best fitted for spring and fall cholera-streamflow respectively.

The correlation (rho) between spring cholera and low flow of streamflow was estimated as 0.7. The negative correlation shows that the relationship between spring cholera and streamflow is inverse in which by increasing low flow amount of spring prevalence cholera could be decreased. In contrast to spring season, the fall prevalence cholera display a positive correlation associated with high flow of streamflow of which is about 0.48 . This result shows that amount of cholera prevalence could be decreased by decreasing high flow of streamflow.

Defined copulas can be used to estimate conditional probability of spring and fall cholera separately using projected streamflow from 2020-2100. To explore effect of changing climate on 
Table 3-6: Projected minimum, first quantile, median, third quantile and maximum combined streamflow under A1B and A2 scenarios from 2020 - 2100

\begin{tabular}{|c|c|c|c|c|c|c|}
\hline & \multicolumn{3}{|c|}{ Spring } & \multicolumn{3}{c|}{ Fall } \\
\cline { 2 - 7 } & Historical & A1B & A2 & Historical & A1B & A2 \\
\hline Min & 4944.166 & 6170.13 & 5779.12 & 57471.23 & 50025.92 & 46314.02 \\
\hline Q1 & 5151.94 & 7637.59 & 7487.04 & 64566.79 & 56121.18 & 54221.28 \\
\hline Median & 5675.85 & 8207.59 & 8274.40 & 75365.84 & 66074.19 & 66113.12 \\
\hline Q3 & 6196.824 & 8831.82 & 9095.43 & 84072.81 & 73116.64 & 75120.44 \\
\hline Max & 6810.431 & 9701.79 & 10215.68 & 117899.8 & 81071.41 & 84953.82 \\
\hline
\end{tabular}

cholera, cumulative distribution of cholera associated with min, $25 \%$ quantile, median, $75 \%$ quantile, and maximum of projected streamflow (Table 3-6) are plotted for historical, A1B and A2 scenarios (Figure 3-7). It can be seen from the first column of Figure 3-7 (a, b, and c) that maximum cholera prevalence with $50 \%$ probability are related to minimum streamflow with about $21 \%, 10 \%$, and $13 \%$ of cholera prevalence with respect to historical, A1B, and A2 scenarios. The result also shows that amount of cholera prevalence with respect to $50 \%$

probability is less under $\mathrm{A} 1 \mathrm{~B}$ and $\mathrm{A} 2$ scenarios in comparison with historical data. The probability of cholera prevalence given $25 \%$ quantile, median, $75 \%$ quantile, and maximum of projected streamflow in Figure 3-7b and 3-7c are very close so that the lines are overlaid. In contrast with the first column, the second column shows that maximum cholera prevalence with $50 \%$ probability are related to maximum streamflow with about $41 \%, 21 \%$, and $23 \%$ of cholera

prevalence for historical, A1B and A2 scenarios. This shows that probability of cholera prevalence may be reduced under A1B and A2 scenarios.

\subsection{Conclusions}

The general way to explore impact of changing climate on streamflow is to downscale 
precipitation and temperature at a local scale from GCMs and use them as inputs to physical and empirical hydrologic models. This way could introduce more uncertainties due to uncertainty of input data, model construction and parameters, and calibration and validation processes (McMillan et al., 2010; Baldassarre and Montanari 2009). In this study we applied a new framework, SVR-PSO, to downscale GCMs directly to streamflow to avoid difficulty of modeling hydrology and reduce uncertainties. In this framework, optimization of SVR parameters and feature selection could be done simultaneously by PSO. We tested this framework on two streamflows of Ganges and Brahmaputra separately which their combination creates one of the largest streamflows in world (Kamal et al., 2013). The results, Figures 3-1, 32, 3-3, and 3-4 and Table 3-2 demonstrated the ability of the model to capture variability of each streamflow. The projected ensemble of Ganges and Brahmaputra streamflow, based on ECHAM5, GFDL, and HadCM3 for each scenario of A1B and A2, indicated that low flow and high flow are affected due to a change of basin climate. It was realized that the low flow may increase about $41.7-45.8 \%$ and $42.8-44.8 \%$ for Ganges and Brahmaputra under A1B and A2 scenarios. High flow may increase in decades of 2020, 2030s, 2040s and 2050s up to $12.1-$ $15.2 \%$ and then decrease in the other decades about $20.4-26.1 \%$ in Ganges. There is also a similar pattern for Brahmaputra streamflow by increasing $4.5 \%$ in decades of 2020,2030 s, and 2040s and decreasing $14.7-17.3 \%$ in the other decades. Unequal variance of two tail t-test following methodology proposed by Maurer and Duffy (2005) were used to estimate the uncertainty for each decade. The result showed that the months of August and September as well as months of October and November for some decades are statistically insignificant due to transition months related to Brahmaputra and Ganges respectively. The developed framework and related results and analysis can be used by decision and policy makers for the purpose of 

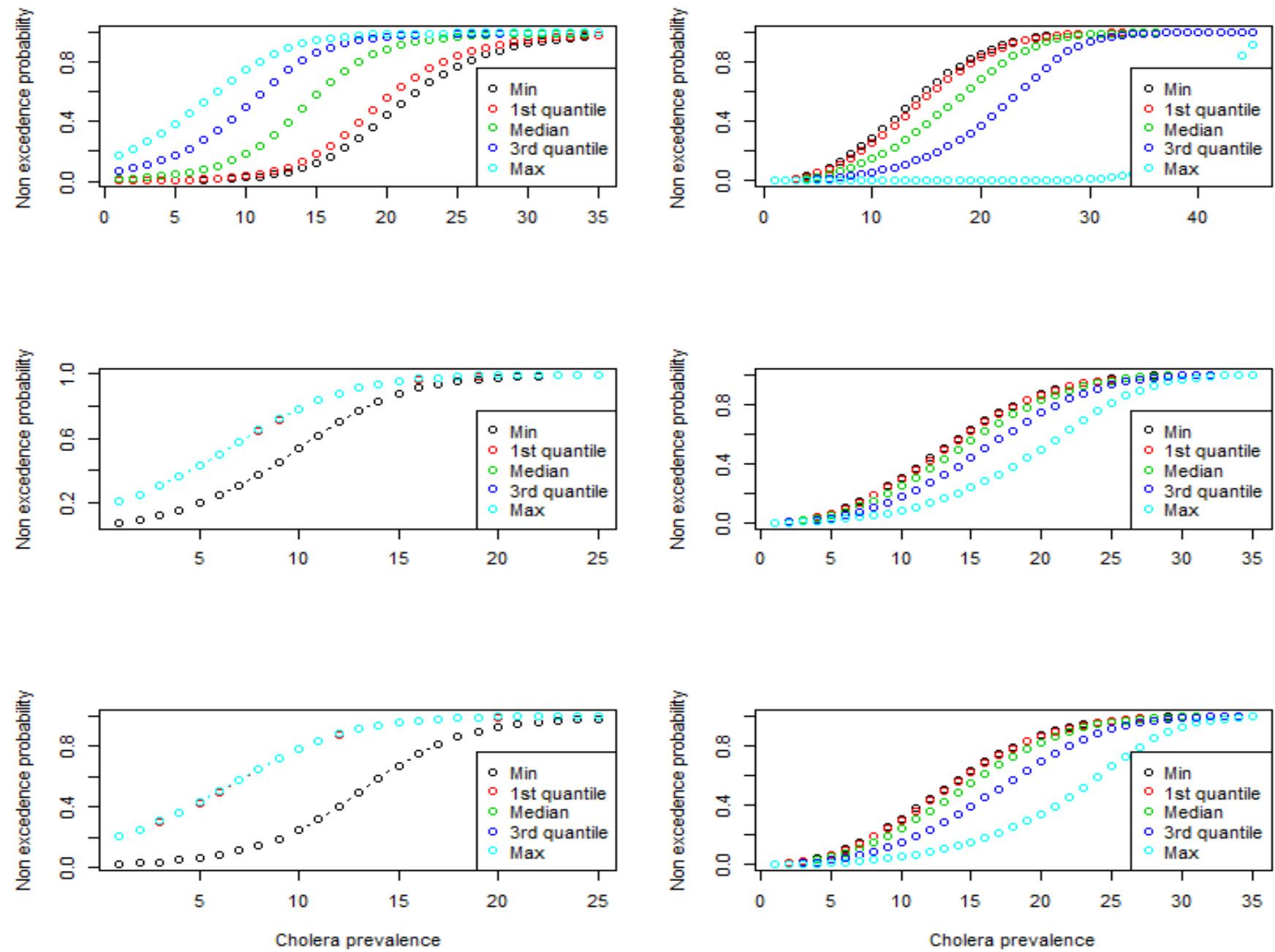

Figure 3-7: Cumulative density function of spring and fall cholera given streamflow. The first and second columns present CDF of cholera prevalence related to spring and fall respectively. The first, second and third rows shows CDF of cholera for historical, A1B and A2 scenarios respectively 
water resources planning and management, environment, and human health. To show the applicability of the framework, we applied this method to estimate probability of cholera endemic occurrence in the Bengal Delta region using copula method.

Cholera cases in the Bengal Delta region is related to hydroclimatological and societal risks (Jutla et al., 2014). The hydroclimatological and societal risks are defined as effects of combined large scale geophysical processes on cholera bacterial growth and absence of safe drinking water and sanitation. Therefor it should be noted that in this study copula were used to obtain conditional cholera prevalence given just combined streamflow and assuming same current conditions for future.

Empirical studies showed that there are relationships between low flow and spring cholera and high flow and fall cholera outbreaks. Therefor two best fitted copulas of Frank and Joe were determined for spring and fall cholera outbreaks respectively. Using conditional distribution of cholera prevalence given projected combined ensemble of streamflow of Ganges and Brahmaputra, it was showed that probability of cholera prevalence may decrease for both spring and fall cholera outbreaks by increasing and decreasing of projected low and high flow respectively. Some studies showed that providing and improving safe drinking water and sanitation could reduce cholera cases (Akanda et al. 2014 and Bartram 2008). To have a better estimation of cholera prevalence in future, the other hydroclimatological variables such as sea level rise and streamflow temperature as well as societal risk can be used by copula method which is beyond the scope of this paper. 


\subsection{Reference}

Akanda AS, Jutla AS, Islam S (2009) Dual peak cholera transmission in Bengal Delta: a hydroclimatological explanation. Geophys Res Lett 36:L19401, doi:10.1029/ 2009GL039312

Anandhi, A., Srinivas, V. V., Nanjundiah, R. S., \& Nagesh Kumar, D. (2008).

Downscaling precipitation to river basin in India for IPCC SRES scenarios using support vector machine. International Journal of Climatology, 28(3), 401-420.

Bartram, J. (2008). Improving on haves and have-nots. Nature, 452(7185), 283-284.

Behnamian J, Ghomi S (2010) Development of a PSO-SA hybrid metaheuristic for a new comprehensive regression model to time-series forecasting. Expert Syst Appl 37:974-984

Behzad M, Asghari K, Eazi M, Palhang M (2009) Generalization performance of support vector machines and neural networks in runoff modeling. Expert Syst Appl 36: $7624-7629$

Chapelle O, Vapnik V, Bousquet O, Mukherjee S (2002) Choosing multiple parameters for support vector machines. Mach Learn 46:131-159

Chen ST, Yu PS, Tang YH (2010) Statistical downscaling of daily precipitation using support vector machines and multivariate analysis. J Hydrol (Amst) 385:13-22

Chen YY, Lin JT (2009) A modified particle swarm optimization for production planning problems in the TFT Array process. Expert Syst Appl 36:12264-12271 
Chowdhury, M. D., \& Ward, N. (2004). Hydro-meteorological variability in the greater Ganges-Brahmaputra-Meghna basins. International Journal of Climatology, 24(12), 1495-1508.

Collins AE (2003) Vulnerability to coastal cholera ecology. Soc Sci Med 57:1397-1407

Cramér, H. (1928). On the composition of elementary errors: First paper: Mathematical deductions. Scandinavian Actuarial Journal, 1928(1), 13-74.

Crane, R. G., \& Hewitson, B. C. (1998). Doubled CO2 precipitation changes for the Susquehanna basin: down-scaling from the GENESIS general circulation model. International Journal of Climatology, 18(1), 65-76.

Cunderlik, J. M., \& Simonovic, S. P. (2005). Hydrological extremes in a southwestern Ontario river basin under future climate conditions/Extrêmes hydrologiques dans un basin versant du sud-ouest de l'Ontario sous conditions climatiques futures. Hydrological Sciences Journal, 50(4).

Di Baldassarre G, Montanari A. 2009. Uncertainty in river discharge observations: a quantitative analysis. Hydrology and Earth System Sciences Discussion 6: 39-61.

Dibike YB, Coulibaly P (2005) Hydrologic impact of climate change in the Saguenay watershed: comparison of downscaling methods and hydrologic models. J Hydrol (Amst) $307: 145-163$

Dibike YB, Coulibaly P (2006) Temporal neural networks for downscaling climate variability and extremes. Neural Netw 19:135-144 
Fowler, H. J., Blenkinsop, S., \& Tebaldi, C. (2007). Linking climate change modelling to impacts studies: recent advances in downscaling techniques for hydrological modelling. International journal of climatology, 27(12), 1547-1578.

Ghosh, S., \& Mujumdar, P. P. (2008). Statistical downscaling of GCM simulations to streamflow using relevance vector machine. Advances in Water Resources, 31(1), 132146.

Giorgi, F., Hewitson. B., Christensen, J., Hulme, M., Von Storch, H., Whetton, P., Jones, R., Mearns, L., and Fu, C. (2001). Climate change 2001, The scientific basis, contribution of working group I to the third assessment report of the IPCC, Published online at http://www.grida.no/, Chapter 10, 583-638.

Guo J, Zhou JZ, Qin H, Zou Q, Li QQ (2011) Monthly streamflow forecasting based on improved support vector machine model. Expert Syst Appl 38:13073-13081

Hanssen-Bauer I, Førland EJ, Haugen JE, Tveito OE (2003) Temperature and precipitation scenarios for Norway: comparison of results from dynamical and empirical downscaling. Clim Res 25:15-27

Haykin, S., 2003. Neural Networks: A comprehensive foundation. Fourth Indian Reprint, Pearson Education, Singapore, pp. 842.

He WW, Wang ZZ, Jiang H (2008) Model optimizing and feature selecting for support vector regression in time series forecasting. Neurocomputing 72:600-611

Hewitson, B. C., \& Crane, R. G. (1992). Regional-scale climate prediction from the GISS GCM. Global and Planetary Change, 5(3), 249-267. 
Jasper K, Calanca P, Gyalistras D, Fuhrer J (2004) Differential impacts of climate change on the hydrology of two alpine river basins. Clim Res 26:113-129

Joe, H. (1997). Multivariate models and multivariate dependence concepts. CRC Press.

Jutla AS, Whitcombe E, Hasan H, Haley B and others (2013) Environmental factors influencing epidemic cholera response. Am J Trop Med Hyg 89:597-604

Kamal R, Matin MA, Nasreen S (2013) Response of river flow regime to various climate change scenarios in Ganges-Brahmaputra-Meghna Basin. J Water Resour Ocean Sci 2:15-24

Kennedy J, Eberhart R (1995) Particle swarm optimization. In: Proceedings of the IEEE International Conference on Neural Networks Vol 4. IEEE, New York, NY, p $1942-1948$

Leander R, Buishand A, Aalders P, De Wit M (2005) Estimation of extreme floods of the River Meuse using a stochastic weather generator and a rainfall-runoff model. Hydrol Sci J 50:1089-1103

Lin JY, Cheng CT, Chau KW (2006) Using support vector machines for long-term discharge prediction. Hydrol Sci J 51:599-612

Lin SW, Ying KC, Chen SC, Lee ZJ (2008) Particle swarm optimization for parameter determination and feature selection of support vector machines. Expert Syst Appl $35: 1817-1824$

Maurer EP, Duffy PB (2005) Uncertainty in projections of streamflow changes due to climate change in California. Geophys Res Lett 32:L03704, doi:10.1029/2004GL021462 
Akanda, A.S., Jutla, A.S. and Colwell, R. 2014. Global diarrhoea action plan needs integrated climate-based surveillance, The Lancet-Global Health, 2(2):69-70.

McMillan, H., Freer, J., Pappenberger, F., Krueger, T., \& Clark, M. (2010). Impacts of uncertain river flow data on rainfall-runoff model calibration and discharge predictions. Hydrological Processes, 24(10), 1270-1284.

Mercer J (1909) Functions of positive and negative type, and their connection with the theory of integral equations. Philos Trans R Soc Lond A 209:415-446

Mises, R. V., \& Pollaczek-Geiringer, H. (1929). Praktische Verfahren der Gleichungsauflösung. ZAMM-Journal of Applied Mathematics and Mechanics/Zeitschrift für Angewandte Mathematik und Mechanik, 9(1), 58-77.

Murphy J (2000) Predictions of climate change over Europe using statistical and dynamical downscaling techniques. Int J Climatol 20:489-501

Nelsen, R., 2006. An Introduction to Copulas (Springer Series in Statistics). Springer Verlag, New York

Pilling CG, Jones JAA (2002) The impact of future climate change on seasonal discharge, hydrological processes and extreme flows in the Upper Wye experimental catchment, mid-Wales. Hydrol Process 16:1201-1213

Raje, D., \& Mujumdar, P. P. (2011). A comparison of three methods for downscaling daily precipitation in the Punjab region. Hydrological Processes,25(23), 3575-3589.

Schweizer, B., \& Sklar, A. (1983). Probability metric spaces. North-Holland, New York. Science, 222, 1293. 
Sklar, M. (1959). Fonctions de répartition à n dimensions et leurs marges. Université Paris 8 .

Teutschbein, C., \& Seibert, J. (2010). Regional climate models for hydrological impact studies at the catchment scale: a review of recent modeling strategies. Geography Compass, 4(7), 834-860.

Tisseuil, C., Vrac, M., Lek, S., \& Wade, A. J. (2010). Statistical downscaling of river flows. Journal of Hydrology, 385(1), 279-291.

Tung CP, Haith DA (1995) Global-warming effects on NewYork streamflows. J Water Resour Plan Manag 121:216-225

Vapnik V (1995) The nature of statistical learning theory. Springer, New York, NY von Storch H, Zorita E, Cubasch U (1993) Downscaling of global climate change estimates to regional scales: an application to Iberian rainfall in wintertime. J Clim 6: $1161-1171$

Wilby RL, Whitehead PG, Wade AJ, Butterfield D, Davis RJ, Watts G (2006) Integrated modelling of climate change impacts on water resources and quality in a lowland catchment: River Kennet, UK. J Hydrol (Amst) 330: 204-220

Wilby, R. L., \& Wigley, T. M. L. (1997). Downscaling general circulation model output: a review of methods and limitations. Progress in Physical Geography, 21(4), 530-548.

Wilby, R. L., \& Wigley, T. M. L. (2000). Precipitation predictors for downscaling: observed and general circulation model relationships. International Journal of Climatology, 20(6), 641-661. 


\section{Chapter 4 Summary, discussion and scope of future work}

\subsection{Summary and Discussion}

In this dissertation, a SVM approach was used to develop model between climate variables, as predictors, and precipitation, as a predictand or a dependent variable. The major issue and cumbersome task of developing model is calibration, validation, and test of each model by adding or removing each climate variable to reach the best model. Hence, a PSO technique was incorporated in the SVM approach to calibrate, validate, and test each model automatically and select the best model. This approach not only could decrease developing model and computation time but also increase accuracy of developed model. Other than downscaling GCM output, two more important models were developed to determine relationship between precipitation with streamflow and then cholera to explore how changing climate could impact on cholera.

To understand changing climate on probability of cholera occurrence, a bivariate joint probability model was developed using copula method. This approach provides an opportunity for policy and decision makers to estimate probability of cholera occurrence given specific streamflow value. In this approach, the GCM outputs were downscaled to streamflow directly to reduce uncertainty, which could be a complementary test for the SVM-PSO approach. The results shows that accuracy of developed model increased that could be related to having more data, from 1950 to 2000, for streamflow. Then I 
developed copula model to understand given a known streamflow value what probability of cholera occurrence could be under each cholera prevalence value.

Mechanistic approach is another way to incorporate hydroclimate variables in a model to simulate and study effects of variables simultaneously on cholera trigger and transmission model. Even though there are some models that tried to incorporate hydroclimate variables by introducing environmental parameter, the major issue regarding them is related to constant and unknown physical procedure behind environmental parameter. Hence, I introduced a way to associate important hydroclimate variables with cholera bacteria and their effects on cholera as trigger mechanism and links that with SIR model to study transmission of the disease through population. This approach can be used as a reliable warning system by predicting the trigger and transmission of cholera two or three months in advanced.

Although effect of changing climate on cholera as a signature of diarrhea disease was explored qualitatively, quantifying the effect was not investigated well. Quantification of changing climate on cholera needs establishing models between hydroclimate variables and cholera outbreaks and linkage those models with GCMs. The GCM output's resolution are coarse which are not suitable resolution for public health studies.

Increasing amount of carbon dioxide and other greenhouse gases lead to increasing global average temperature and changing global climate (IPCC 2001). Effects of changing climate on extreme hydrologic sequences, such as, cold, heat, drought and/or rainfall, could influence on infectious diseases ecology (Scott et al., 2004; Gregory et al., 
2009). Previous studies have showed the association between climate factors and seasonality of widespread human diseases (Emch et al., 20081; de Magny et al., 2008, Akanda et al., 2009; Jutla et al., 2013a). For instance, increasing temperature could directly provide more suitable natural habitat for bacterial growth proliferation and indirectly increase water consumption that could lead to rapid diarrheal diseases transmission (Chekley et al., 2000). Heavy rainfall and flood, as another example, could contaminate fresh water and may prompt diarrhea outbreaks (Auld et al. 2004; Hashizume et al., 2007; Akanda et al., 2009). Hence, changing climate exploration on disease pattern is vital for prevent and control disease strategies. In this dissertation, developing a new framework to project quantitatively effect of changing climate on local hydroclimate variables and their linkages with cholera disease could provide insights for policy and decision makers to prepare some strategies with respect to limited resources for control disease.

In summary, key contributions from this research are:

(1) Statistical downscaling of hydrological processes were achieved with very high accuracy and low uncertainty.

(2) Diarrheal diseases, primarily cholera, was linked to changing climate scenarios through two new methods, thereby making this one of the first studies to quantitatively assess likelihood of occurrence of disease in the Bengal Delta.

\subsection{Scope of future work for development of mechanistic model}

Mathematical models are one of the ways that can be used to reproduce observed 
disease transmission and to simulate what if scenarios for different intervention strategies. Codeco in 2001 introduced a Susceptible-Infectious-Recovered (SIR) model by emphasizing importance of environment role. He analyzed effect of environment on transmission disease in a qualitative way (Grad et al., 2012). His model was adjusted and used several times later by the other researchers (Bertuzzo et al., 2011; Andrews et al., 2011; Mukandavire et al., 2008). The major limitation of these models is related to simplified assumptions which can be affect their conclusion, especially environment parameter (Grad et al., 2012).

As mentioned above, climate and environmental variables are fluctuating over time and simplifying them as a constant parameter in mathematical models could make them less realistic and useful. Hence, the objective of this study is to develop a system dynamic approach to understand relationships between hydroclimate variables and cholera in feedback loop manner by incorporating it in the SIR model. This approach can be used as a robust warning system with two to three month's prediction in advance to help decision makers in developing prevention and control disease strategies.

\subsection{System Dynamics Approach}

System dynamic approach (SD), based on system analysis, is a procedure to understand complex problems. In essence, it is a framework in which assumptions, criteria, objectives, and goals are clearly stated and detailed (Simonovic 2009). In the other hand, the SD provides an opportunity to define a system by some components and their interconnections in which change of one component could effects the other components directly so that change of them could again change that component 
indirectly. The SD has two basic concepts feedback loop and stocks and flows as building blocks of the systems.

The feedback loop is based on the closed system in which change of input effects on output thereby influence on the input again. In other word, system is influenced by past behavior. While, in open system, output does not have any influence on input. Hence, the feedback loop is used as a way to exchange information between different components over time in which could shape system behavior. This is very useful technique to understand nonlinear complex system behavior and find a simple solution for it (Li \& Simonovic 2002). The feedback loop are classified as reinforcing (positive) and balancing (negative) feedback. The positive feedback, referred as exponential growth, strengthens the change which means increase/decrease in variable A could lead to increase/decrease variable B. In contrast, increase/decrease in variable A could lead to decrease/increase variable B in negative feedback. In other world, the negative feedback leads the system to a balance (goal). This means whenever the output is above (below) the goal the negative feedback push it down (up) to make it balanced.

The stocks and flows are developed to describe accumulation and/or depletion of stock(s) and movement of quantities over time in the system. The simplest way to illustrate stock(s) and flow(s) is streamflow (flow) which accumulates water volume in a reservoir (stock). The flows are represented by differential equations and the system is solved by standard numerical equations (Ford, 1999). The stocks (levels) and flows (rates) are measured at specific and interval time respectively to show accumulation or depletion of stocks and flows activities to change the stocks. 
Conceptualization, representation, and exploration of SD could be rather difficult without using easy to learn software. In this study we used an object-based simulation environment, namely Vensim, to model and simulate cholera outbreaks under climate change.

\subsection{Results}

Coastal regions play an important role in cholera and other diarrheal diseases, such as shigella and rotavirus, since more than $50 \%$ of global human population lives within 50 miles of the coastal area (Akanada et al., 2013; Shuval, 2006). Even though relationship between cholera and different hydroclimate variables, such as precipitation (Hashizume et al., 2008; Pascual et al., 2002), flood (Akanda et al., 2009; Koelle et al., 2005) and coastal plankton (de Magny et al., 2008; Emch et al., 2008) were investigated separately but combined effects of the hydroclimate variables simultaneously on cholera trigger and transmission are not well established. In this study, effects of rainfall, flood, and coastal plankton, as the most important hydroclimate variables, were investigated in new formwork using SD approach.

Heavy rainfall during monsoon season could lead to overflow of sewage channel which could reach and contaminate fresh water system. On the other hand, high streamflow level during flood, lead to $20 \%$ inundation of Bangladesh's land area (Akanad et al., 2009), could make the situation worse by inundating and mixing sewage with fresh water. Heavy rainfall and high streamflow level could also wash fertilizer used by farmers, to provide some essential plant nutrients to the growth of plants, and transfer them to the Bay of Bengal. The result of this procedure is increment of nutrition 


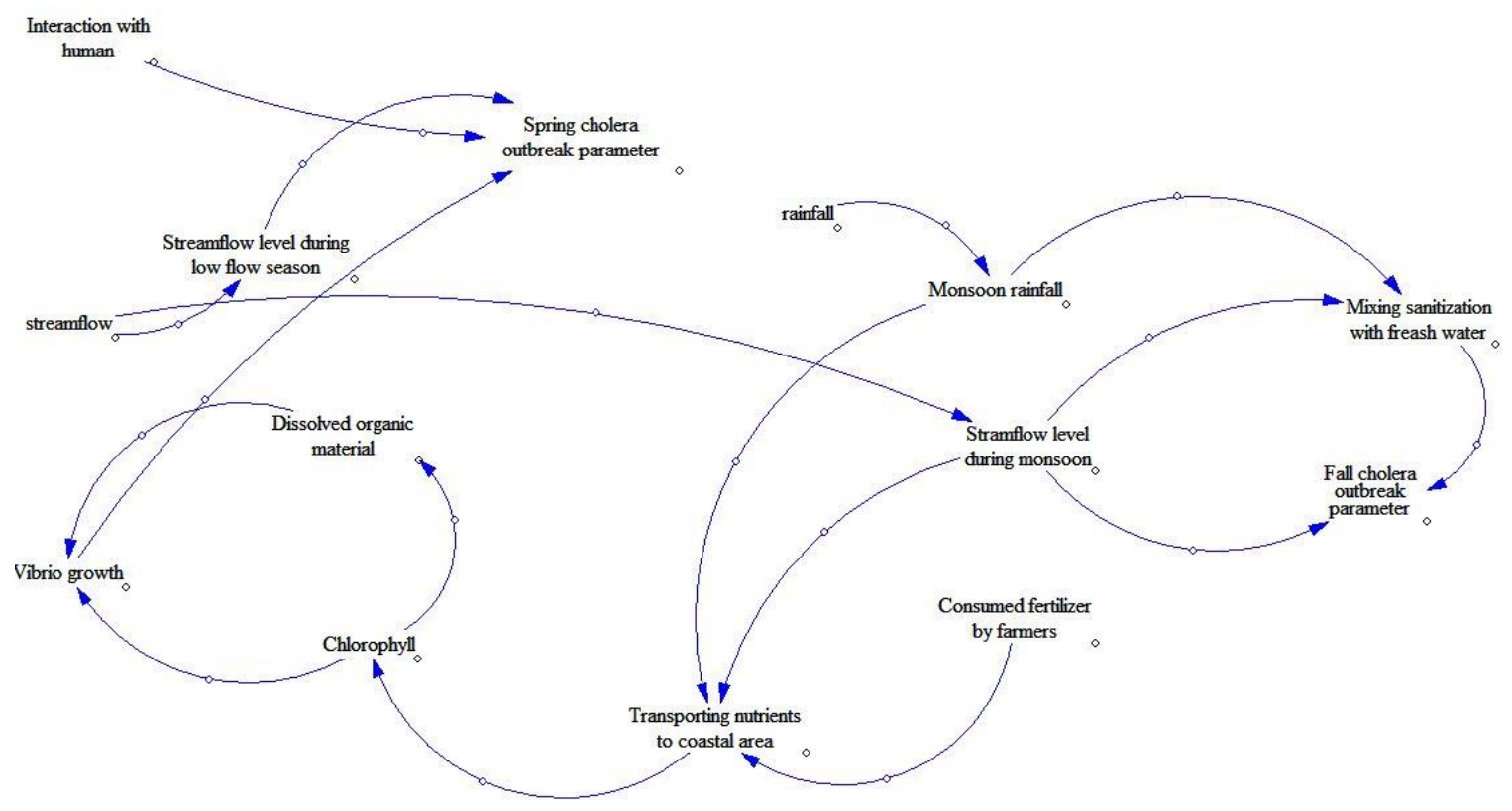

Figure 4-1: Schematic of incorporation of hydroclimate variables with cholera bacteria and trigger

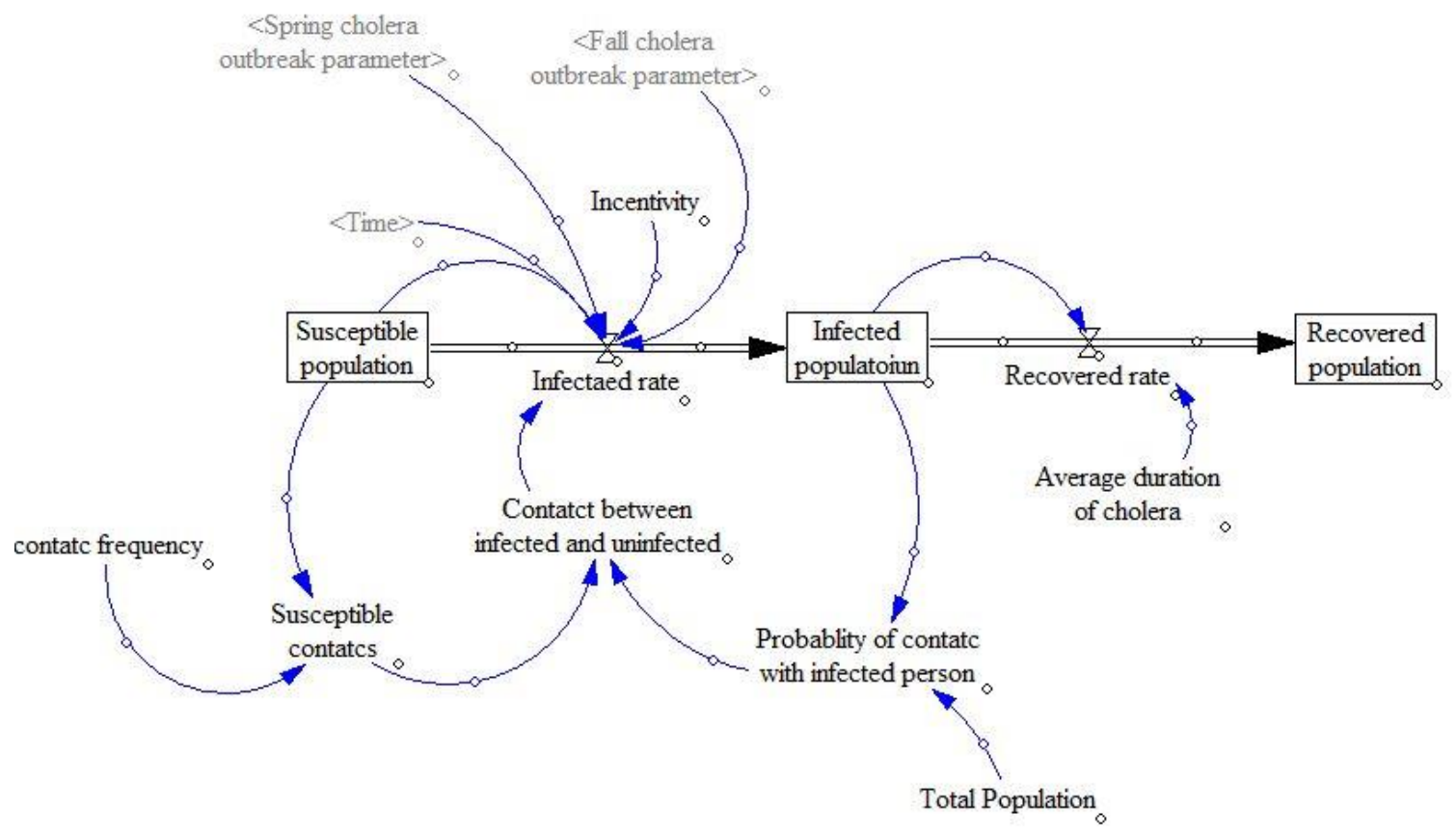

Figure 4-2: Transmission of cholera prevalence in population using SIR model 


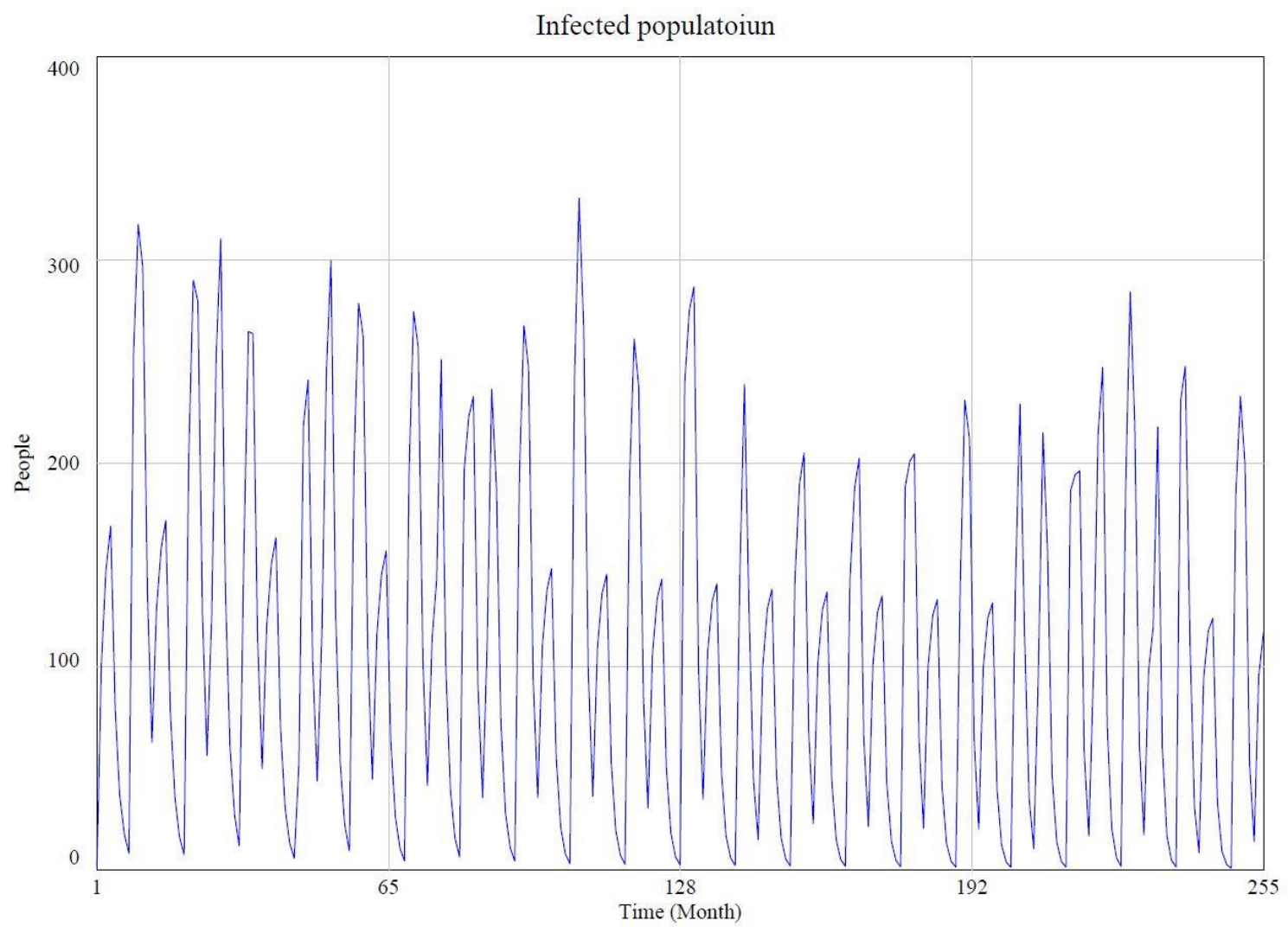

Figure 4-3: Simulated infected people

availability for plankton and phytoplankton which are consumed finally by cholera bacteria and let them to proliferate in the Bay of Bengal. These cholera bacteria could be intruded into inland during low streamflow level. This total procedure are simulated using SD approach (Figure 4-1).

To define the relationships between components, I used logical relationship by defining 1, 2, 3, 4, and 5 as very low, low, medium, high, and very high probability of cholera trigger criteria for each spring and autumn cholera outbreaks. These are incorporated with Susceptible - Infected - Recovered (SIR) model as environmental parameter to simulate transmission of cholera prevalence in population (Figure 4-2). The 
preliminary result (Figure 4-3) shows that this framework has very good ability to capture variability of biannual cholera peaks in each year using variability of hydroclimate variables. The method should be explored further to include effects of changing climate, in terms of river discharge, into SD framework. 


\subsection{Reference}

Akanda AS, Jutla AS, Islam S (2009) Dual peak cholera transmission in Bengal Delta: a hydroclimatological explanation. Geophys Res Lett 36:L19401, doi:10.1029/ 2009GL039312

Akanda, A.S., Jutla, A.S., Gute, D., Sack, R., Alam, M., Huq, A., Colwell, R., and Islam, S. 2013. Population vulnerability to biannual cholera outbreaks and associated macroScale drivers in Bengal Delta, American Journal of Tropical Medicine and Hygiene, 89(5):950-959.

Andrews JR, Basu S. Transmission dynamics and control of cholera in Haiti: an epidemic model.Lancet. 2011;377(9773):1248-55.

Bertuzzo E, Mari L, Righetto L, Gatto M, Casagrandi R, Blokesch M, Rodriguez-Iturbe I, Rinaldo A. Prediction of the spatial evolution and effects of control measures for the unfolding Haiti cholera outbreak.Geophysical Research Letters. 2011;38(6)

Codeço, C. T. (2001). Endemic and epidemic dynamics of cholera: the role of the aquatic reservoir. BMC Infectious diseases, 1(1), 1.

de Magny, Guillaume Constantin, Raghu Murtugudde, Mathew RP Sapiano, Azhar Nizam, Christopher W. Brown, Antonio J. Busalacchi, Mohammad Yunus et al. "Environmental signatures associated with cholera epidemics."Proceedings of the National Academy of Sciences 105, no. 46 (2008): 17676-17681.

Emch, Michael, Caryl Feldacker, Mohammad Yunus, Peter Kim Streatfield, Vu DinhThiem, and Mohammad Ali. "Local environmental predictors of cholera in 
Bangladesh and Vietnam." The American journal of tropical medicine and hygiene 78, no. 5 (2008): 823-832.

Ford, F. A. (1999). Modeling the environment: an introduction to system dynamics models of environmental systems. Island Press.

Grad, Y. H., Miller, J. C., \& Lipsitch, M. (2012). Cholera modeling: challenges to quantitative analysis and predicting the impact of interventions.Epidemiology (Cambridge, Mass.), 23(4), 523.

Hashizume, M., Hayakawa, N., \& Mihara, M. (2008). IL-6 trans-signalling directly induces RANKL on fibroblast-like synovial cells and is involved in RANKL induction by TNF- $\alpha$ and IL-17. Rheumatology, 47(11), 1635-1640.

Jutla AS, Whitcombe E, Hasan H, Haley B and others (2013a) Environmental factors influencing epidemic cholera response. Am J Trop Med Hyg 89:597-604

Koelle, K., Rodó, X., Pascual, M., Yunus, M., \& Mostafa, G. (2005). Refractory periods and climate forcing in cholera dynamics. Nature, 436(7051), 696-700.

Li, L., \& Simonovic, S. P. (2002). System dynamics model for predicting floods from snowmelt in North American prairie watersheds. Hydrological Processes, 16(13), 26452666.

Lobitz, B., Beck, L., Huq, A., Wood, B., Fuchs, G., Faruque, A. S. G., \& Colwell, R. (2000). Climate and infectious disease: use of remote sensing for detection of Vibrio cholerae by indirect measurement. Proceedings of the National Academy of Sciences, 97(4), 1438-1443. 
Miller, C., Drasar, B., \& Feachem, R. (1982). Cholera and estuarine salinity in Calcutta and London. The Lancet, 319(8283), 1216-1218.

Mukandavire Z, Liao S, Wang J, Gaff H, Smith DL, Morris JG., Jr Estimating the reproductive numbers for the 2008-2009 cholera outbreaks in Zimbabwe. Proc Natl Acad Sci U S A. 2011

Pascual, M., \& Ellner, S. P. (2000). Linking ecological patterns to environmental forcing via nonlinear time series models. Ecology, 81(10), 2767-2780.

Shuval, J. (2006). Nurses in alternative health care: integrating medical paradigms. Social Science \& Medicine, 63(7), 1784-1795.

Siddique, A.K. et al. 1994. Tropical and Geographical Medicine, Vol. 46, No. 3, 147-150.

Simonovic, S. P. (2012). Managing water resources: methods and tools for a systems approach. Routledge.

WHO 2012. http://www.who.int/mediacentre/factsheets/fs107/en/index.html

WHO 2008. Water-related diseases. Water sanitation and health (WSH), vol. 2008. World Health Organization. 